\title{
AN OVERVIEW OF FUZZY TECHNIQUES IN SUPPLY CHAIN MANAGEMENT: BIBLIOMETRICS, METHODOLOGIES, APPLICATIONS AND FUTURE DIRECTIONS
}

\author{
Keyu LU ${ }^{1}{ }^{1}$, Huchang LIAO ${ }^{1 *}{ }^{*}$, Edmundas Kazimieras ZAVADSKAS ${ }^{2}$ \\ ${ }^{1}$ Business School, Sichuan University, 610064 Chengdu, China \\ ${ }^{2}$ Institute of Sustainable Construction, Vilnius Gediminas Technical University, Vilnius, Lithuania
}

Received 13 November 2020; accepted 24 January 2021

\begin{abstract}
Every practice in supply chain management (SCM) requires decision making. However, due to the complexity of evaluated objects and the cognitive limitations of individuals, the decision information given by experts is often fuzzy, which may make it difficult to make decisions. In this regard, many scholars applied fuzzy techniques to solve decision making problems in SCM. Although there were review papers about either fuzzy methods or SCM, most of them did not use bibliometrics methods or did not consider fuzzy sets theory-based techniques comprehensively in SCM. In this paper, for the purpose of analyzing the advances of fuzzy techniques in SCM, we review 301 relevant papers from 1998 to 2020 . By the analyses in terms of bibliometrics, methodologies and applications, publication trends, popular methods such as fuzzy MCDM methods, and hot applications such as supplier selection, are found. Finally, we propose future directions regarding fuzzy techniques in SCM. It is hoped that this paper would be helpful for scholars and practitioners in the field of fuzzy decision making and SCM.
\end{abstract}

Keywords: supply chain management, fuzzy sets, decision making, multi-criteria decision making (MCDM), overview.

JEL Classification: C51, C61, D81, L00.

\section{Introduction}

Supply chain (SC) refers to the process that enterprises purchase, transport and process raw materials, then distribute and finally deliver products to customers. Supply chain management (SCM) refers to the process of planning, implementing and controlling the system of supply chain to meet the demand of customers and reduce total costs. In recent years, with the development of big data and the Internet, the research on SCM conducted by scholars and practitioners who try to integrate supply chain in various ways to improve efficiency has become more and more in-depth and diversified. Every practice in SCM, such as supplier se-

^Corresponding author. E-mail: liaohuchang@163.com

Copyright (c) 2021 The Author(s). Published by Vilnius Gediminas Technical University

This is an Open Access article distributed under the terms of the Creative Commons Attribution License (http://creativecommons. $\mathrm{org} / \mathrm{licenses} / \mathrm{by} / 4.0 /$ ), which permits unrestricted use, distribution, and reproduction in any medium, provided the original author and source are credited. 
lection and inventory management, requires decision making. However, due to the complexity of evaluated objects and the cognitive limitations of individuals, the decision information given by managers is often fuzzy, which would make it difficult to make decisions. Therefore, many scholars applied fuzzy techniques to solve decision making problems in SCM. Zadeh (1965) first introduced the concept of fuzzy sets in his article Fuzzy Sets, where he suggested that we can use membership functions, valued arbitrarily on the closed interval $[0,1]$, to describe the degree to which an element belongs to a set. Based on the theory of original fuzzy sets, many scholars gradually proposed various forms of fuzzy sets, such as the L-fuzzy sets (Goguen, 1967), type-2 fuzzy sets (Zadeh, 1975), intuitionistic fuzzy sets (Atanassov, 1986), non-stationary fuzzy sets (Garibaldi et al., 2008), hesitant fuzzy sets (Torra, 2010), and hesitant fuzzy linguistic term sets (Rodríguez, 2012). Given that decision making in SCM under uncertain condition has been the focus of lots of research, in order to find out the current research hot spots and explore the future development directions of this research field, it is necessary to analyze and summarize the literature about fuzzy techniques in SCM.

There have been several literature reviews about supply chain. Divided by specific practices of SCM, reviews about supplier evaluation and selection (Govindan et al., 2015), product planning (Bhamu \& Sangwan, 2014), transport planning (Centobelli et al., 2017), distribute planning (Fahimnia et al., 2013), inventory planning (Janssen et al., 2016) and retail management (Grewal \& Levy, 2007) have been published. In addition, some papers reviewed the studies on SCM from the perspective of methodologies. For example, Wang et al. (2016) studied the role of big data analytics in SCM, while Soheilirad et al. (2018) reviewed the applications of data envelopment analysis models in SCM. Notably, there are a large number of articles concerning the green SCM (Tseng et al., 2019) and sustainable SC development (Barbosa-Povoa et al., 2018), which indicates that environmental protection is a critical research direction of SCM. Although sufficient reviews about SCM have been published, there is still room for improvement. Firstly, in terms of the analysis methods, most papers only used content analysis, lacking statistical analysis, which may be not conducive for us to have a systematic perception to the study of SCM. Additionally, the current overviews of SCM were not comprehensive enough. For example, Keshavarz Ghorabaee et al. (2017) provided a review on the applications of multi-criteria decision making (MCDM) methods in supplier evaluation and selection which was just a small part of SCM. Besides, we notice that there are few papers that considered SCM comprehensively from a fuzzy decision-making perspective. Therefore, in order to have a clear and comprehensive understanding of decision making in SCM within the context of uncertainty, a survey of fuzzy methods in SCM following the trend of time is needed to give researchers more enlightenment.

This paper aims to find research focus and explore future development directions of fuzzy techniques in SCM by conducting bibliometric analysis and summarizing the specific decision making methodologies used in reviewed papers and their applications in SCM. In this study, first, we searched the literature using the following retrieval strategy: TS = ("fuzzy set" OR "fuzzy sets") AND TS = ("supply chain") (here "TS" means topics) in the Web of Science Core Collection database and it returned 563 records from 1998 to 2020 (by October 31, 2020). There were 463 pieces of literature left after we refined the records by keeping the document types as article. For these 463 papers, we downloaded title, author, keywords, 
source journal, field, abstract, references and other data in the form of text for bibliometric analyses. To ensure the accuracy of analysis results, we checked the keywords and abstract of each publication manually and eliminated the articles which are not very relevant to the topic of this study. Finally, there were 301 papers focusing on fuzzy sets theory and supply chain left to review.

There are two innovative points in this study. First, we use both bibliometric analysis and content analysis, which not only benefits us to have a systematical cognition of this research field, but also helps us to study the details. In addition, this study focuses on the applications of fuzzy techniques in the whole system of SC, considering every practice in SCM, which will provide more useful information to researchers and practitioners compared with those papers only involving several practices of SCM.

This paper is structured as follows: Section 1 presents the results of bibliometric analysis, including publication trend, citation structure and analysis by region, institution, category, highly cited papers and keywords. Section 2 distinguishes and presents different fuzzy techniques applied in the reviewed papers. Section 3 classifies and presents specific SCM applications. Section 4 proposes future directions of this research area.

\section{Bibliometrics}

Bibliometric analysis is widely used to describe and analyze the status quo and predict development trends of a discipline or a research direction based on a large number of literature, using mathematical and statistical methods. Given that there is little literature studying the applications of fuzzy methods in SCM with bibliometric methods, this section uses VOSviewer (Van Eck \& Waltman, 2020) a bibliometric tool, to analyze the research status and identify the development trends of fuzzy techniques in SCM.

\subsection{Publication trend and citation structure}

To some extent, the number of publications and citations can help to measure the development of a research direction. Figure 1 shows the volume of annual publications and citations of each cited paper, while Table 1 presents the total quantity of publications and citations, citations per papers, citations per cited papers and detailed referenced situation per year.

As can be seen, an article about fuzzy sets theory and supply chain was published by a scholar in 1998, and the number of publications increases at a low rate from then on until 2005. Although the quantity of publications declines in 2007, 2010, 2012 and 2017, in general, since 2006, the publications volume shows a high growth trend. What is different from the development of publications volume is the change of citations quantity year by year. Figure 1 clearly shows that the citations are not proportional to the number of publications directly. In some years such as 2016 , the publication quantity is large, while the number of citations is small. Furthermore, the number of publications has increased a lot since 2013 but the number of citations has declined considerably in recent years. From Table 1, we can see that the quantity of publications in 2019 (48) is the largest, followed by 42 in October 2020; however, the number of citations in 2013 (1319), instead of 2019, is the largest, followed by 


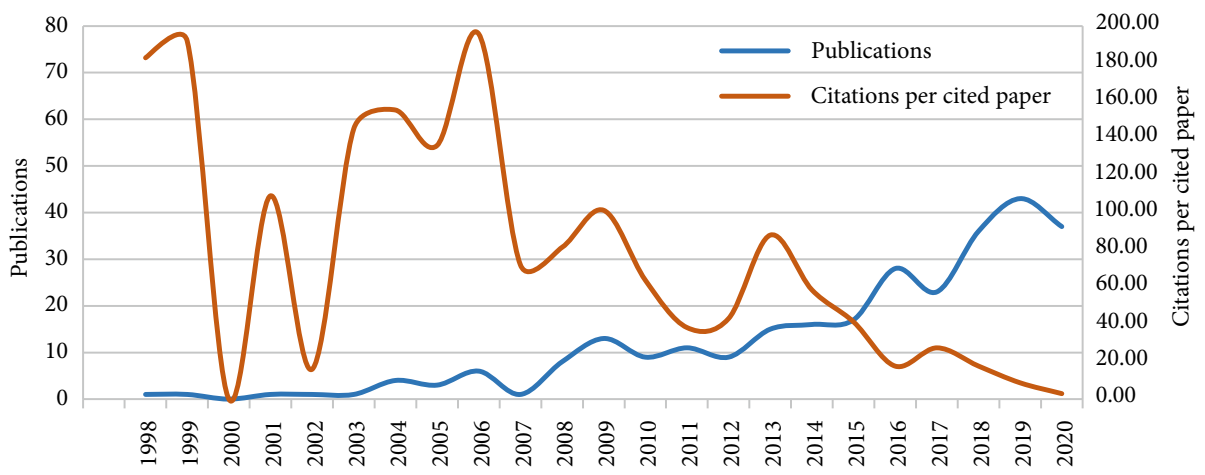

Figure 1. Publications and citations per cited paper from 1998 to 2020 (by October 2020)

Table 1. Publication trend and citation structure from 1998 to October 2020

\begin{tabular}{|c|c|c|c|c|c|c|c|c|c|c|}
\hline \multirow{2}{*}{ Year } & \multirow{2}{*}{$\mathrm{TP}$} & \multirow{2}{*}{$\mathrm{CP}$} & \multirow{2}{*}{$\mathrm{TC}$} & \multirow{2}{*}{$\mathrm{C} / \mathrm{P}$} & \multirow{2}{*}{$\mathrm{C} / \mathrm{CP}$} & \multicolumn{5}{|c|}{ Publications with citations } \\
\hline & & & & & & $\geq 250$ & $\geq 100$ & $\geq 50$ & $\geq 25$ & $\geq 1$ \\
\hline 1998 & 1 & 1 & 183 & 183.00 & 183.00 & 0 & 1 & 1 & 1 & 1 \\
\hline 1999 & 1 & 1 & 192 & 192.00 & 192.00 & 0 & 1 & 1 & 1 & 1 \\
\hline 2000 & 0 & 0 & 0 & 0.00 & 0.00 & 0 & 0 & 0 & 0 & 0 \\
\hline 2001 & 1 & 1 & 109 & 109.00 & 109.00 & 0 & 1 & 1 & 1 & 1 \\
\hline 2002 & 1 & 1 & 16 & 16.00 & 16.00 & 0 & 0 & 0 & 0 & 1 \\
\hline 2003 & 1 & 1 & 145 & 145.00 & 145.00 & 0 & 1 & 1 & 1 & 1 \\
\hline 2004 & 4 & 4 & 620 & 155.00 & 155.00 & 1 & 3 & 3 & 3 & 4 \\
\hline 2005 & 3 & 3 & 408 & 136.00 & 136.00 & 1 & 2 & 2 & 2 & 3 \\
\hline 2006 & 6 & 5 & 979 & 163.17 & 195.80 & 1 & 1 & 2 & 4 & 5 \\
\hline 2007 & 1 & 1 & 72 & 72.00 & 72.00 & 0 & 0 & 1 & 1 & 1 \\
\hline 2008 & 8 & 8 & 651 & 81.38 & 81.38 & 0 & 3 & 4 & 5 & 8 \\
\hline 2009 & 13 & 13 & 1316 & 101.23 & 101.23 & 1 & 4 & 6 & 9 & 13 \\
\hline 2010 & 9 & 9 & 574 & 63.78 & 63.78 & 1 & 1 & 4 & 6 & 9 \\
\hline 2011 & 11 & 11 & 422 & 38.36 & 38.36 & 0 & 2 & 2 & 6 & 11 \\
\hline 2012 & 9 & 9 & 389 & 43.22 & 43.22 & 0 & 1 & 2 & 7 & 9 \\
\hline 2013 & 15 & 15 & 1319 & 87.93 & 87.93 & 2 & 4 & 6 & 11 & 15 \\
\hline 2014 & 16 & 16 & 937 & 58.56 & 58.56 & 1 & 2 & 7 & 11 & 16 \\
\hline 2015 & 17 & 15 & 621 & 36.53 & 41.40 & 0 & 2 & 4 & 6 & 15 \\
\hline 2016 & 30 & 30 & 650 & 21.67 & 21.67 & 0 & 1 & 2 & 7 & 30 \\
\hline 2017 & 26 & 24 & 658 & 25.31 & 27.42 & 0 & 1 & 1 & 8 & 24 \\
\hline 2018 & 38 & 37 & 716 & 18.84 & 19.35 & 0 & 1 & 3 & 6 & 37 \\
\hline 2019 & 48 & 42 & 388 & 8.08 & 9.23 & 0 & 0 & 1 & 4 & 42 \\
\hline 2020 & 42 & 19 & 53 & 1.33 & 2.79 & 0 & 0 & 0 & 0 & 19 \\
\hline Total & 301 & 266 & 11418 & 37.93 & 42.92 & 8 & 32 & 54 & 100 & 266 \\
\hline
\end{tabular}

Note: $\mathrm{TP}=$ total number of publications; $\mathrm{CP}=$ number of cited papers; $\mathrm{TC}=$ total number of citations; $\mathrm{C} / \mathrm{P}=$ citations per publication; $\mathrm{C} / \mathrm{CP}=$ citations per cited paper. 
1316 in 2009. This phenomenon demonstrates that there is no necessary relationship between the volume of publications and the number of citations. From the perspective of citations per cited papers, the numbers in first two years are the largest, with 183 and 192 citations respectively, which indicates that the early articles, as the basis of this research direction, have attached great importance by later scholars. In addition, Table 1 shows that 8 articles have been cited more than 250 times, 32 received at least 100 citations, 54 articles cited at least 50 times, 100 cited at least 25 times, and 266 articles cited at least once from 1998 to October 2020.

\subsection{Regions and institutions with most publications}

Academic research is closely related to the overall development of a region, and academic institutions are the main places for national academic research. This section conducts a bibliometric analysis from the perspective of regions and institutions.

Table 2 presents the top 10 regions with the largest number of publications. We can see that China (70) was the largest publication source in the world and far ahead of other regions, accounting for about a quarter, followed by Iran (49), Taiwan (40), India (37) and Turkey (24). It is worth noting that on the top 10 list, China, Iran, Taiwan, India, Turkey and Malaysia are all developing countries/regions, which to some extent indicates that developing countries/regions have made a greater contribution to this research area.

Table 3 shows the number of publications of the top 20 institutions. We can observe that scholars of Islamic Azad University (13) and University of Tehran (13) have published the most papers, followed by Vilnius Gediminas Technical University (7), National Institute of Technology (7), Polytechnic University of Valencia (6), and National Taiwan University of Science and Technology (6). Among them, most institutions are from Iran and China, which make up half of the top 20 together. Although the number of publications in Taiwan is large, there are few institutions of Taiwan having published a large quantity of papers, with only two Taiwan institutions in the top 20.

Table 2. Top 10 regions with most publications

\begin{tabular}{|c|c|c|c|}
\hline Rank & Region & Publications & Share (\%) \\
\hline 1 & China & 70 & 23.26 \\
\hline 2 & Iran & 49 & 16.28 \\
\hline 3 & Taiwan & 40 & 13.29 \\
\hline 4 & India & 37 & 12.29 \\
\hline 5 & Turkey & 24 & 7.97 \\
\hline 6 & UK & 10 & 3.32 \\
\hline 7 & Canada & 9 & 2.99 \\
\hline 8 & Lithuania & 7 & 2.33 \\
\hline 9 & Malaysia & 7 & 2.33 \\
\hline 10 & Spain & 6 & 1.99 \\
\hline
\end{tabular}


Table 3. Top 20 institutions with most publications

\begin{tabular}{|c|l|c|c|c|}
\hline Rank & \multicolumn{1}{|c|}{ Institution } & Region & Publications & Share (\%) \\
\hline 1 & Islamic Azad University & Iran & 13 & 4.31 \\
\hline 2 & University of Tehran & Iran & 13 & 4.31 \\
\hline 3 & Vilnius Gediminas Technical University & Lithuania & 7 & 2.33 \\
\hline 4 & National Institute of Technology & India & 7 & 2.33 \\
\hline 5 & Polytechnic University of Valencia & Spain & 6 & 1.99 \\
\hline 6 & $\begin{array}{l}\text { National Taiwan University of Science and } \\
\text { Technology }\end{array}$ & Taiwan & 6 & 1.99 \\
\hline 7 & Sichuan University & China & 5 & 1.66 \\
\hline 8 & Shandong University of Finance and Economics & China & 5 & 1.66 \\
\hline 9 & Lunghwa University Science and Technology & Taiwan & 5 & 1.66 \\
\hline 10 & Istanbul Technical University & Turkey & 4 & 1.33 \\
\hline 11 & Amirkabir University of Technology & Iran & 4 & 1.33 \\
\hline 12 & Indian Institute of Technology & India & 3 & 1.00 \\
\hline 13 & Coventry University & UK & 3 & 1.00 \\
\hline 14 & Yildiz Technical University & Turkey & 3 & 1.00 \\
\hline 15 & Xidian University & China & 3 & 1.00 \\
\hline 16 & Wuhan University of Technology & China & 3 & 1.00 \\
\hline 17 & University of Regina & Canada & 3 & 1.00 \\
\hline 18 & Shanghai University & China & 3 & 1.00 \\
\hline 19 & Shahed University & Iran & 3 & 1.00 \\
\hline 20 & National Institute of Technology Agartala & India & 3 & 1.00 \\
\hline
\end{tabular}

\subsection{Categories involved in this research area}

In this section, we analyze the distribution of papers in various research categories. Here the categories were chosen in accordance with those provided by Web of Science. Table 4 presents all involved research categories and the frequency of their occurrence while Figure 2 reflects both the publication volume of each category and the links between them.

As can be seen from Table 4, among all the studies involving fuzzy sets theory and SCM, most of them were conducted in the category of "Engineering" (125), followed by "Computer Science" (111). In addition, the number of publications in the categories of "Operation Research \& Management Science" (80), "Business Economics" (52) and "Science TechnologyOther Topics" (44) was also large. We conclude that the top 10 categories were dominated by the natural sciences represented by engineering and computer science, while the papers belonging to social sciences were less.

According to Figure 2, first, we can see that the circles of "engineering", "computer science", "operations research and management science" and "business and economics" are bigger than others, reflecting the number of papers of those categories is large, which is consistent with the contents in Table 4. From the perspective of links, we can find that the lines around "engineering", "computer science" and "business and economics" are denser, 
Table 4. Research categories and their appearing frequency

\begin{tabular}{|c|l|c|}
\hline Rank & \multicolumn{1}{|c|}{ Category } & Frequency \\
\hline 1 & Engineering & 125 \\
\hline 2 & Computer Science & 111 \\
\hline 3 & Operations Research and Management Science & 80 \\
\hline 4 & Business and Economics & 52 \\
\hline 5 & Science and Technology - Other Topics & 44 \\
\hline 6 & Environmental Sciences and Ecology & 36 \\
\hline 7 & Mathematics & 21 \\
\hline 8 & Automation and Control Systems & 17 \\
\hline 9 & Transportation & 5 \\
\hline 10 & Materials Science & 3 \\
\hline 11 & Information Science and Library Science & 2 \\
\hline 12 & Telecommunications & 2 \\
\hline 13 & Mechanics & 1 \\
\hline 14 & Thermodynamics & 1 \\
\hline 15 & Robotics & 1 \\
\hline 16 & Oceanography & 1 \\
\hline 17 & Metallurgy and Metallurgical Engineering & 1 \\
\hline 18 & Energy and Fuels & \\
\hline 19 & Biodiversity and Conservation & \\
\hline & & \\
\hline
\end{tabular}

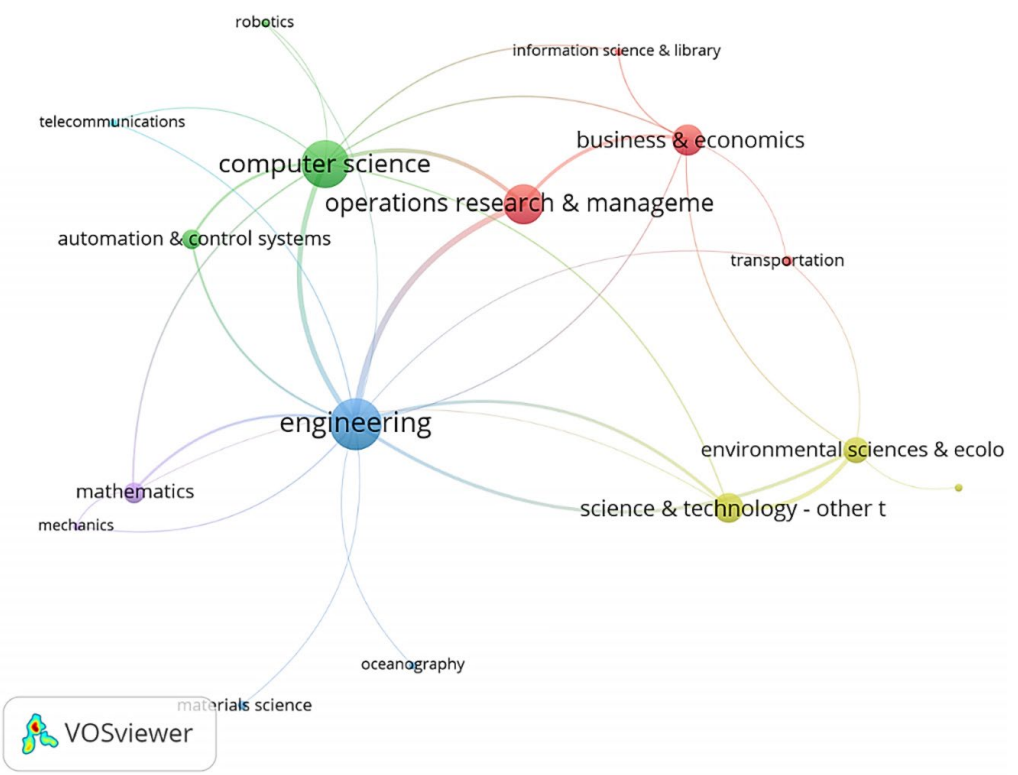

Figure 2. Publication volume and connections of each category 
which denotes that most papers take them as the center to carry out researches. In addition, it can be observed that "operations research and management science", "science and technology - other topics" and "environmental sciences and ecology" are linked with "engineering" closely, while the categories related to "computer science" mainly include "automation and control system", "operations research and management science" and "information science and library science".

\subsection{Top 10 highly cited papers of reviewed literature}

Through statistical analysis of cited papers, we can obtain a lot of valuable information. Table 5 shows the top 10 highly cited papers, along with their author(s), publication year, journal name, region(s), and citations.

First, in terms of time, we can see that all these papers were published between 2004 and 2017 , and half of them were published before 2010. There was only one highly cited paper in the past five years. Considering the increasing number of published papers as mentioned above, we infer that there has been no great breakthrough in this research field in recent years, or we still need more time to attract more attention to this research area. In terms of content, there are 7 papers concerning the supplier selection problem (Chen et al., 2006; Boran et al., 2009; Govindan et al., 2013; Kannan et al., 2014; Sanayei et al., 2010; Kumar et al., 2004; Qin et al., 2017b), while 2 articles studied how to optimize the whole supply chain system with fuzzy approaches (Lin, 2013; Chen \& Lee, 2004), and the remaining paper applied fuzzy methods to select transportation company (Kulak \& Kahraman, 2005). In conclusion, scholars are more interested in the applications of fuzzy techniques in supplier selection. From the perspective of journal, we find that these papers were published in the journals of production, systems, operations research and computer science, which denotes the strong practicality of this research field. By analyzing the regions, it can be seen that 3 papers were from Taiwan, which indicates the strong influence of that region in this research direction. However, China, the country with the most publications, has only one paper entering the top 10 list, and Iran, whose publication volume is also large, has only two articles in the top 10 list.

\subsection{Keywords co-occurrence}

Next, we analyze the literature from the perspective of keywords. Figure 3 shows the frequency and co-occurrence of keywords of all papers.

First, we can see the keywords used frequently, such as fuzzy set theory, fuzzy sets, supplier selection, SCM, which indicates that among all the papers studying fuzzy techniques in SCM, there are more articles analyzing and solving problems about supplier selection under uncertain environment. Later scholars can get more cutting-edge information from those articles using high frequency keywords, but they can also find new ideas according to the papers using lower frequency keywords. In terms of co-occurrence, we can observe that the keywords in the figure are closely linked together. The lines around keywords such as fuzzy sets, fuzzy set theory, supply chain management, and supplier selection are especially dense, reflecting the central position of those words, which is also consistent with the topic of our paper. Warm colored lines and circles represent that those keywords are used in recent years. 
In this regard, we can observe that some keywords such as sustainable supplier selection, multi-objective optimization and sustainable development were used in recent years, which to some extent reflects the current hot spots and future development directions.

Table 5. Top 10 highly cited papers of reviewed publications

\begin{tabular}{|c|c|c|c|c|c|c|}
\hline Rank & Title & Author(s) & Journal & Year & Region(s) & $\begin{array}{l}\text { Cita- } \\
\text { tions }\end{array}$ \\
\hline 1 & $\begin{array}{l}\text { A fuzzy approach for supplier } \\
\text { evaluation and selection in } \\
\text { supply chain management }\end{array}$ & $\begin{array}{l}\text { Chen, CT; Lin, CT; } \\
\text { Huang, SF }\end{array}$ & $\begin{array}{l}\text { International } \\
\text { Journal of } \\
\text { Production } \\
\text { Economics }\end{array}$ & 2006 & Taiwan & 818 \\
\hline 2 & $\begin{array}{l}\text { A multi-criteria intuitionistic } \\
\text { fuzzy group decision making } \\
\text { for supplier selection with } \\
\text { TOPSIS method }\end{array}$ & $\begin{array}{l}\text { Boran, Fatih Emre; } \\
\text { Genc, Serkan; } \\
\text { Kurt, Mustafa; } \\
\text { Akay, Diyar }\end{array}$ & $\begin{array}{l}\text { Expert } \\
\text { Systems with } \\
\text { Applications }\end{array}$ & 2009 & Turkey & 684 \\
\hline 3 & $\begin{array}{l}\text { A fuzzy multi criteria } \\
\text { approach for measuring } \\
\text { sustainability performance } \\
\text { of a supplier based on triple } \\
\text { bottom line approach }\end{array}$ & $\begin{array}{l}\text { Govindan, } \\
\text { Kannan; } \\
\text { Khodaverdi, } \\
\text { Roohollah; } \\
\text { Jafarian, Ahmad }\end{array}$ & $\begin{array}{l}\text { Journal of } \\
\text { Cleaner } \\
\text { Production }\end{array}$ & 2013 & $\begin{array}{l}\text { Denmark; } \\
\text { USA; } \\
\text { Iran }\end{array}$ & 425 \\
\hline 4 & $\begin{array}{l}\text { Selecting green suppliers } \\
\text { based on GSCM practices: } \\
\text { Using fuzzy TOPSIS applied } \\
\text { to a Brazilian electronics } \\
\text { company }\end{array}$ & $\begin{array}{l}\text { Kannan, Devika; } \\
\text { Lopes de Sousa } \\
\text { Jabbour, Ana } \\
\text { Beatriz; Chiappetta } \\
\text { Jabbour, Charbel } \\
\text { Jose }\end{array}$ & $\begin{array}{l}\text { European } \\
\text { Journal of } \\
\text { Operational } \\
\text { Research }\end{array}$ & 2014 & $\begin{array}{l}\text { Denmark; } \\
\text { Brazil }\end{array}$ & 295 \\
\hline 5 & $\begin{array}{l}\text { Fuzzy multi-attribute selection } \\
\text { among transportation } \\
\text { companies using axiomatic } \\
\text { design and analytic hierarchy } \\
\text { process }\end{array}$ & $\begin{array}{l}\text { Kulak, O; } \\
\text { Kahraman, C }\end{array}$ & $\begin{array}{l}\text { Information } \\
\text { Sciences }\end{array}$ & 2005 & Turkey & 269 \\
\hline 6 & $\begin{array}{l}\text { Group decision making } \\
\text { process for supplier selection } \\
\text { with VIKOR under fuzzy } \\
\text { environment }\end{array}$ & $\begin{array}{l}\text { Sanayei, Amir; } \\
\text { Mousavi, S. Farid; } \\
\text { Yazdankhah, A. }\end{array}$ & $\begin{array}{l}\text { Expert } \\
\text { Systems with } \\
\text { Applications }\end{array}$ & 2010 & USA; Iran & 265 \\
\hline 7 & $\begin{array}{l}\text { Using fuzzy DEMATEL to } \\
\text { evaluate the green supply } \\
\text { chain management practices }\end{array}$ & Lin, Ru-Jen & $\begin{array}{l}\text { Journal of } \\
\text { Cleaner } \\
\text { Production }\end{array}$ & 2013 & Taiwan & 259 \\
\hline 8 & $\begin{array}{l}\text { A fuzzy goal programming } \\
\text { approach for vendor selection } \\
\text { problem in a supply chain }\end{array}$ & $\begin{array}{l}\text { Kumar, M; Vrat, P; } \\
\text { Shankar, R }\end{array}$ & $\begin{array}{l}\text { Computers } \\
\text { \& Industrial } \\
\text { Engineering }\end{array}$ & 2004 & India & 254 \\
\hline 9 & $\begin{array}{l}\text { An extended TODIM multi- } \\
\text { criteria group decision } \\
\text { making method for green } \\
\text { supplier selection in interval } \\
\text { type-2 fuzzy environment }\end{array}$ & $\begin{array}{l}\text { Qin, Jindong; Liu, } \\
\text { Xinwang; Pedrycz, } \\
\text { Witold }\end{array}$ & $\begin{array}{l}\text { European } \\
\text { Journal of } \\
\text { Operational } \\
\text { Research }\end{array}$ & 2017 & $\begin{array}{l}\text { China; } \\
\text { Canada }\end{array}$ & 234 \\
\hline 10 & $\begin{array}{l}\text { Multi-objective optimization } \\
\text { of multi-echelon supply chain } \\
\text { networks with uncertain } \\
\text { product demands and prices }\end{array}$ & $\begin{array}{l}\text { Chen, CL; Lee, } \\
\text { WC }\end{array}$ & $\begin{array}{l}\text { Computers } \\
\text { \& Chemical } \\
\text { Engineering }\end{array}$ & 2004 & Taiwan & 233 \\
\hline
\end{tabular}




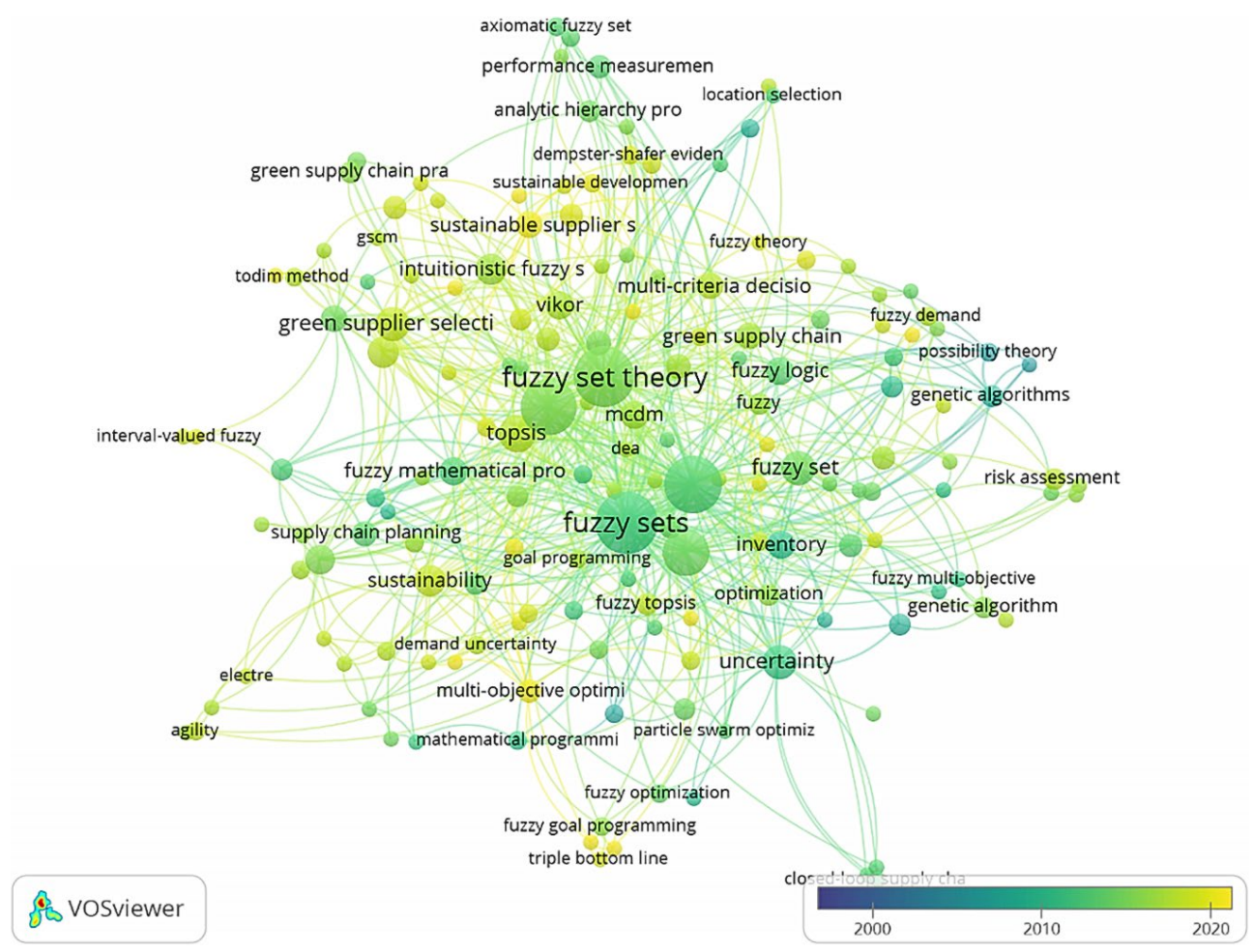

Note: Each node represents a keyword, and the larger the circle is, the more frequently the keyword appears. Lines represent there are some papers using several keywords simultaneously. The warmer the color is, the closer the time is to the present, while the colder the color is, the farther away it is.

Figure 3. Keywords Co-occurrence

\section{Fuzzy methodologies applied in reviewed papers}

Fuzzy methodologies used by scholars to study SCM problems mainly incorporated the methods of MCDM, operations research (OR), artificial intelligence (AI), statistic, and the hybrid of above and others integrating with fuzzy sets theory. Figure 4 presents the proportion of each method. Fuzzy MCDM methods were most commonly used (33\%), followed by fuzzy OR (31\%), hybrid methods (17\%) and other fuzzy techniques (11\%). There were also papers applying fuzzy AI approaches (6\%) and fuzzy statistic approaches (2\%) to solve problems. The main techniques included in each type of methods are presented in Table 6.

\subsection{Fuzzy MCDM methods in SCM}

MCDM methods include a great number of techniques such as AHP, ANP and TOPSIS, which are useful tools for managers to make decisions. Statistical results show that there are 94 papers among our collected publications using one fuzzy MCDM method to study SCM problems. 


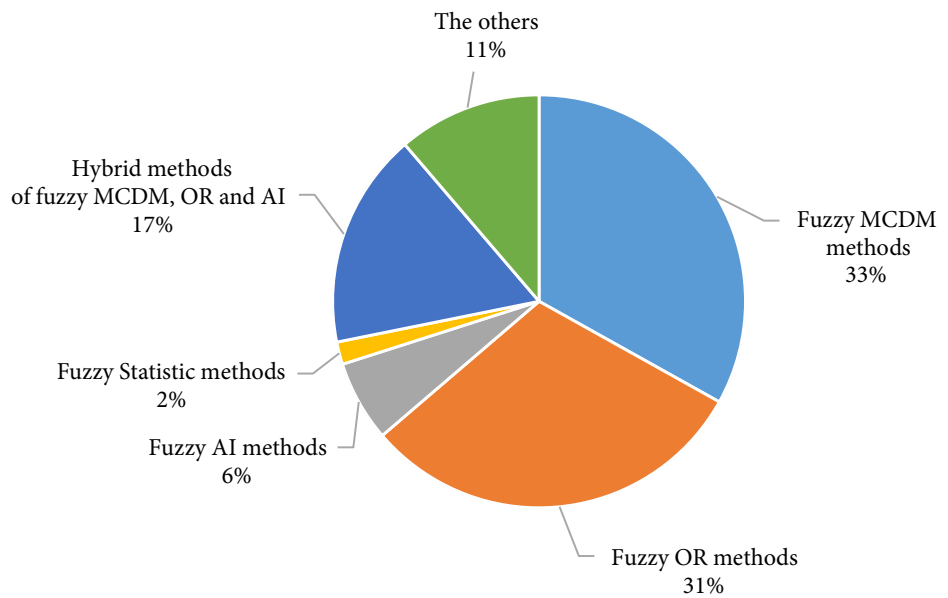

Figure 4. Distribution of the types of fuzzy methodologies

Table 6. Techniques included in each type of methods

\begin{tabular}{|l|l|}
\hline \multicolumn{1}{|c|}{ Type of methods } & \multicolumn{1}{c|}{ Techniques } \\
\hline $\begin{array}{l}\text { Fuzzy MCDM } \\
\text { methods }\end{array}$ & $\begin{array}{l}\text { AHP, ANP, TOPSIS, VIKOR, DEMATEL, ELECTRE, TODIM, MOORA, } \\
\text { BWM, DA, ARAS, SIR, SAW, SMART, PROMETHEE, COPRAS, MABAC }\end{array}$ \\
\hline Fuzzy OR methods & $\begin{array}{l}\text { DEA, LP, non-linear programming, goal programming, multi-objective } \\
\text { programming, integer programming, PERT, chance-constrained } \\
\text { programming, inventory model, game theory }\end{array}$ \\
\hline Fuzzy AI methods & $\begin{array}{l}\text { Genetic algorithms, inference system, particle swarm optimization, } \\
\text { artificial immune optimization technology, DST, neural network }\end{array}$ \\
\hline Fuzzy statistic methods & Possibilistic statistical approach, cluster analysis \\
\hline
\end{tabular}

Note: Analytic Hierarchy Process (AHP); Analytical Network Process (ANP); Technique for Order Preference by Similarity to Ideal Solution (TOPSIS); Vlsekriterijumska Optimizacija I Kompromisno Resenje (VIKOR); DEcision MAking Trail and Evaluation Laboratory (DEMATEL); ELimination Et Choix Traduisant la REalité (ELECTRE); TOmada de Decisao Interativa e Multicritevio (TODIM); Multi-Objective Optimization by Ratio Analysis (MOORA); Best Worst Method (BWM); Dimensional Analysis (DA); Additive Ratio ASsessment (ARAS); Superiority and Inferiority Ranking (SIR); Simple Additive Weighting (SAW); Simple Multiple Attribute Rating Technique (SMART); Preference Ranking Organization Method for Enrichment Evaluation (PROMETHEE); COmplex PRoportional ASsessment (COPRAS); Multi-Attributive Border Approximation area Comparison (MABAC); Data Envelopment Analysis (DEA); Linear Programming (LP); Non-Linear Programming (NLP); Program Evaluation and Review Technique (PERT); Dempster-Shafer evidence Theory (DST).

Fuzzy AHP: Shete et al. (2020) used the Pythagorean fuzzy AHP to investigate the sustainable SC innovation enablers to achieve the sustainability of SC. Ho et al. (2020) used the fuzzy AHP to identify various impact recycling levels and their impact on recycling items. Narayanan et al. (2019) prioritized the barriers in implementing sustainable practices in rubber product manufacturing by adopting the fuzzy AHP. Duric et al. (2019) applied the fuzzy AHP to determine the relative importance of risk factors in SC by fuzzy pairwise comparison matrices. Ulutas (2019) combined the fuzzy AHP and the fuzzy operational competitiveness rating method to solve a supplier selection problem for a textile company. Abbasianjahromi 
et al. (2018) used the fuzzy AHP to extract the weights of criteria for questionnaire based on the Kano model, and then developed a fuzzy MCDM framework to select the best SC. Tyagi et al. (2015) applied the fuzzy AHP to evaluate the performance of third-party logistics providers. Chiu et al. (2013) used the fuzzy AHP to tackle the uncertainty of SC when highlighting product disassemblability, carbon footprint and other sustainable design concepts. Wang et al. (2012) proposed a risk assessment approach to perform structured analysis of aggregative food safety risk in the food SC using the fuzzy AHP. Cifci and Buyukozkan (2011) presented a group decision framework based on the fuzzy AHP for evaluating and selecting green suppliers. To find the weight of each manufacturing activity, El-Baz (2011) presented a performance measurement approach based on the fuzzy AHP to ensure the consistency of the designer's assignments of importance of one factor over another. Amid et al. (2011) proposed a model using the fuzzy AHP to determine the weights of criteria, which can help decision makers find out the appropriate order of each supplier and allow managers to manage SC performance on cost, quality and service. Kulak and Kahraman (2005) used both the multi-attribute axiomatic design and the fuzzy AHP to select the best transportation company under cost, damage/loss, documentation ability and other determined criteria. Cebi et al. (2016) selected the fuzzy AHP to solve the problem of selecting the most appropriate location when examining both quantitative and qualitative criteria. Xu et al. (2019) proposed a way combining AHPSort II and interval type-2 fuzzy sets to select representative points for inferring suppliers' priorities. Kumar et al. (2018) employed the fuzzy AHP to find the priorities of factors related to the changing pattern of consumer decision making in the process of building a structural hierarchy model for analyzing customers' preferences and the changing pattern of those. From the above papers, we can know that there are a large number of papers applied the fuzzy AHP method to deal with SCM problems, especially in determining the weights of supplier evaluation criteria.

Fuzzy ANP: Ocampo et al. (2015) adopted the fuzzy ANP approach to develop a sustainable manufacturing strategy under the influence of stakeholders' interests. Malviya et al. (2018) used the fuzzy ANP to explore the implementation of green SCM (GSCM) strategies. Wicher et al. (2016) applied the fuzzy ANP to measure the SC resilience considering ambiguous pairwise comparisons expressed by fuzzy sets. Tseng et al. (2014a) used the fuzzy ANP to evaluate green SCs considering qualitative preferences. Tseng et al. (2016) applied the fuzzy ANP to deal with linguistic preferences in a hierarchical structure regarding the green SC capabilities of firms. Tseng et al. (2018) established a generalized quantitative evaluation model on the basis of the fuzzy Delphi method and fuzzy ANP, considering the interdependence among measures and the fuzziness of subjective measures in sustainable service SCM. Although there are fewer papers, compared with the fuzzy AHP, using the fuzzy ANP to solve problems in SCM, it is still a practical approach to assess and select SCM strategies. Kumar et al. (2019) used the fuzzy AHP to prioritize the risks in uncertain environment.

Fuzzy TOPSIS: Grillo et al. (2018) adopted the fuzzy TOPSIS to analyze the suitability of the minimum degree of possibility and then applied that to improve the performance of one production sector. Sahu et al. (2016) used the fuzzy TOPSIS to transform the evaluation information against subjectivity indices into mathematical dimensionless numbers in order to develop a multiple criterion appraisement index model for supplier selection. Ozbek and 
Yildiz (2020) built a model using the fuzzy TOPSIS method to select the best digital supplier for a company. Gunduz and Gunduz (2019) calculated a closeness coefficient based on the fuzzy TOPSIS to obtain the performance ranking of suppliers. Shi et al. (2018) put forward an approach combining the fuzzy TOPSIS method and grey relational analysis technique to evaluate green suppliers. Rostamzadeh et al. (2018) developed a framework for the sustainable SC risk evaluation by proposing a fuzzy MCDM approach based on the TOPSIS. Dos Santos et al. (2017) used the fuzzy TOPSIS to assess the performance of a company in green SC. Kannan et al. (2014) proposed a framework built on the criteria of GSCM practices using the fuzzy TOPSIS to select green suppliers for a Brazilian company. Shen et al. (2013) applied the fuzzy sets theory to translate individual perceptions into a solid crisp value, and then combined linguistic preferences to generate an overall performance score for each supplier through the fuzzy TOPSIS. Wang and Chan (2013) built an assessment system to evaluate different green initiatives of a company by proposing a fuzzy hierarchical TOPSIS approach. Govindan et al. (2013) used fuzzy numbers to find criteria weights and conduct the qualitative performance evaluation, and then proposed a fuzzy TOPSIS method to find the ranking of suppliers. Boran et al. (2009) used the fuzzy TOPSIS method to select appropriate suppliers in a group decision making (GDM) environment. Chen et al. (2006) defined a closeness coefficient to determine the ranking of all suppliers based on the fuzzy TOPSIS. Khemiri et al. (2017) used the fuzzy TOPSIS to determine the performance and risk measures related to each possible tactical plan in managing risks in the SCM. Mousavi and Vahdani (2016) introduced a novel intuitionistic fuzzy TOPSIS model to solve the problem of cross-docking location problem. Rani et al. (2020b) developed an approach on the basis of the fuzzy TOPSIS to solve sustainable recycling partner selection problems with completely unknown weights of decision makers and criteria. Rouyendegh et al. (2020) used the fuzzy TOPSIS to evaluate the classical and environmental criteria in order to select a green supplier. Chen (2019) proposed the intuitionistic fuzzy entropy-based TOPSIS combined with the grey relation analysis technique so as to select an appropriate sustainable supplier. Chatterjee and Kar (2016) used the fuzzy TOPSIS method to develop a model so as to select an optimal supplier under uncertainty. Bali et al. (2015) proposed a group dynamic intuitionistic fuzzy TOPSIS to select the most appropriate third-party logistics provider under uncertainty and in different time periods. Van et al. (2018) used the fuzzy TOPSIS to obtain a ranking of green suppliers. Yazdani et al. (2017) proposed a decision support system based on fuzzy TOPSIS to select logistics providers.

Through the review of above papers, first, we find that there are many papers combining TOPSIS with fuzzy sets and intuitionistic fuzzy sets, which denotes the common usage of fuzzy TOPSIS. Additionally, most papers applied the fuzzy TOPSIS to help to make decisions in an uncertain environment, from which later researchers could obtain many valuable ideas. However, it also indicates that the knowledge system of this research direction has already been mature, and thus it is difficult for scholars to make greater progress in this aspect.

Fuzzy VIKOR: Similar to the fuzzy MCDM methods mentioned above, the fuzzy VIKOR has also been used to determine criteria weights for selecting suppliers and green supply chains. Liu et al. (2019b) used the fuzzy VIKOR to select third-party logistics suppliers in the process of studying the recycling of abandoned bicycles. Meksavang et al. (2019) developed 
a modified fuzzy VIKOR which used the ordered weighted distance operator to aggregate the picture fuzzy information so as to further evaluate and select supplier. Zhao et al. (2017) selected the fuzzy VIKOR to determine criteria weights and then rank alternatives on each criterion for the supplier evaluation and selection. Rostamzadeh et al. (2015a) developed a quantitative model to evaluate the uncertainty of GSCM and then used the fuzzy VIKOR to solve a GSCM problem. Sanayei et al. (2010) proposed a hierarchy MCDM model based on the VIKOR to deal with supplier selection problems. Mahmoudi et al. (2016) proposed an extended fuzzy VIKOR approach using an efficient fuzzy distance measure to solve an applicable supplier selection problem under the GDM process.

Fuzzy DEMATEL: To assess the interrelationships among attributes and examine the influential criteria of a SC, the fuzzy DEMATEL was used widely in reviewed papers. Dou et al. (2015) built a portfolio evaluation model applying the fuzzy scoring method to measure the effect of environmental supplier development programs (ESDPs) on the performance of supplier, and using the fuzzy DEMATEL to examine the causal relations among the ESDPs. Govindan et al. (2015) used the fuzzy DEMATEL to handle the importance and causal relations between GSCM practices. Wu et al. (2015) used the fuzzy DEMATEL to investigate the effects of each criterion within green SC practices. Lin (2013) utilized the fuzzy DEMATEL to form a structural model to find out the causal relations among the criteria of three main GSCM practices. Mavi et al. (2013) examined the influential logistical criteria of green SCs using the fuzzy DEMATEL. Tseng et al. (2020) used the fuzzy DEMATEL to assess the interrelationships of attributes in the process of establishing a framework to enhance the performance of an industry. Dahooie et al. (2020) used the fuzzy Delphi and fuzzy DEMATEL to reduce the decision criteria in the sustainable SCM. Malviya and Kant (2016) used the fuzzy DEMATEL to evaluate the weights of criteria for the GSCM implementation.

Fuzzy ELECTRE: Kumar et al. (2017) evaluated the performance of suppliers based on green practices using the fuzzy ELECTRE, which helped managers incorporate linguistic information and convert it into a quantitative scale. Kefer et al. (2016) used a modified fuzzy ELECTRE method to select an optimal portfolio of suppliers, which represented a valuable input for establishing a long time purchasing strategy and cooperating with the best suppliers. Nestic et al. (2018) used the fuzzy ELECTRE to determinate the ranking of reverse SC entities upon key stakeholders requirements' fulfillment. In conclusion, there are 3 papers using the fuzzy ELECTRE method to determine the ranking of suppliers and SC entities.

Fuzzy TODIM: Meng et al. (2019) proposed an extended TODIM method with interval type-2 fuzzy sets to evaluate the risk of the SC of social commerce for handling the problem with the risk preference of decision makers and the criteria ambiguity. Wang and Li (2018) extended the TODIM method into the q-rung orthopair fuzzy environment to rank green suppliers. Li et al. (2015) proposed a decision model based on the intuitionistic fuzzy TODIM to improve the validity and reliability of the distributor selection model. Tseng et al. (2014c) used the fuzzy TODIM to identify the best performing units in a green SC. Tseng et al. (2014b) used the fuzzy TODIM to create a mechanism which can help to select alternatives and then explore the importance and performance levels in green SC practices. Sang and Liu (2016) applied the interval type-2 fuzzy sets based the TODIM method to a green supplier selection problem. Qin et al. (2017b) developed an extended TODIM method to solve multi- 
criteria GDM (MCGDM) problems within the context of type-1 fuzzy sets. We find that when researchers analyzed and selected alternatives in SCM, different from other MCDM methods, the TODIM method was combined with interval type-2 fuzzy sets frequently.

Fuzzy MOORA: Liu et al. (2019c) used the q-rung interval-valued orthopair fuzzy MULTIMOORA method to determine the best green supplier. Mohammadi et al. (2017) proposed a supplier selection model on the basis of the fuzzy MOORA method. Mi et al. (2020) applied the stochastic multi-criteria acceptability analysis integrated with the MULTIMOORA method to select green suppliers. Compared with the fuzzy MOORA, the fuzzy MULTIMOORA seems to be a more popular method in handling supplier selection problems.

Fuzzy BWM: Nearly all reviewed papers using fuzzy BWM focused on solving supplier selection problems. Liu et al. (2019a) combined the interval Pythagorean hesitant fuzzy set and the BWM to determine the optimal third-party reverse logistics providers. Ghoushchi et al. (2019) used the fuzzy BWM method to weight the criteria for supplier selection and then used the piecewise linear value function to rank suppliers. Amiri et al. (2021) presented a fuzzy model based on the BWM to select sustainable suppliers. Hendiani et al. (2020b) proposed a multi-stage multi-criteria hierarchical decision making method based on the BWM to select sustainable suppliers.

Other fuzzy MCDM methods: Villa Silva et al. (2019) evaluated suppliers in a SC cycle using fuzzy DA. Rostamzadeh et al. (2017) presented a framework to assess the SCM performance of small-medium sized enterprises using the fuzzy ARAS method. Chai et al. (2012) proposed an intuitionistic fuzzy SIR approach to select suppliers. Chou et al. (2008) proposed a model integrating fuzzy SAW and factor rating system to evaluate facility location alternatives. Chou and Chang (2008) presented a strategy-aligned fuzzy SMART approach to solve a supplier selection problem. Liu et al. (2020) proposed an interactive MCDM method with intuitionistic fuzzy sets, hesitant fuzzy sets and real numbers to deal with a third-party logistics provider selection problem. Mousavi et al. (2019) presented an MCDM model involving interval-valued intuitionistic fuzzy sets to handle the uncertainties when determining locations. Mishra et al. (2019) developed an integrated method to solve the MCDM problems with hesitant fuzzy information based on the weighted aggregated sum product assessment (WASPAS) method, aiming at selecting green suppliers. Chang (2019) proposed a supplier selection approach with the intuitionistic fuzzy weighted averaging method. Deng et al. (2018) developed an algorithm with intuitionistic fuzzy numbers to evaluate the performance of alternative GSCM practices across all evaluation criteria in an uncertain environment. Jiang and Huang (2018) proposed an approach called the fuzzy generalized regret decision making method based on the ordered weighted averaging operator to evaluate GSCM performance. Osiro et al. (2018) proposed a GDM model on the basis of the hesitant fuzzy linguistic term sets and the quality function deployment (QFD) method to select the metrics for SC sustainability management. Foroozesh et al. (2018b) introduced a failure mode and effects analysis (FMEA) model with interval-valued fuzzy sets and asymmetric uncertainty information to rank the suppliers. Pang et al. (2017) proposed an MCDM method integrating fuzzy sets and grey relational analysis to select green suppliers in low-carbon SC. Wang et al. (2017b) established an integrated framework taking account of multiple types of risks in SC and ranking alternative risk mitigation strategies based on fuzzy sets and MCDM methods. Ke- 
shavarz Ghorabaee et al. (2016b) proposed an MCGDM method with interval type-2 fuzzy sets based on the WASPAS method to deal with green supplier selection problems. Lee et al. (2016) proposed a fuzzy MCDM model based on interval-valued fuzzy numbers to solve a supplier selection problem. Keshavarz Ghorabaee et al. (2014) proposed a method based on the centroid of fuzzy sets to solve a supplier selection problems. Chou (2010) established an integrated quantitative and qualitative MCDM model with objective crisp data and subjective fuzzy ratings to determine the locations of international distribution centers. Vahdani and Zandieh (2010) presented a fuzzy MCDM model not requiring the weights of decision criteria where linguistic variables were expressed as triangular fuzzy numbers to select suppliers. Chen (2009) proposed a practical decision support model including fuzzy numbers to deal with a supplier selection problem considering multi-criteria. Wadhwa et al. (2009) proposed an MCDM model based on fuzzy sets which can help design effective and efficient flexible return policy according to various criteria. Chatterjee and Kar (2018) developed a method involving the COPRAS approach for ranking potential supplier alternatives. Matawale et al. (2016) examined the application potential of a fuzzy multi-level MCDM approach within the context of supplier selection in agile SC. Keshavarz Ghorabaee et al. (2016a) proposed a method based on the fuzzy ranking and aggregated weights to assess suppliers. Wen et al. (2019) combined the hesitant fuzzy linguistic set and the combined compromise solution (CoCoSo) method to select third-party logistics.

In conclusion, many fuzzy MCDM methods such as fuzzy DA, fuzzy SAW, fuzzy ARAS and fuzzy WASPAS, have been applied with low frequency in reviewed papers, which could be a breakthrough for later researchers who want to use fuzzy MCDM methods to deal with SCM problems. Additionally, we find that there are few papers considering GDM which is also critical in real life. In this sense, further studies could try to use fuzzy MCGDM methods more often.

\subsection{Fuzzy operations research methods in SCM}

Many issues related to supply chain, such as transportation problem, are solved by operations research models. In this sense, it is necessary for SC managers to use operations research methods when making decisions. 87 among 301 collected papers, formulated SCM problems as various types of operations research models.

Fuzzy linear programming: LP is a strong tool to allocate resources under various constraints to achieve the objective of saving costs and increasing profits. Under the uncertain condition, fuzzy parameters can expand the scopes of the use of LP. There are many papers solving provider selection and production planning problems based on the fuzzy LP. Wan and Li (2015) developed a fuzzy LP method to solve heterogeneous MCDM problems aiming at selecting green suppliers. Figueroa-Garcia et al. (2012) developed a model for production planning using fuzzy LP techniques. Qin et al. (2017a) developed an LP to solve interval type2 fuzzy MCGDM problems and applied that method to select suppliers. Wang et al. (2017a) established a fuzzy LP to compute the weights of criteria related to supplier performance, with unknown or incompletely known weight information. Khalili-Damghani and Ghasemi (2016) modelled an uncertain decentralized decision making problem through fuzzy mathematical programming. Li and Wan (2014) developed a fuzzy LP to solve the outsourcing 
provider selection problem. Ariafar et al. (2014) applied fuzzy sets in the LP modeling to solve the issue of uncertainty of a real-world production system. Wan and Li (2013) extended the LP for multi-dimensional analysis of preference for solving supplier selection problems. Jung and Jeong (2012) built a SC planning model based on the fuzzy LP. Kabak and Ulengin (2011) used a possibilistic LP to make strategic resource-planning decisions using fuzzy demand forecasts and fuzzy yield rates. Peidro et al. (2010a) developed a fuzzy LP model for tactical SC planning. Onar and Ates (2008) used a fuzzy LP to optimize SC decisions. Chen and Chang (2006) proposed an approach based on fuzzy mathematical programming which can represent SC models with fuzzy parameters accurately for designing SC.

Fuzzy non-linear programming: Chen and Cheng (2014) proposed a pair of two-level mathematical programming problems to identify the lower and upper bounds of the fuzzy performance at different possibility levels for conserving the fuzziness of the input information of an SC. Liu and Kao (2004) formulated a pair of mathematical programming problems to calculate the bounds of the fuzzy total transportation cost at a possibility level alpha. Compared with the fuzzy LP, the fuzzy non-linear programming was used less in SCM research, which leaves room for researchers to develop.

Fuzzy chance-constrained programming: Chance-constrained programming means that the constraints contain random variables in programming, and for dealing with the chance constraints, fuzzy approaches are required. Through the overview of literature, we find that most researchers used the fuzzy chance-constrained programming to select suppliers and solve production planning issues. Sun (2020a) proposed a model to solve a decentralized bi-level vendor selection problem where demand and supply were supposed to be normal random variables and the objective value was a fuzzy number, and then used the fuzzy chance-constrained programming to derive results. Zhang et al. (2011) proposed a framework combining scatter evolutionary algorithm, fuzzy programming and stochastic chance-constrained programming to solve the production planning issue considering bill of materials, production costs and other factors. On account of involving random variables, we suggest that further studies could take fuzzy chance-constrained programming into account when addressing risks in SC.

Fuzzy integer programming: Integer programming is a special case of LP and nonlinear programming, which is suitable to solve practical problems. To minimize the total costs created in road-rail intermodal transportation activities, Sun (2020b) designed a fuzzy mixed-integer nonlinear programming model. Sun et al. (2019b) established two fuzzy mixed integer linear programming problems to solve the green logistics center location and allocation problem under mixed uncertainties. Sun and Li (2019) established a fuzzy mixed integer nonlinear programming with the objectives of minimizing costs and maximizing the service level to accomplish transportation orders. Sun et al. (2019a) established a fuzzy mixed integer nonlinear programming model to solve the capacitated road-rail multimodal routing problem with uncertain demand and time windows. Yazici et al. (2016) proposed a mixed integer linear programming problem, aiming at managing the reverse material flow as a part of production planning to utilize resources. Gupta and Mohanty (2015) formulated the production process as a fuzzy mixed integer programming problem. Ozkan et al. (2015) developed a fuzzy mixed integer linear programming problem to cope with uncertainties related to a 
reverse logistic network. Rahmanzadeh et al. (2020) proposed a fuzzy mathematical model to determine the optimal tactics according to SC objectives. Khalifehzadeh and Fakhrzad (2019) presented a mixed integer linear programming problem to describe the object problem for optimizing the total cost of a production-distribution network. Sharahi et al. (2018) proposed an equivalent auxiliary crisp model converted from a type-2 fuzzy mixed-integer linear programming problem, which can provide an integrated approach to make optimal decisions subject to operational and tactical constraints. Mahdiraji et al. (2018a) proposed a bi-objective mixed integer fuzzy programming which is applicable in network transportation cases. Amin and Zhang (2013) presented a fuzzy multi-objective mixed-integer linear programming problem to select suppliers, refurbishing sites and remanufacturing subcontractors, and determine the order allocation. Chen (2011) formulated a pair of mixed integer nonlinear programming problems to calculate the bounds of the minimal total cost per unit time in the inventory management. Mula et al. (2010) proved the effectiveness of fuzzy mathematical programming in solving the problem of production planning in SC. Peidro et al. (2010b) proposed a fuzzy programming problem to handle an SC planning problem. Amid et al. (2009) developed a fuzzy weighted additive and mixed integer linear programming problem to solve a supplier selection problem including three objective functions. Peidro et al. (2009) used fuzzy mixed-integer linear programming to plan SCs considering supply, demand and process uncertainties. Chen and Lee (2004) constructed a mixed-integer nonlinear programming problem to meet several SC goals, such as minimizing safe inventory levels and maximizing customer service levels. Tabrizi and Razmi (2013) used a mixed-integer non-linear mathematical model when designing a SC.

We can see that there are lots of papers applying fuzzy integer programming to handle SC planning problems, which is a wake-up call for future researchers to consider integer constraints in supply chain decision making.

Fuzzy goal programming and multi-objective programming: Gitinavard et al. (2020) extended a multi-choice goal programming problem regarding the dynamic hesitant fuzzy closeness indexes to concern the preferred compromise response of demand centers. Sun (2020b) established a multi-objective fuzzy mixed integer nonlinear programming problem to solve the specific reliable and green routing problem. Lu et al. (2015) minimized the related operation costs and maximized the average safety stock holding level and service level by fuzzy multi-objective mixed integer programming. Liang (2013) used multi-objective possibilistic programming to solve possibilistic programming problems with imprecise goals, forecast demand and uncertain cost/time coefficients. Tsai et al. (2008) formulated a steel supplier's channel allocation problem as a fuzzy mixed integer multiple goal programming problem including many business competitive advantages. Calik (2020) utilized fuzzy multi-objective programming to solve the developed open-loop SC model. Mahmoodirad et al. (2020) reformulated the closed loop SC network design problem as a multi-objective fuzzy mixed integer linear programming problem using the credibility measure of fuzzy constraints, and then solved by several hybrid fuzzy programming. Charles et al. (2019) formulated a probabilistic fuzzy SC network problem and solved it with three different approaches. Rabbani and Talebi (2019) proposed bi-objective nonlinear mathematical programming to minimize the present value of total system costs and the geographical inequalities in the location selection. 
Babbar and Amin (2018) proposed a mathematical model comprising a two-stage QFD and a stochastic multi-objective mathematical model to select suppliers and assign the order quantity. Dalman and Sivri (2017) implemented fuzzy programming and some techniques of the fuzzy sets theory to solve the multi-objective solid transportation problem in uncertain environment. Pandey et al. (2017) proposed a two-phase fuzzy goal programming problem integrating a hyperbolic membership function to select suppliers. Dai and Dai (2016) used fuzzy multi-objective linear programming to handle the proposed bi-objective closed-loop SC network model with risks caused by fuzziness. Khalili-Damghani et al. (2014) proposed a fuzzy bi-objective mixed-integer linear programming problem to enhance the material flow in SCs with multiple echelons in an uncertain condition. Ramezani et al. (2014) designed a closed-loop SC network with multi-products and multi-periods, and used an equivalent auxiliary crisp model converted from a fuzzy multi-objective mixed-integer linear programming problem to obtain relevant solutions. Mirakhorli (2014) employed interactive fuzzy multi-objective linear programming to design a fuzzy bi-objective reverse logistics network. Kristianto et al. (2014) designed a reconfigurable SC network based on two-stage programming. Wu et al. (2013) developed a stochastic fuzzy multi-objective programming problem to manage the risk of SC outsourcing. Amin and Zhang (2012) proposed a multi-objective mixed-integer linear programming problem to select suppliers and refurbishing sites, and determine the appropriate number of parts and products in closed loop SC network. Paksoy et al. (2012) proposed fuzzy multi-objective linear programming to minimize the total transportation cost. Woo and Saghiri (2011) presented a fuzzy multiple-objective mixed-integer programming problem considering three main parties of the SC to tackle order assignment problems. Liang (2008) developed a fuzzy multi-objective linear programming problem to solve production/distribution planning problems within an integrated multi-product and multi-time period. Kumar et al. (2004) applied a fuzzy goal programming to select vendors with multiple objectives. Balaman et al. (2018) presented a bi-level decision support system to help model and optimize multiple product SCs and co-modal transportation networks combining two multi-objective programming problems, and then proposed a hybrid resolution method integrating fuzzy sets theory and epsilon-constraint method. Mahdiraji et al. (2018b) proposed a method involving a stochastic multi-objective problem and then used a fuzzy set approach to solve that problem.

The problem of multi-objective decision making was often encountered in SCM. When SC managers draws up a plan, they should consider not only the profit, but also the cost, product quality and relationships between suppliers and customers. Given that many goals often contradict each other, for example, corporate profits may conflict with environmental goals, the application of goal programming is a good solution to this kind of problems. Given that many papers used fuzzy goal programming and multi-objective programming, we can know that researchers have realized the importance of considering conflicting goals in decision making, which is also crucial for future studies.

Fuzzy DEA: Cavone et al. (2020) used a cross-efficiency fuzzy DEA method allowing evaluating the efficiency of SC members to solve a partner selection problem. Zhou et al. (2019) used the fuzzy DEA to evaluate 20 sustainable SCs. Amindoust (2018) used the fuzzy DEA to propose a model to evaluate and rank suppliers. Zhou et al. (2016) developed a type- 
2 fuzzy multi-objective DEA model for evaluating and selecting the most optimal sustainable supplier. Pournader et al. (2016) built a fuzzy network DEA model to assess the risk resilience ability of SCs. Mirhedayatian et al. (2014) proposed a fuzzy network DEA model to evaluate the GSCM with dual-role factors and undesirable outputs. Khalili-Damghani and Tavana (2013) proposed a fuzzy network DEA model to measure the performance of agility in SCs. Through the literature review, we find that two papers proposed a fuzzy network DEA model to assess risk resilience ability and measure the performance of agility of an SC, which is a relatively special perspective to study SCM problems.

Integrated fuzzy and inventory model: Inventory problem is one of the key problems in SCM. Wan and Chen (2020) provided a spot purchasing model based on the newsboy model in which the market demand was regarded as a triangular fuzzy variable. Kumar (2018) developed an inventory model with imperfect quality items in a fuzzy environment. Handfield et al. (2009) developed a (Q, r) model based on fuzzy-set representations in an SC. Wang (2009) built a continuous review model using the method with continuous review model to maximize the order quantity and minimize the total cost. Petrovic et al. (2008) considered a single product inventory control in a distributed SC with the demands described by fuzzy linguistic expressions. Xie et al. (2006) used fuzzy sets to describe customer demand when presenting a hierarchical, two-level approach to the inventory management and control. Shekarian et al. (2016) proposed a reverse inventory model including fuzzy demand and fuzzy collection rate of recoverable products. Ryu and Yucesan (2010) used fuzzy parameters for the demand, wholesale price, and market sales price to solve the newsboy problem.

The existing inventory model has been developed maturely, but there are still some issues. For example, the consumer demand could be fuzzy and hard to predict, which can be solved by introducing the fuzzy sets theory into the inventory model. Through the papers presented above, we can see that many scholars have proposed inventory models including fuzzy parameters to determine inventory level and ordering strategy.

Integrated fuzzy and game theory: Sharanlou et al. (2021) developed a fuzzy mathematical model based on the Stackelberg game to determine the price and refund of products in a SC considering the costs of quality and advertising. Jafarian et al. (2019) studied the selling and the acquisition price decisions based on the Stackelberg game in an intuitionistic fuzzy environment. Chavoshlou et al. (2019) developed a fuzzy game which can provide a solution to increase the confidence of players to choose green strategies in SCM. Ke et al. (2018) studied a pricing and remanufacturing decision problem combined with Stackelberg game in a fuzzy closed-loop SC. Sang (2017) considered a greening policies problem on the basis of the game theory in a fuzzy decision making environment. Pang et al. (2006) built two models based on the coalition and income's distribution in fuzzy SC systems using the fuzzy sets theory and fuzzy cooperative game theory.

Game theory can help to balance strategies and benefits among multiple parties, which is useful for managers to analyze the behaviors of suppliers and customers in SCM. The introduction of fuzzy sets theory enables the game theory to adapt to uncertain environments. Through the above papers, we find that most of the fuzzy mathematical models established in the aforementioned articles were based on the Starkberg game, while many other games were not used. In this regard, the fuzzy model based on the Cournot model and Bertrand model could be considered in future study. 
Other approaches integrating fuzzy and operations research: Canbulut and Torun (2020) proposed a closed-form solution to the buyback contract model with fuzzy demand based on the credibility theory. Sahin and Soylu (2020) developed a multi-layer, multi-segment iterative optimization algorithm for the operations of an individual agent in the fuzzy environment. Ruppert et al. (2020) provided a cycle time control algorithm to improve the efficiency of assembly lines and developed a fuzzy model-based solution to deal with the uncertainty of activity time. Mezei and Bjork (2015) incorporated backorders in a fuzzy economic production quantity model. Chen and Huang (2006) proposed a fuzzy model involving the fuzzy sets theory and program evaluation and review technique to calculate the total turnover time of a SC system. Salam et al. (2017) applied the asymmetrical model via fuzzy set qualitative comparative analysis to stress the combinatory causal relation of latent variables when analyzing different types of SC uncertainties.

In conclusion, the papers using other fuzzy OR methods mainly combined the fuzzy sets theory and production management methods to solve production planning and quality control problems. Compared with other OR methods, the approaches about production were applied less frequently, and thus researchers are supposed to use those methods, which may bring a new perspective. Regarding production, besides the methods mentioned above, further studies could consider using dynamic programming to improve the efficiency of production.

\subsection{Fuzzy AI methods in SCM}

AI related methods have become the focus of research in recent years. As a relatively new research branch, there are still few methods that combined the fuzzy sets theory with AI related methods used to study SCM. 18 papers used AI approaches in this research.

Fuzzy genetic algorithms: Concerning fuzzy genetic algorithms, researchers generally utilized genetic algorithms to determine solutions about transportation problems and stock planning problems based on a fuzzy model. Ko (2020) proposed an intelligent empty container dispatching system model where the fuzzy sets theory was used for cost estimation and a genetic algorithm was utilized to obtain an appropriate solution for empty container dispatching. Zhao et al. (2019) used intuitionistic fuzzy sets and the immune genetic algorithm to solve the proposed MCDM model considering operation costs, market conditions and other criteria from a comprehensive view. Nakandala et al. (2016) used the fuzzy genetic algorithm to illustrate the practical application of the proposed total cost model which included various costs incurred during transportation. Xu et al. (2009) presented the spanningtree based oil genetic algorithm to solve a multi-stage SC design problem in a fuzzy environment. Wang and Shu (2007) established a fuzzy SC model to evaluate the performance of SC and applied a genetic algorithm-based approach to determine near-optimal solutions. Wang and Shu (2005) developed a genetic algorithm-based approach to decide the order-up-tolevels of stock keeping units in SC based on the proposed fuzzy SC model.

Fuzzy inference system: Dixit et al. (2019) constructed a fuzzy inference system which was incorporated into a system dynamic model to interact with the main SC structure. Pourjavad and Shahin (2018a) applied the fuzzy inference system to evaluate the GSCM performance of companies with respect to green criteria. Amindoust and Saghafinia (2017) 
proposed a modular model based on the fuzzy inference system to cope with the subjectivity of opinions of decision-makers. Carrera and Mayorga (2008) proposed a fuzzy inference system to handle the impreciseness and uncertainty existed in the process of supplier selection. Sremac et al. (2019) proposed a neuro-fuzzy inference systems approach to determine the amount of economic order. We find that many scholars would apply fuzzy inference systems to deal with problems when facing uncertain environments in SCM.

Integrated fuzzy and Dempster-Shafer theory: Similar to fuzzy genetic algorithms, researchers usually adopted fuzzy sets to express the fuzziness of criteria and established models, and then used the Dempster-Shafer theory to determine solutions. Shankar et al. (2018) developed a risk analysis approach integrating the intuitionistic fuzzy sets theory and D-number theory to assess the sustainability risks in freight transportation systems. Zheng et al. (2017) constructed an influence diagram evaluation system and modified a corresponding algorithm based on the fuzzy sets theory and Dempster-Shafer theory. Yu et al. (2018) adopted interval-valued intuitionistic fuzzy sets to express the fuzziness of multiple criteria and utilized an improved Dempster-Shafer theory to synthesize decision results of experts in order to solve a supplier selection problem.

Integrated fuzzy and particle swarm optimization: Besides genetic algorithms and the Dempster-Shafer theory, there were also papers using the integrated fuzzy and particle swarm optimization to solve SCM models with fuzzy parameters. Jana et al. (2016) established a chance-constrained expected value model where supply capacities and demands were considered as Gaussian type-2 fuzzy variables to deal with a transportation problem, which was solved by using a modified particle swarm optimization. Grillo et al. (2015) modelled uncertainty in SCM using fuzzy sets and proposed the particle swarm optimization metaheuristics technique as a resolution method. Mahnam et al. (2009) used the hybridization of multi-objective particle swarm optimization and simulation optimization to solve a bicriteria inventory model involving fuzzy demand.

Other approaches integrating fuzzy and artificial intelligence: Wang et al. (2014) developed a fuzzy clustering algorithm based on axiomatic fuzzy sets to divide customers into different groups. Wu and Barnes (2016) integrated the fuzzy set theory and artificial immune optimization technology to consider quantitative and qualitative criteria simultaneously in the process of partner selection for reverse logistic centers in GSCs. Wu and Barnes (2014) proposed a fuzzy intelligent approach combining fuzzy sets and radial basis function artificial neural network to select partners in a agile SC.

Although there have been many papers using fuzzy AI methods to handle SCM issues, compared with the developments of AI techniques in recent years, the number of papers with fuzzy AI methods increased at a slow rate. AI is a strong instrument to deal with fuzzy problems. Therefore, further studies could apply more AI techniques to handle fuzziness in the real world.

\subsection{Fuzzy statistic methods in SCM}

Statistic methods are helpful for managers to have a comprehensive understanding of various data which can be used to find and solve problems. There are 5 papers utilizing fuzzy statistic approaches to deal with SCM problems. 
Fuzzy possibilistic statistical methods: Foroozesh et al. (2018a) defined the mathematical relations of mean, variance and skewness in a location decision model based on a fuzzy possibilistic statistical approach. Foroozesh et al. (2017) presented a GDM approach integrating interval-valued fuzzy sets and possibilistic-statistical concepts, and implemented it to schedule flexible manufacturing systems. Foroozesh et al. (2019) presented a possibilistic statistical GDM approach with interval-valued fuzzy sets and asymmetric information to deal with resilient supplier selection problems in SC networks. We find that all papers using fuzzy possibilistic statistical methods were written by the research team of Foroozesh, which indicates that the researchers of that team created a new method to deal with SCM problems.

Integrated fuzzy and clustering methods: Given that a large amount of data is difficult to collect in reality, there are few papers using integrated fuzzy and clustering methods. Wang et al. (2014) presented a fuzzy-based customer clustering algorithm to handle the customer clustering issue. Ewbank et al. (2020) proposed a methodology combining fuzzy time series with clustering techniques to handle a problem in which producers presented several uncertainties about demand logs.

\subsection{Hybrid methods of fuzzy MCDM, OR and AI}

In some cases, it is difficult to deal with issues with only one fuzzy method. Therefore, many researchers chose to use hybrid methods when analyzing SCM problems. In this section, we present papers which applied hybrid methods of fuzzy MCDM, OR and AI techniques.

Hybrid methods of fuzzy MCDM: Pournamazi et al. (2020) proposed a hybrid MCDM methodology of ANP and VIKOR in a hesitant environment to determine the position of customer order decoupling point in a SC. Kumar and Anbanandam (2020) used a datadriven method based on the intuitionistic fuzzy-set-based AHP and VIKOR to evaluate alternative transport firms. Dey et al. (2016) used the fuzzy TOPSIS-SAW-MOORA to assess subjective criteria of a warehouse location problem. Xiong et al. (2020) proposed a hybrid method integrating the BWM, WASPAS, and TOPSIS to solve a problem that no comprehensive criteria system and performance values were expressed by crisp numbers. Rani et al. (2020a) proposed a framework on the basis of the COPRAS and SWARAS methods to select the desirable sustainable supplier within the hesitant fuzzy sets context. Wang et al. (2020) applied the fuzzy AHP to determine the weights of potential suppliers and used the PROMETHEE II to rank the suppliers. Pinar and Boran (2020) introduced the q-ROF TOPSIS and q-ROF ELECTRE method for GDM to select the best supplier. Chen et al. (2020) proposed a hybrid rough-fuzzy DEMATEL-TOPSIS method to select sustainable suppliers for a smart SC. Kumar and Anbanandam (2019) employed the intuitionistic fuzzy AHP to compute the importance of criteria and used the intuitionistic fuzzy TOPSIS to measure the sustainability assessments of alternative locations. Mohd et al. (2019) proposed a method integrating the Pythagorean fuzzy AHP and Pythagorean fuzzy VIKOR to select green supplier development programs. Mohammed et al. (2019) proposed an integrated fuzzy AHP-TOPSIS method to rank suppliers depending on three sets of criteria. Kang et al. (2019) adopted the fuzzy DEMATEL to understand the interrelationships among criteria, applied the fuzzy ANP to calculate the importance of factors and used the fuzzy TOPSIS to rank the business process information systems. Gupta et al. (2019) proposed an MCDM framework based on 
the fuzzy AHP, MABAC, WASPAS and TOPSIS to evaluate green suppliers. Phochanikorn and Tan (2019) proposed an MCDM model consisting of the intuitionistic fuzzy DEMATEL, ANP and VIKOR for sustainable supplier selection. Wu et al. (2019) built a model combining the fuzzy DEMATEL with the fuzzy ANP to determine the global weights of SC paradigms and practices and developed their impact relation map. Darbari et al. (2019) used the fuzzy AHP-TOPSIS to model the multi-criteria perspectives of stakeholders in a closed loop SC. Hou and Xie (2019) presented green supplier evaluation indexes by the DEMATEL method and used an improved TOPSIS method to calculate the relative closeness for ranking green suppliers. Abdel-Basset et al. (2018) employed the ANP to calculate the weights of selected criteria and used the TOPSIS to rank alternative suppliers. Sen et al. (2018) applied the intuitionistic fuzzy TOPSIS, MOORA and grey relation analysis to solve a sustainable supplier selection problem. Tian et al. (2018) developed a method integrating the fuzzy TOPSIS and BWM to solve an MCGDM problem about selecting green suppliers. Chakraborty et al. (2018) used the fuzzy ANP to identify the weights of sub-issues, according to the causal relations obtained by the DEMATEL method which developed the causal framework among the identified strategical and tactical issues for setting up a reverse SC. Sahu et al. (2018) used the fuzzy VIKOR, SAW and grey relation analysis to select the optimal alternative for GSCM. Wu et al. (2017) used the fuzzy Delphi method to screen unnecessary attributes, and then applied the fuzzy DEMATEL and ANP to evaluate the SC agility. Rostamzadeh et al. (2015b) adapted the fuzzy AHP to evaluate objective function weights in SCM and then used the TOPSIS to determine the weights of objective functions for designing a SCM system. Li et al. (2012b) constructed a fuzzy AHP model to determine the weights of various quantitative and qualitative criteria and employed the TOPSIS to select suppliers. Zandi et al. (2011) proposed an MCGDM method combining real option analysis and the AHP with the ELECTRE method for electronic SCM framework evaluation and selection. Ertay et al. (2011) constructed a methodology using the fuzzy AHP and ELECTRE III to evaluate criteria for evaluating and monitoring the performance of suppliers. Tuzkaya et al. (2009) proposed a methodology utilizing a hybrid fuzzy ANP and fuzzy PROMETHEE approach to evaluate the environmental performance of suppliers. Liao et al. (2019) integrated the BWM and ARAS under the hesitant linguistic environment to select digital SC finance suppliers. Liao et al. (2020) applied different MCDM methods to promote the development of economy. Chatterjee et al. (2018) proposed a multi-criteria evaluation framework based on the DEMATEL-ANP method to solve green supplier selection problems. Debnath et al. (2017) proposed a hybrid MCDM method combining DEMATEL and MABAC to select strategic project portfolio. Liou et al. (2016) used the DEMATEL technique to construct the relationships between criteria and applied the ANP method to acquire the weights of the criteria. Mahdiraji et al. (2020) used a hybrid method combing fuzzy BWM and TODIM to evaluate strategies. Pamucar et al. (2019) presented a fuzzy approach based on the BWM, WASPAS and MABAC to assess third-party logistics. Tamošaitienè et al. (2017) proposed a hybrid MCDM approach combing fuzzy AHP and ARAS to select suppliers.

Similar to the usage of single fuzzy MCDM methods, hybrid methods involving fuzzy TOPSIS and fuzzy AHP were used most in research papers, which shows the practicality of those methods in SCM. All in all, according to the large quantity of papers, we can know that whether single or hybrid methods were used, when dealing with alternative evaluation and 
selection problems in SCM, fuzzy MCDM is the most popular among researchers.

Hybrid methods of MCDM and OR: Khalilzadeh et al. (2020) proposed a multiple objectives mixed integer mathematical programming problem with fuzzy parameters where the weights of suppliers were determined by the fuzzy TOPSIS to select suppliers and allocate orders considering multiple periods. Haldar et al. (2017) proposed a DEA-TOPSIS-LP model to evaluate and select third-party logistics vendors. Afzali et al. (2016) presented a fuzzy multi-objective LP problem with GDM where the TOPSIS method was used to determine the weights of criteria and constraints to select suppliers. Igoulalene et al. (2015) formulated the strategic supplier selection problem as a multi-stakeholder MCDM problem and used two hybrid approaches involving the fuzzy consensus-based possibility measure, fuzzy TOPSIS, fuzzy consensus-based neat OWA and GP. Singh (2015) proposed a hybrid fuzzy TOPSIS and mixed linear integer programming to provide information for supplier evaluation and demand allocation among suppliers in a SC. Mohaghar et al. (2013) proposed a method integrating the fuzzy VIKOR and the assurance region-DEA to select and rank suppliers. Li et al. (2012c) outlined a hybrid method to select competitive suppliers in a SC where the fuzzy AHP was established to calculate the weights of various factors and the DEA was presented to decide the backup suppliers. Kuo et al. (2010) developed a performance evaluation method incorporating the fuzzy AHP and fuzzy DEA to help organizations select suppliers. Giallanza and Puma (2020) constructed a multi-objective fuzzy chance-constrained programming problem to minimize the total costs and carbon emissions to solve a three-echelon fuzzy green vehicle routing problem and applied the ELECTRE III to select the best solution belonging to each Pareto front.

Through the papers presented above, we can find that most researchers combined fuzzy TOPSIS, AHP, LP, integer programming, GP and DEA to select suppliers, while there were still lots of MCDM methods unused. Therefore, further studies could not be limited to the methods mentioned above.

Hybrid methods of MCDM and AI: When integrating fuzzy MCDM and AI methods, researches seem to tend to apply the Dempster-Shafer theory. Fei et al. (2019a) proposed a DS-VIKOR method which expended the VIKOR by the Dempster-Shafer theory to select suppliers. Fei et al. (2019b) developed an MCDM method based on the ELECTRE where the evaluation information was expressed and handled by the Dempster-Shafer theory to select optimal SC. Pourjavad and Shahin (2018b) used the fuzzy DEMATEL method to determine important criteria by avoiding low influences and then adopted a Mamdani fuzzy inference system model to evaluate sustainable SCs.

Hybrid methods of fuzzy OR and AI: Usually, when addressing SCM problems with hybrid methods of fuzzy OR and AI, researchers would propose a fuzzy OR model firstly and then apply AI techniques to generate optimal solutions. Wang and Lin (2006) proposed a fuzzy hybrid decision-aid model integrating a fuzzy multi-criteria outranking approach with a fuzzy LP problem to deal with qualitative and quantitative factors, and then applied a genetic algorithm approach to select the most appropriate set of partners. Sengupta et al. (2018) established a chance-constraint programming problem to solve a multi-objective solid transportation problem considering carbon emissions, and then used a genetic algorithm and particle swarm optimization algorithm to generate efficient and optimal solutions. Jana et al. (2017) reformulated the transportation problem as a chance-constrained programming 
problem which was solved using generalized reduced gradient and modified particle swarm optimization techniques. Das et al. (2016) established two chance-constrained programming problems to tackle the multi-item multi-stage solid transportation problem which were solved by genetic algorithms. Pirayesh and Yazdi (2010) built a fuzzy nonlinear programming problem to reduce the total cost of a two level SC system and developed a genetic algorithm to obtain a near-optimal solution.

\subsection{Other fuzzy methods}

On the basis of the fuzzy sets theory, many researchers proposed novel approaches to solve SCM problems. Giannoccaro et al. (2003) presented a method based on the concept of echelon stock and fuzzy sets theory to define a SC inventory management policy. Shen and $\mathrm{Yu}$ (2009) presented a fuzzy approach including a risk judgmental procedure to help managers link the criteria of facility location with the operation strategy requirements. Temur (2016) applied an MCDM approach using a notion called cloud based design optimization, which can consider certain and uncertain factors simultaneously and provide a solution in the worst case, to decided location under high uncertainty. Chan and Qi (2002) proposed a channel-spanning performance measurement method in the perspective of system where the fuzzy sets theory was introduced to deal with the real situation in the process of evaluation. Mousavi et al. (2020) built an MCGDM model by interval type-2 trapezoidal fuzzy numbers to tackle a green supplier selection problem. Wang et al. (2019) developed a fuzzy gain-loss evolutionary computational approach to evaluate the performance of a supplier in percentage. Olfat et al. (2019) proposed a performance measurement approach based on the extended type-2 fuzzy network to determine the efficiency of distribution centers in fast moving consuming goods industry. Dai and Bai (2020) proposed an agricultural product supplier selection algorithm on the basis of the Pythagorean fuzzy power Bonferroni mean operator to deal with a supplier selection problem. Shamout (2020) applied the fuzzy setsbased qualitative comparative analysis technique to establish causal relations for achieving high scores of SC agility. Abdullah and Otheman (2017) proposed a modified technique with interval type-2 fuzzy sets and the linguistic weighted average operator to handle the problem of supplier selection. Samantra et al. (2013) adopted an approach based on generalized trapezoidal fuzzy sets to evaluate the agility of SC. Cigolini and Rossi (2008) investigated a method by applying fuzzy sets to assess SC integration. Hendiani et al. (2020a) proposed a framework based on a hierarchical soft computing method to obtain a sustainable indicator. Wu and Liao (2020) introduced a utility-based hybrid fuzzy axiomatic design approach to assess credit risk in SC finance.

In addition, the fuzzy sets theory has been applied to establish SCM models in many papers. Petrovic et al. (1999) developed a SC model to determine the order quantities for each inventory under uncertainty and the uncertainties appeared in the model were described by fuzzy sets. Petrovic et al. (1998) described fuzzy modelling and simulation of a SC in a fuzzy environment. Petrovic (2001) developed a simulation tool named the SCSIM to analyze SC behaviour and performance in an uncertainty environment where uncertainties perceived in SC data were expressed by imprecise natural language and then modeled in the SCSIM by fuzzy sets. Li et al. (2012) established a comprehensive evaluation model for third-party 
logistics suppliers based on fuzzy sets. Yu and Jin (2011) designed a return policy for suppliers by considering a supplier-retailer channel where the retail price and customer demand were described as fuzzy numbers. Deshpande et al. (2004) proposed an algorithm using the fuzzy set method to assign tasks for the real-time operation in a SC. Jain et al. (2005) proposed a fuzzy enhanced high level petri net model for providing an instrument for dynamic modelling and analysis of SC operations within the uncertain context. Sang (2016b) studied coordination mechanisms between one manufacturer and one retailer within the context of fuzzy decision making where the parameters of the models were expressed as triangular fuzzy variables. Sang (2016a) considered the revenue sharing contract among SC stakeholders where customer demand and retail price were expressed by fuzzy variables. Gill (2009) used a fuzzy approach to deal with the dock bay requirements of a loading facility involving fuzzy throughput, truck capacity, dock availability and loading times. Liu et al. (2019d) established a decentralized SC coordination model and an integrated SC coordination model where the demand was a triangular fuzzy number.

The following papers introduced language preference into SCM problems in uncertain environments. Tseng (2011) proposed a fuzzy method where the weights of criteria and alternatives for GSCM were expressed by linguistic terms to select an optimal green supplier. Buyukozkan and Cifci (2013) applied an extended QFD in sustainable SCM by means of introducing a GDM approach which considered multiple preference formats and incomplete information, and used the fuzzy sets theory to fusion different formats of expressions into comprehensive values. Islam et al. (2018) applied the fuzzy importance and performance analysis method to identify the importance and performance levels of GSC practices. Reimann et al. (2017) used the fuzzy set-based qualitative comparative analysis technique to explore the ways that cognitive, behavioral, and structural factors across the individual and group level combined, to give rise to either dysfunctional conflict or constructive interaction after supplier-induced disruptions.

The rest of the papers proposed framework and practical procedure in the fuzzy environment to select suppliers and determine locations. Wu et al. (2020) proposed a framework in interval type-2 fuzzy environment to select the most appropriate green supplier of electric vehicle charging facility. Wang et al. (2018) developed a precise evaluation framework based on the fuzzy interpretive structural model which provided a theoretical foundation to strengthen the understanding of responsible consumption and production in the fields of academic and industrial. Wu et al. (2014) provided a practical procedure involving fuzzy information given that the measurement errors were usually unavoidable in the inspection phase to rank suppliers. Ou and Chou (2009) investigated six factors for international distribution center selection and presented a weighted fuzzy factor rating system to solve this problem. Goker et al. (2020) introduced a distance-based hierarchical intuitionistic fuzzy decision making procedure which uses intuitionistic fuzzy numbers to represent the hesitancy in identifying optimal agile suppliers.

In general, if the papers were focused on evaluating and selecting suppliers and SCs, the conventional fuzzy MCDM approaches would be used frequently. In other hand, if researchers wanted to build an SC with high performance and high level of agility and coordination from scratch, they usually considered establishing a new supply chain model based on the fuzzy sets theory. 


\section{Applications of fuzzy techniques in SCM}

Fuzzy techniques have been applied to solve issues regarding the fields of the whole SC system, supplier, production, inventory, distribution, transportation, location, customer, and the others. According to Figure 5, we can clearly see that a large proportion of papers focused on the SC system optimization (37\%) and supplier management (34\%), followed by transportation management (9\%), inventory management (5\%), location determination (4\%) and production management $(4 \%)$, while there are also some researches in fields of distribution management $(2 \%)$, customer management $(2 \%)$ and the others $(3 \%)$.

SC system optimization: There are 30 papers aiming at reducing cost and increasing profit in SCM by presenting a SC model and designing a SC network, 19 papers identifying and evaluating factors affecting SCM to improve SC performance, 13 papers assessing SC alternatives and selecting the best one, 10 papers presenting different approaches to solve planning and decision problem of SC practices, 9 papers focusing on managing and controlling SC risk. Table 7 presents the details of papers mentioned above.

Pournamazi et al. (2020) addressed the positioning problem of a push-pull boundary in a fuzzy hesitant condition. Zheng et al. (2017) proposed a fuzzy evidential influence diagram to evaluate an SC financial system. Shete et al. (2020) investigated sustainable SC innovation enablers to achieve sustainability in an SC. Shamout (2020) examined a configural combination subsuming SC data analytics, firm size, age and annual sales to predict SC agility. Canbulut and Torun (2020) analyzed different configurations of buyback contracts on SC performance in a fuzzy environment. Narayanan et al. (2019) identified, modeled, analyzed and prioritized the barriers in conducting sustainable SC practices. Kang et al. (2019) proposed a hybrid MCDM approach to evaluate business process information systems. Poornikoo and

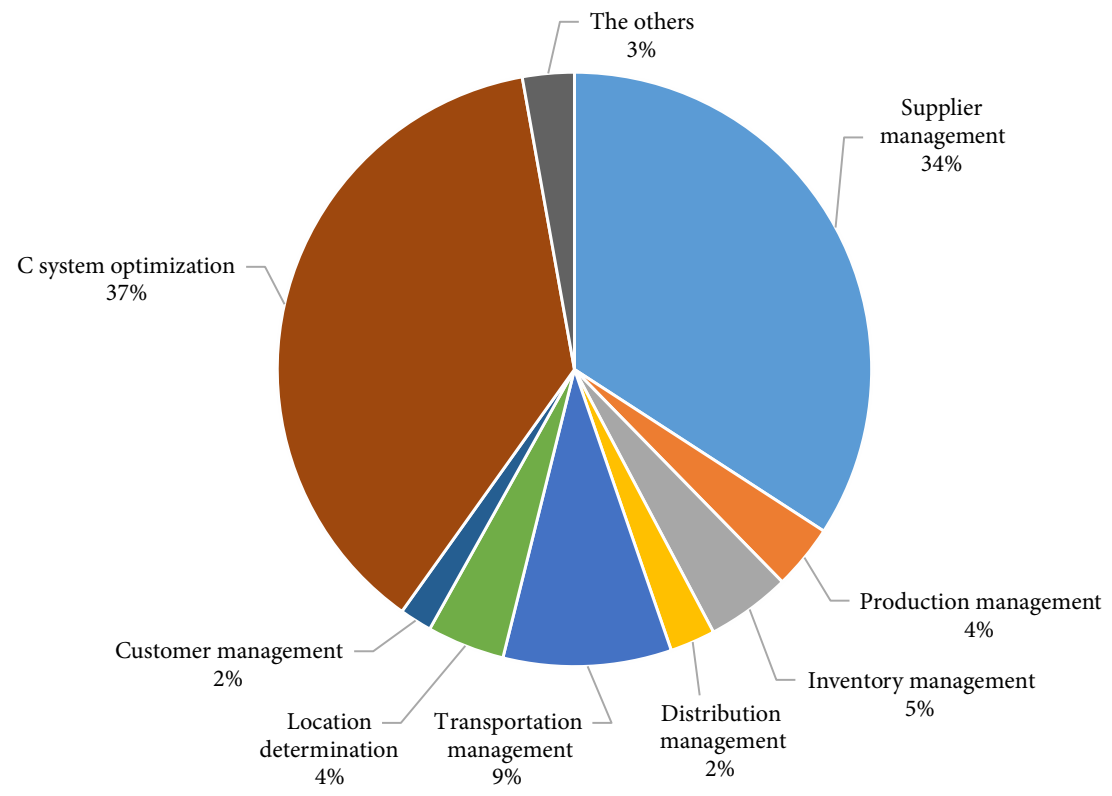

Figure 5. Distribution of the types of applications 
Qureshi (2019) provided a holistic system-based perspective and proposed a fuzzy logic decision making implementation to mitigate bullwhip effect in SCM. Chavoshlou et al. (2019) proposed a fuzzy game of three SC stakeholders' payoffs, which can help to increase the confidence of players to choose green SCM strategies. Liu et al. (2019d) studied the SC returning strategy and quantity discount coordination considering product quality defects. Wang et al. (2018) provided a theoretical basis to enhance the understanding of responsible consumption and production. Sahu et al. (2018) developed an appraisement platform to benchmark green alternatives in an SC network. Salam et al. (2017) analyzed different types of SC uncertainties and suggested tactics to address unexpected contingencies for providing superior operational performance. Wu et al. (2017) benchmarked the core competencies and established a set of attributes for augmenting the SC agility. Sang (2016) considered the revenue sharing contract between SC stakeholders in a multi-echelon SC, where the customer demand and retail price were fuzzy variables. Wicher et al. (2016) presented a fuzzy methodology to measure the metallurgical SC resilience. Grillo et al. (2015) used fuzzy sets to model uncertainty in SC planning problems. Khalili-Damghani et al. (2014) proposed a fuzzy model to enhance the material flow in dual-channel, multi-item, multi-objective and multiple echelons SCs in an ambiguous environment. Chen and Cheng (2014) investigated decision making in multi-echelon serial SCM under the condition of uncertainty caused by human reasoning. Chiu and Teng (2013) proposed a method based on fuzzy sets to tackle the uncertainty of SC while highlighting sustainable design concepts. Khalili-Damghani and Tavana (2013) proposed a network-based DEA model to measure the performance of agility in SCs. Samantra et al. (2013) adopted an approach based on generalized trapezoidal fuzzy sets to evaluate the agility in SC. Woo and Saghiri (2011) presented a fuzzy multiple-objective mixed-integer programming problem to address different features of order assignment problems. Wadhwa et al. (2009) proposed a fuzzy MCDM model to design flexible return policy depending on various criteria. Deshpande et al. (2004) proposed an algorithm with fuzzy sets for the real-time operation in an SC. Debnath et al. (2017) proposed a hybrid MCDM method to select strategic project portfolio. Hendiani et al. (2020a) proposed a framework to acquire a sustainable index for SC. Kumar et al. (2019) used fuzzy MCDM methods to determine potential risks in adopting GSC plans. Mahdiraji et al. (2020) combined the fuzzy BWM and TODIM to evaluate and select SC strategies. Wu and Liao (2020) used fuzzy axiomatic design to assess credit risk in SC finance.

All in all, more than a third of the reviewed papers applied fuzzy techniques to study the whole SC, including selecting optimal SC, evaluating SCM factors, optimizing existing SCs, building new SC models and controlling SC risk, which indicates that in the research field of SCM, compared with the study of a certain practice of the SC, most researchers tended to optimize the whole SC system.

Supplier management: 96 papers concerning supplier concentrated on using various fuzzy techniques to evaluate and select suppliers, the details of which are presented in Table 7. In addition, Reimann et al. (2017) conducted a research on the supplier-induced disruptions problem. The large number of papers concerning supplier selection suggests that fuzzy methods are applicable to supplier evaluation in uncertain environments. 
Table 7. Literature on fuzzy methods in SC system optimization and supplier evaluation

\begin{tabular}{|c|c|c|}
\hline Application & Year & Authors \\
\hline \multirow{11}{*}{$\begin{array}{l}\text { SC } \\
\text { modelling }\end{array}$} & 1998 & Petrovic et al. \\
\hline & 1999 & Petrovic et al. \\
\hline & 2005 & Jain et al. \\
\hline & 2006 & Chen \& Chang; Chen \& Huang \\
\hline & 2007 & Wang \& Shu \\
\hline & 2008 & Onar \& Ates \\
\hline & 2009 & Peidro et al. \\
\hline & 2010 & Peidro et al. \\
\hline & 2015 & Rostamzadeh et al. \\
\hline & 2016 & Sang; Khalili-Damghani \& Ghasemi \\
\hline & 2020 & Rahmanzadeh et al. \\
\hline \multirow{9}{*}{$\begin{array}{l}\text { SC network } \\
\text { designing }\end{array}$} & 2004 & Chen \& Lee \\
\hline & 2009 & Xu et al. \\
\hline & 2011 & Kabak \& Ulengin \\
\hline & 2012 & Amin \& Zhang; Paksoy et al. \\
\hline & 2013 & Tabrizi \& Razmi; Amin \& Zhang \\
\hline & 2014 & Ramezani et al.; Mirakhorli; Kristianto et al. \\
\hline & 2018 & Sharahi et al. \\
\hline & 2019 & Charles et al.; Darbari et al. \\
\hline & 2020 & Cavone et al.; Calik; Mahmoodirad et al. \\
\hline \multirow{7}{*}{$\begin{array}{l}\text { SCM factors } \\
\text { evaluation }\end{array}$} & 2013 & Buyukozkan \& Cifci; Lin; Mavi et al. \\
\hline & 2014 & Tseng et al. \\
\hline & 2015 & Govindan et al.; Rostamzadeh et al.; Wu et al.; Tyagi et al. \\
\hline & 2016 & Malviya \& Kant; Tseng et al. \\
\hline & 2018 & Osiro et al.; Malviya et al.; Islam et al.; Chakraborty et al. \\
\hline & 2019 & Akbarzadeh et al. \\
\hline & 2020 & Tseng et al.; Dahooie et al. \\
\hline \multirow{8}{*}{$\begin{array}{l}\text { SC } \\
\text { evaluation } \\
\text { and } \\
\text { selection }\end{array}$} & 2001 & Petrovic \\
\hline & 2002 & Chan \& Qi \\
\hline & 2008 & Cigolini \& Rossi \\
\hline & 2011 & El-Baz; Zandi et al. \\
\hline & 2014 & Mirhedayatian et al. \\
\hline & 2017 & Rostamzadeh et al. \\
\hline & 2018 & Deng et al.; Pourjavad \& Shahin; Pourjavad \& Shahin; Nestic et al. \\
\hline & 2019 & Zhou et al.; Wang et al. \\
\hline \multirow{6}{*}{$\begin{array}{l}\text { SC risk } \\
\text { management }\end{array}$} & 2012 & Wang et al. \\
\hline & 2013 & Wu et al.; Wang \& Chan \\
\hline & 2016 & Pournader et al.; Dai \& Dai \\
\hline & 2017 & Wang et al. \\
\hline & 2018 & Rostamzadeh et al. \\
\hline & 2019 & Duric et al.; Meng et al. \\
\hline
\end{tabular}


End of Table 7

\begin{tabular}{|c|c|c|}
\hline Application & Year & Authors \\
\hline \multirow{16}{*}{$\begin{array}{l}\text { Supplier } \\
\text { evaluation } \\
\text { and } \\
\text { selection }\end{array}$} & 2004 & Kumar et al. \\
\hline & 2006 & Chen et al. \\
\hline & 2008 & Chou \& Chang; Carrera \& Mayorga \\
\hline & 2009 & Chen; Boran et al.; Amid et al.; Tuzkaya et al. \\
\hline & 2010 & Sanayei et al.; Vahdani \& Zandieh; Kuo et al. \\
\hline & 2011 & Tseng; Cifci \& Buyukozkan; Amid et al.; Ertay et al. \\
\hline & 2012 & Li et al.; Chai et al. \\
\hline & 2013 & Wan \& Li; Shen et al.; Govindan et al.; Mohaghar et al. \\
\hline & 2014 & Keshavarz Ghorabaee et al.; Wu et al.; Kannan et al. \\
\hline & 2015 & Wan \& Li; Dou et al.; Igoulalene et al.; Bali et al.; Singh \\
\hline & 2016 & $\begin{array}{l}\text { Keshavarz Ghorabaee et al.; Afzali et al.; Chatterjee \& Kar; Zhou et al.; } \\
\text { Mahmoudi et al.; Lee et al.; Sang \& Liu; Kefer et al.; Matawale et al.; Sahu } \\
\text { et al.; Liou et al. }\end{array}$ \\
\hline & 2017 & $\begin{array}{l}\text { Dos Santos et al.; Mohammadi et al.; Zhao et al.; Qin et al.; Wang et al.; } \\
\text { Kumar et al.; Abdullah \& Othema; Pang et al.; Pandey et al.; Amindoust \& } \\
\text { Saghafinia; Tamošaitienè et al. }\end{array}$ \\
\hline & 2018 & $\begin{array}{l}\text { Wang \& Li; Amindoust; Abdel-Basset et al.; Jiang \& Huang; Foroozesh et al.; } \\
\text { Luu et al.; Shi et al.; Babbar \& Amin; Sen et al.; Banaeian et al.; Tian et al.; } \\
\text { Tseng et al.; Chatterjee \& Kar; Chatterjee et al. }\end{array}$ \\
\hline & 2019 & $\begin{array}{l}\text { Mohd et al.; Mishra et al.; Mohammed et al.; Foroozesh et al.; Gunduz \& } \\
\text { Gunduz; Gupta et al.; Phochanikorn \& Tan; Wu et al.; Liu et al.; Xu et al.; } \\
\text { Chen; Meksavang et al.; Villa Silva et al.; Fei et al.; Ulutas; Fei et al.; Hou \& } \\
\text { Xie; Chang; Liao et al. }\end{array}$ \\
\hline & 2020 & $\begin{array}{l}\text { Dai \& Bai; Xiong et al.; Rani et al.; Muneeb et al.; Wang et al.; Khalilzadeh } \\
\text { et al.; Wu et al.; Pinar \& Boran Rouyendegh; Chen et al.; Mousavi et al.; } \\
\text { Ozbek \& Yildiz; Goker et al.; Mi et al.; Liao et al.; Hendiani et al. }\end{array}$ \\
\hline & 2021 & Amiri et al. \\
\hline
\end{tabular}

Transportation management: 10 papers used fuzzy methods to evaluate and select transport companies (Kumar \& Anbanandam, 2020; Liu et al., 2020; Liu et al., 2019; Liu et al., 2019a, 2019b; Haldar et al., 2017; Li et al., 2012a; Kulak \& Kahraman, 2005; Pamucar et al., 2019; Wen et al., 2019; Yazdani et al., 2017). 5 articles focused on solving the freight routing problem by fuzzy approaches (Sun, 2020a, 2020b; Sun \& Li, 2019; Sun et al., 2019a; Giallanza \& Puma, 2020). 7 papers extended the traditional transportation problem by considering fuzzy conditions (Sengupta et al., 2018; Mahdiraji et al., 2018a; Jana et al., 2017; Dalman \& Sivri, 2017; Das et al., 2016; Jana et al., 2016; Liu \& Kao, 2004). Shankar et al. (2018) proposed a fuzzy method to identify and assess the sustainability risks existed in a freight transportation system. Ozkan et al. (2015) designed a reverse logistics network to minimize costs. Sahin and Soylu (2020) developed an optimization algorithm for the operations of an agent in a transportation system. Kumar and Anbanandam (2019) used an intuitionistic fuzzy based MCDM framework to assess the sustainability of multimodal freight terminal. Balaman et al. (2018) presented a bi-level decision support system to help model and optimize multi-technology, multi-product SCs and co-modal transportation networks. Nakandala et al. (2016) 
developed a method to help make cost optimized transportation decisions to minimize the total cost and maintain the quality of food products above acceptable levels simultaneously. Gill (2009) used a method based on fuzzy sets to handle the dock bay requirement of a loading facility involving imprecise throughput, truck capacity, dock availability and loading time.

Summarizing the above papers, we find that, to reduce costs and improve the efficiency of transportation, researchers have applied fuzzy techniques into various aspects of transportation management, including transport company selection, freight routing determination, and conventional transportation problems with OR solutions.

Inventory management: The uncertainty of customer demand makes it difficult for managers to determine the inventory level and order strategy. In this regard, many papers applied fuzzy techniques to deal with such type of uncertainty. Through the reviewed papers, we can know that inventory problems of OR such as diverse EOQ models and the newsboy problem have been considered with the fuzzy sets theory. Ko (2020) proposed an intelligent empty container dispatching system model to calculate the container dispatching cost and solve the empty container dispatching problem. Kumar (2018) proposed an inventory model considering items with imperfect quality and shortage backlogging. Shekarian et al. (2016) developed a reverse inventory model considering the learning theory affected the recoverable manufacturing process. To improve the overall supply chain performance, Yu and Jin (2011) formulated an inventory model with fuzzy demand and fuzzy price for suppliers to make appropriate return policies which can motivate retailers to make optimal order decisions. Chen (2011) developed a method to solve an inventory problem with a fuzzy objective value and the decision variables being a fuzzy lot size re-order point. Pirayesh and Yazdi (2010) studied a SC system with an inventory control policy of (r, Q) where unsatisfied demand was assumed to be backordered to minimize the inventory cost. Ryu and Yucesan (2010) used a fuzzy approach to solve the newsvendor problem which can help to quantify the cost of misalignment and evaluate the influence of coordination initiatives. Handfield et al. (2009) developed a (Q, r) model including demand, lead time, supplier yield, and penalty cost with fuzzy parameters to control risk in the inventory management. Mahnam et al. (2009) developed an inventory model for an assembly SC network where the fuzzy demand for single product and fuzzy reliability of external suppliers had an effect on the determination of inventory policy. Petrovic et al. (2008) studied a single inventory control problem in a distribution SC which was operated under the condition of uncertain customer demands described by discrete fuzzy sets. Xie et al. (2006) presented a hierarchical, two-level approach to manage and control inventory in SCs. Wang and Shu (2005) handled SC uncertainties and determined SC inventory strategies by developing a fuzzy decision methodology. Giannoccaro et al. (2003) defined a SC inventory management policy based on the concept of echelon stock and fuzzy sets. Sremac et al. (2019) determined the economic order quantity by a fuzzy decision support system.

Location determination: Similar to the applications of fuzzy techniques in supplier evaluation and selection, many fuzzy methods, especially fuzzy MCDM methods, are suitable to assess the criteria of facilities and then determine locations. Sun et al. (2019b) explored a logistics center location and allocation problem in a logistics network consisting of suppliers, logistics centers, and customers. Mousavi et al. (2019) presented an MCGDM model 
to select the locations of cross-docking centers. Foroozesh et al. (2018a) presented a fuzzy MCDM model to solve the warehouse location problem. Cebi et al. (2016) investigated the most appropriate biomass power plant location by examining quantitative and qualitative criteria. Dey et al. (2016) used a fuzzy decision making model to deal with the cross-docking location problem. Rabbani and Talebi (2019) established a mathematical model for locationallocation of organ harvesting centers and transplant centers. Zhao et al. (2019) proposed an MCDM model considering cost, infrastructure, market, policy, technology and natural resources to solve a distribution center location problem. Temur (2016) applied an MCDM method for location decision under high uncertainty. Chou (2010) established an integrated quantitative and qualitative fuzzy MCDM model to determine the locations of international logistics centers. Shen and $\mathrm{Yu}$ (2009) used a dynamic product-process change matrix to link the selection criteria for meeting the need of facility location. Chou et al. (2008) solved facility location problems by a fuzzy MCDM approach.

Production management: There are 6 papers studying the production planning problem under uncertain conditions (Yazici et al., 2016; Gupta et al., 2015; Mahima \& Mohanty, 2015; Lu et al., 2015; Figueroa-Garcia et al., 2012; Zhang et al., 2011; Mula et al.,2010). Besides, Foroozesh et al. (2017) used fuzzy methods to choose proper scheduling types and dispatching rules in flexible management systems. Ruppert et al. (2020) provided a cycle time control algorithm aiming at improving the efficiency of assembly lines. Mezei and Bjork (2015) incorporated backorders in a fuzzy economic production quantity model. Regarding the applications of fuzzy techniques in production management, most papers used fuzzy methods to determine production planning, while few articles focused on improving the efficiency of assembly lines and controlling production quantity, which can be a novel research direction for future studies. Mahdiraji et al. (2018b) used a bi-objective mean-variance method to deal with a manpower allocation problem.

Distribution management: Olfat et al. (2019) evaluated the efficiency and sustainability of distribution centers in fast moving goods sector using a fuzzy measurement approach. Tsai et al. (2008) presented a model to handle a steel supplier's channel allocation issue including decisions of channel mix and capacity allocation for each distribution channel. Abbasianjahromi et al. (2018) used the Kano model, AHP, and a fuzzy MCDM framework to select criteria, determine the weights of criteria, and select the best subcontractor. Sang (2017) studied the green policies in a decentralized channel between one manufacturer and one retailer within the context of fuzzy decision making. Li et al. (2015) proposed a decision model based on fuzzy techniques to improve the reliability and accuracy of distributor evaluation and selection model. Ou and Chou (2009) studied the international distribution center selection problem by investigating six factors. Wang (2009) presented a method with triangular fuzzy numbers to address traditional distribution requirement planning weakness and improve the performance of a distribution requirement planning system.

In summary, there are mainly three applications of fuzzy techniques in distribution management, including evaluating distributor, assessing distribution centers and improving the performance of a distribution planning system.

Customer management: Kumar et al. (2018) proposed a structural hierarchy model to analyze the changing pattern of customer decision making. Grillo et al. (2018) proposed a 
fuzzy model to support the promising process under the condition of lacking homogeneity to meet the homogeneity requirement of customers. Wang et al. (2014) presented a customer clustering algorithm with a hierarchical analysis structure based on fuzzy sets to deal with a customer clustering problem. Ewbank et al. (2020) built a model to analyze demand forecast strategies considering the excess of zeros and low demands simultaneously. Jung and Jeong (2012) investigated methods to manage the irregular and uncertain demands in the process of supply chain planning. The uncertainty of customer demand was mostly taken into account in inventory management. The applications of fuzzy methods in customer management presented above mainly involve analyzing the changing pattern of customer decision, supporting the promising process to meet the homogeneity requirements of customers, and solving customer clustering problems.

Other applications: The remaining papers used fuzzy techniques to assess and select feedstock and SC partners. Gitinavard et al. (2020) proposed a framework with dynamic hesitant fuzzy sets on the basis of a consensus assessment method to select the optimal sustainable feedstock. Additionally, there are 6 papers using fuzzy techniques to evaluate and select SC partners (Wang \& Lin, 2006; Rani et al., 2020b; Yu et al., 2018; Wu \& Barnes, 2014, 2016; Li \& Wan, 2014).

\section{Lesson learnt and future directions in SCM}

We can learn many lessons and explore future development directions of fuzzy techniques in SCM after reviewing the selected papers.

Bibliometric analysis: Based on the results of bibliometric analysis, we can draw the following four directions of future developments:

(1) Given that the number of publications has increased fast in recent years, we think the research of fuzzy techniques in SCM will continue to develop quickly in the next few years. Compared with earlier papers, the recent ones were cited less, and thus the quality of paper should be emphasized in further studies even though sometimes we need more time to get citations.

(2) From the analysis of regions and institutions with most publications, we find that most regions and institutions publishing many papers were from Asia, which denotes that Asia is at a leading position in this research field. Therefore, institutions of other continents could cooperate with those Asia ones in the future.

(3) Through the table of research category, we observe that compared with "engineering", "computer science", "operations research \& management science" and "business \& economics", the papers belonging to the category of "environmental science \& ecology" are less. Given that environmental protection has received more and more attention from people, researchers are supposed to study sustainable and green SC problems more in the future.

(4) From the figure of keywords co-occurrence, we can observe that keywords such as sustainable supplier selection, multi-objective optimization, and sustainable development are used frequently in recent years, which to some extent reflects the future development directions of this research field. 
Fuzzy techniques: Through the analysis of fuzzy techniques applied in reviewed papers, there are five suggestions that should be noted by future researchers:

(1) MCDM methods are so popular among scholars that nearly a third of papers used fuzzy MCDM approaches to solve SCM problems. However, we find that although there are papers using fuzzy DA, ARAS, SMART, SIR and SAW (Villa Silva et al., 2019; Rostamzadeh et al., 2017; Chou \& Chang, 2008; Chai et al., 2012; Chou et al., 2008), they are much less than the papers applying TOPSIS, ANP, and AHP. Therefore, future studies could consider using those less-used methods to support decision making in SCM.

(2) We observe that many papers used different fuzzy MCDM methods to address the same issue; for example, TOPSIS method and AHP method were both used to evaluate and select suppliers (Kannan et al., 2014; Ulutas, 2019). However, there are few studies that compared the effectiveness of different methods. Therefore, to find the most effective and efficient approach, there is still a demand of comparative studies. A widely-accepted benchmark is needed to evaluation different MCDM methods.

(3) We find that there are few papers considering GDM which is also critical in real life. Therefore, further studies could try to use fuzzy MCGDM methods more often.

(4) SCM is closely related to operations research, which suggests that we can use various methods to combine the fuzzy sets theory and diverse operations research models to solve problems. However, in our study, most papers using fuzzy OR methods only took into account fuzzy linear programming, fuzzy integer programming, fuzzy goal programming and multi-objective programming, while few articles applied models such as inventory model and transportation model, which are also useful to deal with SCM problems. Therefore, when handling SCM problems, further studies could try to use different OR methods.

(5) In recent years, with the development of big data and the Internet, methods related to AI have become the hotspot of research. As a relatively new research branch, there are still few methods that combine the fuzzy sets theory with AI techniques to study SCM. Therefore, further studies could apply more fuzzy AI approaches to handle SCM issues.

Applications: The future directions of specific practical applications are presented as follows:

(1) Although nearly all SC practices have been involved in the reviewed papers, we can find that more than half of the articles focused on supplier evaluation and selection and the whole SC system optimization, while the papers concerning production, distribution, and customer management are less. Therefore, to improve the performance of SC, scholars could try to study SCM from the aforementioned perspectives.

(2) There is no doubt that environment protection problem has attracted the attention of more and more people. Therefore, further studies are supposed to pay more attention to sustainable and green SCM.

(3) Under the background of reality, due to the outbreak of COVID-19, many materials need to be manufactured and transported in time. Therefore, researchers could use the fuzzy OR method to improve production efficiency and solve the routing problem under uncertain environment for transmitting medical materials as soon as possible. 


\section{Conclusions}

This paper presented a literature review of 301 papers about fuzzy techniques in SCM from 1998 to 2020. First, we conducted a bibliometric analysis to the reviewed papers, including the analysis of publication trend, citation structure, country, institution, category, highly cited papers and keywords. According to statistical tables and figures, we can know that the volume of publications showed a growth trend from 1998 to 2020 while the citation quantity of articles published each year was volatile. In terms of region and institution, the institutions from China, Taiwan and Iran published the most papers. For research category, most papers belonged to the fields of engineering, computer science, operations research \& management science and business \& economics. In the top 10 highly cited papers, there were 3 articles from Taiwan, which indicated the strong influence of that region in this research direction. We presented the figure of keywords co-occurrence. Concerning the fuzzy methodologies used in reviewed papers, first, fuzzy MCDM methods and fuzzy operations research methods have been applied heavily. In addition, there were also many papers combining fuzzy methods and statistic and AI approaches to solve SCM problems. Furthermore, we found many papers used hybrid techniques. Regarding specific SCM applications, through statistical results, we can see that more than half of papers concentrating on optimizing the whole SC and evaluating suppliers. Besides, there are papers applying fuzzy techniques to deal with other SCM problems such as inventory management, transportation problem, distribution management and customer management. Finally, this study proposed the future directions of fuzzy techniques in SCM based on the literature review.

We found that there may be some references which applied fuzzy techniques to SCM but were not included in the collected records. It is truly hard to determine an ideal retrieval strategy to include all relevant references. This could be regarded as the limitation of this study since we have to make a tradeoff regarding the efficiency and effectiveness of the data collection process. If we change the retrieval strategy to TS = ("fuzzy *") AND TS = ("supply chain") and the time period as from 1998 to 2020, there would return more records. However, it would take more time to conduct such a review. In addition, due to a large number of reviewed papers and limited length, this paper only stated the content of those papers briefly, ignoring the specific methodology construction and application process of each paper. In some ways, it is necessary to read and summarize the related papers carefully for our research development. Besides, there is no doubt that the papers published in recent years involved advanced methods and applications. Therefore, the papers published recently should be given special attention and literature reviews that limit their time span to recent years deserve to be written. Anyway, we hope this work would be helpful for scholars and practitioners to have a general understanding about the state of the art of fuzzy techniques in SCM.

\section{Funding}

The work was supported by the National Natural Science Foundation of China under Grant [numbers 71771156, 71971145]. 


\section{Author contributions}

Keyu LU, Huchang LIAO and Edmundas Kazimieras ZAVADSKAS proposed the original idea and conceived the study. Keyu LU, Huchang LIAO and Edmundas Kazimieras ZAVADSKAS were responsible for developing the method, collecting and analyzing the data. Keyu LU and Huchang LIAO were responsible for data interpretation. Keyu LU and Huchang LIAO wrote the first draft of the article. Edmundas Kazimieras ZAVADSKAS revised the paper.

\section{Disclosure statement}

The authors have no competing financial, professional, or personal interests from other parties that are related to this paper.

\section{References}

Abbasianjahromi, H., Sepehri, M., \& Abbasi, O. (2018). A decision-making framework for subcontractor selection in construction projects. Engineering Management Journal, 30(2), 141-152. https://doi.org/10.1080/10429247.2018.1448967

Abdel-Basset, M., Mohamed, M., \& Smarandache, F. (2018). A hybrid neutrosophic group ANP-TOPSIS framework for supplier selection problems. Symmetry, 10(6), 226. https://doi.org/10.3390/sym10060226

Abdullah, L., \& Otheman, A. (2017). Multi-criteria decision making method based on interval type-2 fuzzy sets for supplier selection. Journal of Informatics and Mathematical Sciences, 9(1), 45-56.

Afzali, A., Rafsanjani, M. K., \& Saeid, A. B. (2016). A fuzzy multi-objective linear programming model based on interval-valued intuitionistic fuzzy sets for supplier selection. International Journal of Fuzzy Systems, 18(5), 864-874. https://doi.org/10.1007/s40815-016-0201-1

Akbarzadeh, Z., Ghadikolaei, A. H. S., Madhoushi, M., \& Aghajani, H. (2019). A hybrid fuzzy multicriteria decision making model based on fuzzy DEMATEL with fuzzy analytical network process and interpretative structural model for prioritizing LARG supply chain practices. International Journal of Engineering, 32(3), 413-423. https://doi.org/10.5829/ije.2019.32.03c.09

Amid, A., Ghodsypour, S. H., \& O’Brien, C. (2009). A weighted additive fuzzy multiobjective model for the supplier selection problem under price breaks in a supply Chain. International Journal of Production Economics, 131(1), 139-145. https://doi.org/10.1016/j.ijpe.2007.02.040

Amid, A., Ghodsypour, S. H., \& O’Brien, C. (2011). A weighted max-min model for fuzzy multiobjective supplier selection in a supply chain. International Journal of Production Economics, 121(2), 323-332. https://doi.org/10.1016/j.ijpe.2010.04.044

Amin, S. H., \& Zhang, G. Q. (2012). An integrated model for closed-loop supply chain configuration and supplier selection: Multi-objective approach. Expert Systems with Applications, 39(8), 67826791. https://doi.org/10.1016/j.eswa.2011.12.056

Amin, S. H., \& Zhang, G. Q. (2013). A three-stage model for closed-loop supply chain configuration under uncertainty. International Journal of Production Research, 51(5), 1405-1425. https://doi.org/10.1080/00207543.2012.693643

Amindoust, A. (2018). Supplier selection considering sustainability measures: an application of weight restriction fuzzy-DEA approach. RAIRO-Operations Research, 52(3), 981-1001.

https://doi.org/10.1051/ro/2017033 
Amindoust, A., \& Saghafinia, A. (2017). Textile supplier selection in sustainable supply chain using a modular fuzzy inference system model. Journal of the Textile Institute, 108(7), 1250-1258. https://doi.org/10.1080/00405000.2016.1238130

Amiri, M., Hashemi-Tabatabaei, M., Ghahremanloo, M., Keshavarz-Ghorabaee, M., Zavadskas, E. K., \& Banaitis, A. (2021). A new fuzzy BWM approach for evaluating and selecting a sustainable supplier in supply chain management. International Journal of Sustainable Development \& World Ecology, 28(2), 125-142. https://doi.org/10.1080/13504509.2020.1793424

Ariafar, S., Ahmed, S., Choudhury, I. A., \& Bakar, M. A. (2014). Application of fuzzy optimization to production-distribution planning in supply chain management. Mathematical Problems in Engineering, 2014, 218132. https://doi.org/10.1155/2014/218132

Atanassov, K. T. (1986). Intuitionistic fuzzy sets. Fuzzy Sets and Systems, 20(1), 87-96. https://doi.org/10.1016/s0165-0114(86)80034-3

Babbar, C., \& Amin, S. H. (2018). A multi-objective mathematical model integrating environmental concerns for supplier selection and order allocation based on fuzzy QFD in beverages industry. Expert Systems with Applications, 92, 27-38. https://doi.org/10.1016/j.eswa.2017.09.041

Balaman, S. Y., Matopoulos, A., Wright, D. G., \& Scott, J. (2018). Integrated optimization of sustainable supply chains and transportation networks for multi technology bio-based production: A decision support system based on fuzzy epsilon-constraint method. Journal of Cleaner Production, 172, 2594-2617. https://doi.org/10.1016/j.jclepro.2017.11.150

Bali, O., Gumus, S., \& Kaya, I. (2015). A multi-period decision making procedure based on intuitionistic fuzzy sets for selection among third-party logistics providers. Journal of Multiple-Valued Logic and Soft Computing, 24(5-6), 547-569.

Banaeian, N., Mobli, H., Fahimnia, B., Nielsen, I. E., \& Omid, M. (2018). Green supplier selection using fuzzy group decision making methods: A case study from the agri-food industry. Computers \& Operations Research, 89, 337-347. https://doi.org/10.1016/j.cor.2016.02.015

Barbosa-Povoa, A. P., da Silva, C., \& Carvalho, A. (2018). Opportunities and challenges in sustainable supply chain: An operations research perspective. European Journal of Operational Research, 268(2), 399-431. https://doi.org/10.1016/j.ejor.2017.10.036

Bhamu, J., \& Sangwan, K. S. (2014). Lean manufacturing: literature review and research issues. International Journal of Operations \& Production Management, 34(7), 876-940. https://doi.org/10.1108/ijopm-08-2012-0315

Boran, F. E., Genc, S., Kurt, M., \& Akay, D. (2009). A multi-criteria intuitionistic fuzzy group decision making for supplier selection with TOPSIS method. Expert Systems with Applications, 36(8), 11363-11368. https://doi.org/10.1016/j.eswa.2009.03.039

Buyukozkan, G., \& Cifci, G. (2013). An integrated QFD framework with multiple formatted and incomplete preferences: A sustainable supply chain application. Applied Soft Computing, 13(9), 3931-3941. https://doi.org/10.1016/j.asoc.2013.03.014

Calik, A. (2020). An integrated open-loop supply chain network configuration model with sustainable supplier selection: fuzzy multi-objective approach. SN Applied Sciences, 2(3), 405. https://doi.org/10.1007/s42452-020-2200-y

Canbulut, G., \& Torun, H. (2020). Analysis of fuzzy supply chain performance based on different buyback contract configurations. Soft Computing, 24(3), 1673-1682. https://doi.org/10.1007/s00500-019-03996-3

Carrera, D. A., \& Mayorga, R. V. (2008). Supply chain management: a modular fuzzy inference system approach in supplier selection for new product development. Journal of Intelligent Manufacturing, 19(1), 1-12. https://doi.org/10.1007/s10845-007-0041-9

Cavone, G., Dotoli, M., Epicoco, N., Morelli, D., \& Seatzu, C. (2020). Design of modern supply chain networks using fuzzy bargaining game and data envelopment analysis. IEEE Transactions on Automation Science and Engineering, 17(3), 1221-1236. https://doi.org/10.1109/TASE.2020.2977452 
Cebi, S., Ilbahar, E., \& Atasoy, A. (2016). A fuzzy information axiom based method to determine the optimal location for a biomass power plant: a case study in Aegean Region of Turkey. Energy, 116, 894-907. https://doi.org/10.1016/j.energy.2016.10.024

Centobelli, P., Cerchione, R., \& Esposito, E. (2017). Environmental sustainability in the service industry of transportation and logistics service providers: Systematic literature review and research directions. Transportation Research Part D-Transport and Environment, 53, 454-470. https://doi.org/10.1016/j.trd.2017.04.032

Chai, J. Y., Liu, J. N. K., \& Xu, Z. S. (2012). A new rule-based sir approach to supplier selection under intuitionistic fuzzy environments. International Journal of Uncertainty Fuzziness and KnowledgeBased Systems, 20(3), 451-471. https://doi.org/10.1142/S0218488512500237

Chakraborty, K., Mondal, S., \& Mukherjee, K. (2018). Developing a causal model to evaluate the critical issues in reverse supply chain implementation. Benchmarking-An International Journal, 25(7), 1992-2017. https://doi.org/10.1108/BIJ-12-2016-0181

Chan, F. T. S., \& Qi, H. J. (2002). A fuzzy basis channel-spanning performance measurement method for supply chain management. Proceedings of the Institution of Mechanical Engineers, Part B-Journal of Engineering Manufacture, 216(8), 1155-1167. https://doi.org/10.1243/095440502760272421

Chang, K. H. (2019). A novel supplier selection method that integrates the intuitionistic fuzzy weighted averaging method and a soft set with imprecise data. Annals of Operations Research, 272(1-2), 139-157. https://doi.org/10.1007/s10479-017-2718-6

Charles, V., Gupta, S., \& Ali, I. (2019). A fuzzy goal programming approach for solving multi-objective supply chain network problems with pareto-distributed random variables. International Journal of Uncertainty Fuzziness and Knowledge-Based Systems, 27(4), 559-593. https://doi.org/10.1142/S0218488519500259

Chatterjee, K., \& Kar, S. (2016). Multi-criteria analysis of supply chain risk management using interval valued fuzzy TOPSIS. Opsearch, 24(2), 765-791. https://doi.org/10.1007/s12597-015-0241-6

Chatterjee, K., \& Kar, S. (2018). Supplier selection in telecom supply chain management: a fuzzy-rasch based COPRAS-G method. Technological and Economic Development of Economy, 53(3), 474-499. https://doi.org/10.3846/20294913.2017.1295289

Chatterjee, K., Pamucar, D., \& Zavadskas, E. K. (2018). Evaluating the performance of suppliers based on using the R'AMATEL-MAIRCA method for green supply chain implementation in electronics industry. Journal of Cleaner Production, 184, 101-129. https://doi.org/10.1016/j.jclepro.2018.02.186

Chavoshlou, A. S., Khamseh, A. A., \& Naderi, B. (2019). An optimization model of three-player payoff based on fuzzy game theory in green supply chain. Computers \& Industrial Engineering, 128, 782-794. https://doi.org/10.1016/j.cie.2018.12.057

Chen, C. M. (2009). A fuzzy-based decision-support model for rebuy procurement. International Journal of Production Economics, 122(2), 714-724. https://doi.org/10.1016/j.ijpe.2009.06.037

Chen, C. H. (2019). A new multi-criteria assessment model combining GRA techniques with intuitionistic fuzzy entropy-based TOPSIS method for sustainable building materials supplier selection. Sustainability, 11(8), 2265. https://doi.org/10.3390/su11082265

Chen, C. T., \& Huang, S. F. (2006). Order-fulfillment ability analysis in the supply-chain system with fuzzy operation times. International Journal of Production Economics, 101(1), 185-193. https://doi.org/10.1016/j.ijpe.2005.05.003

Chen, C. L., \& Lee, W. C. (2004). Multi-objective optimization of multi-echelon supply chain networks with uncertain product demands and prices. Computers \& Chemical Engineering, 28(6-7), 1131-1144. https://doi.org/10.1016/j.compchemeng.2003.09.014

Chen, C. T., Lin, C. T., \& Huang, S. F. (2006). A fuzzy approach for supplier evaluation and selection in supply chain management. International Journal of Production Economics, 102(2), 289-301.

https://doi.org/10.1016/j.ijpe.2005.03.009 
Chen, S. P. (2011). A membership function approach to lot size re-order point inventory problems in fuzzy environments. International Journal of Production Research, 49(13), 3855-3871. https://doi.org/10.1080/00207543.2010.495956

Chen, S. P., \& Chang, P. C. (2006). A mathematical programming approach to supply chain models with fuzzy parameters. Engineering Optimization, 38(6), 647-669. https://doi.org/10.1080/03052150600716116

Chen, S. P., \& Cheng, B. H. (2014). Optimal echelon stock policies for multi-stage supply chains in fuzzy environments. International Journal of Production Research, 52(11), 3431-3449. https://doi.org/10.1080/00207543.2014.885145

Chen, Z. H., Ming, X. G., Zhou, T. T., \& Chang, Y. (2020). Sustainable supplier selection for smart supply chain considering internal and external uncertainty: An integrated rough-fuzzy approach. Applied Soft Computing, 87, 106004. https://doi.org/10.1016/j.asoc.2019.106004

Chiu, M. C., \& Teng, L. W. (2013). Sustainable product and supply chain design decisions under uncertainties. International Journal of Precision Engineering and Manufacturing, 14(11), 1953-1960. https://doi.org/10.1007/s12541-013-0265-x

Chou, C. C. (2010). An integrated quantitative and qualitative FMCDM model for location choices. Soft Computing, 14(7), 757-771. https://doi.org/10.1007/s00500-009-0463-8

Chou, S. Y., \& Chang, Y. H. (2008). A decision support system for supplier selection based on a strategyaligned fuzzy SMART approach. Expert Systems with Applications, 34(4), 2241-2253. https://doi.org/10.1016/j.eswa.2007.03.001

Chou, S. Y., Chang, Y. H., \& Shen, C. Y. (2008). A fuzzy simple additive weighting system under group decision-making for facility location selection with objective/subjective attributes. European Journal of Operational Research, 189(1), 132-145. https://doi.org/10.1016/j.ejor.2007.05.006

Cifci, G., \& Buyukozkan, G. (2011). A fuzzy MCDM approach to evaluate green suppliers. International Journal of Computational Intelligence Systems, 4(5), 894-909. https://doi.org/10.1080/18756891.2011.9727840

Cigolini, R., \& Rossi, T. (2008). Evaluating supply chain integration: a case study using fuzzy logic. Production Planning \& Control, 19(3), 242-255. https://doi.org/10.1080/09537280801916249

Dahooie, J. H., Babgohari, A. Z., Meidutè-Kavaliauskienè, I., \& Govindan, K. (2020). Prioritising sustainable supply chain management practices by their impact on multiple interacting barriers. International Journal of Sustainable Development \& World Ecology, 1-24. https://doi.org/10.1080/13504509.2020.1795004

Dai, L. N., \& Bai, S. Z. (2020). An approach to selection of agricultural product supplier using Pythagorean fuzzy sets. Mathematical Problems in Engineering, 2020, 1816028. https://doi.org/10.1155/2020/1816028

Dai, Z., \& Dai, H. M. (2016). Bi-objective closed-loop supply chain network design with risks in a fuzzy environment. Journal of Industrial and Production Engineering, 33(3), 169-180. https://doi.org/10.1080/21681015.2015.1126655

Dalman, H., \& Sivri, M. (2017). Multi-objective solid transportation problem in uncertain environment. Iranian Journal of Science and Technology Transaction A-Science, 41(A2), 505-514. https://doi.org/10.1007/s40995-017-0254-5

Darbari, J. D., Kannan, D., Agarwal, V., \& Jha, P. C. (2019). Fuzzy criteria programming approach for optimising the TBL performance of closed loop supply chain network design problem. Annals of Operations Research, 273(1-2), 693-738. https://doi.org/10.1007/s10479-017-2701-2

Das, A., Bera, U. K., \& Maiti, M. (2016). A breakable multi-item multi stage solid transportation problem under budget with Gaussian type-2 fuzzy parameters. Applied Intelligence, 45(3), 923-951. https://doi.org/10.1007/s10489-016-0794-y 
Debnath, A., Roy, J., Kar, S., Zavadskas, E. K., \& Antucheviciene, J. (2017). A hybrid MCDM approach for strategic project portfolio selection of agro by-products. Sustainability, 9(8), 1302. https://doi.org/10.3390/su9081302

Deng, H. P., Luo, F., \& Wibowo, S. (2018). Multi-criteria group decision making for green supply chain management under uncertainty. Sustainability, 10(9), 3150. https://doi.org/10.3390/su10093150

Deshpande, U., Gupta, A., \& Basu, A. (2004). Task assignment with imprecise information for real-time operation in a supply chain. Applied Soft Computing, 5(1), 101-117. https://doi.org/10.1016/j.asoc.2004.06.001

Dey, B., Bairagi, B., Sarkar, B., \& Sanyal, S. K. (2016). Warehouse location selection by fuzzy multicriteria decision making methodologies based on subjective and objective criteria. International Journal of Management Science and Engineering Management, 11(4), 262-278. https://doi.org/10.1080/17509653.2015.1086964

dos Santos, B. M., Neto, C. R. P., Ferreira, A. R., Bueno, W. P., Soares, M., Blesz, A. E., Borchardt, M., \& Godoy, L. P. (2017). Performance of green suppliers in supply chain management. Interciencia, $42(12), 805-811$.

Dou, Y. J., Zhu, Q. H., \& Sarkis, J. (2015). Integrating strategic carbon management into formal evaluation of environmental supplier development programs. Business Strategy and the Environment, 24(8), 873-891. https://doi.org/10.1002/bse.1851

Duric, G., Todorovic, G.., Dordevic, A., \& Tisma, A. B. (2019). A new fuzzy risk management model for production supply chain economic and social sustainability. Economic Research-Ekonomska Istraživanja, 32(1), 1697-1715. https://doi.org/10.1080/1331677X.2019.1638287

El-Baz, M. A. (2011). Fuzzy performance measurement of a supply chain in manufacturing companies. Expert Systems with Applications, 38(6), 6681-6688. https://doi.org/10.1016/j.eswa.2010.11.067

Ertay, T., Kahveci, A., \& Tabanli, R. M. (2011). An integrated multi-criteria group decision-making approach to efficient supplier selection and clustering using fuzzy preference relations. International Journal of Computer Integrated Manufacturing, 24(12), 1152-167. https://doi.org/10.1080/0951192X.2011.615342

Ewbank, H., Roveda, J. A. F., Roveda, S. R. M. M., Ribeiro, A. I., Bressane, A., Hadi-Vencheh, A., \& Wanke, P. (2020). Sustainable resource management in a supply chain: a methodological proposal combining zero-inflated fuzzy time series and clustering techniques. Journal of Enterprise Information Management, 33(5), 1059-1076. https://doi.org/10.1108/JEIM-09-2019-0289

Fahimnia, B., Farahani, R. Z., Marian, R., \& Luong, L. (2013). A review and critique on integrated production-distribution planning models and techniques. Journal of Manufacturing Systems, 32(1), 1-19. https://doi.org/10.1016/j.jmsy.2012.07.005

Fei, L. G., Deng, Y., \& Hu, Y. (2019a). DS-VIKOR: A new multi-criteria decision-making method for supplier selection. International Journal of Fuzzy Systems, 21(1), 157-175. https://doi.org/10.1007/s40815-018-0543-y

Fei, L. G., Xia, J., Feng, Y. Q., \& Liu, L. N. (2019b). An ELECTRE-based multiple criteria decision making method for supplier selection using Dempster-Shafer theory. IEEE Access, 7, 84701-84716. https://doi.org/10.1109/ACCESS.2019.2924945

Figueroa-Garcia, J. C., Kalenatic, D., \& Lopez-Bello, C. A. (2012). Multi-period mixed production planning with uncertain demands: fuzzy and interval fuzzy sets approach. Fuzzy Sets and Systems, 206, 21-38. https://doi.org/10.1016/j.fss.2012.03.005

Foroozesh, N., Tavakkoli-Moghaddam, R., \& Mousavi, S. M. (2018a). A novel group decision model based on mean-variance-skewness concepts and interval-valued fuzzy sets for a selection problem of the sustainable warehouse location under uncertainty. Neural Computing \& Applications, 30(11), 3277-3293. https://doi.org/10.1007/s00521-017-2885-z 
Foroozesh, N., Tavakkoli-Moghaddam, R., Mousavi, S. M., \& Vahdani, B. (2017). Dispatching rule evaluation in fflexible manufacturing systems by a new fuzzy decision model with possibilisticstatistical uncertainties. Arabian Journal for Science and Engineering, 42(7), 2947-2960. https://doi.org/10.1007/s13369-017-2448-8

Foroozesh, N., Tavakkoli-Moghaddam, R., \& Mousavi, S. M. (2018b). Sustainable-supplier selection for manufacturing services: a failure mode and effects analysis model based on interval-valued fuzzy group decision-making. International Journal of Advanced Manufacturing Technology, 95(9-12), 3609-3629. https://doi.org/10.1007/s00170-017-1308-8

Foroozesh, N., Tavakkoli-Moghaddam, R., Mousavi, S. M., \& Vahdani, B. (2019). A new comprehensive possibilistic group decision approach for resilient supplier selection with mean-variance-skewnesskurtosis and asymmetric information under interval-valued fuzzy uncertainty. Neural Computing \& Applications, 31(11), 6959-6979. https://doi.org/10.1007/s00521-018-3506-1

Garibaldi, J. M., Jaroszewski, M., \& Musikasuwan, S. (2008). Nonstationary fuzzy sets. IEEE Transactions on Fuzzy Systems, 16(4), 1072-1086. https://doi.org/10.1109/tfuzz.2008.917308

Ghoushchi, S. J., Khazaeili, M., Amini, A., \& Osgooei, E. (2019). Multi-criteria sustainable supplier selection using piecewise linear value function and fuzzy best-worst method. Journal of Intelligent \& Fuzzy Systems, 37(2), 2309-2325. https://doi.org/10.3233/JIFS-182609

Giallanza, A., \& Puma, G. L. (2020). Fuzzy green vehicle routing problem for designing a three echelons supply chain. Journal of Cleaner Production, 259, 120774.

https://doi.org/10.1016/j.jclepro.2020.120774

Giannoccaro, I., Pontrandolfo, P., \& Scozzi, B. (2003). A fuzzy echelon approach for inventory management in supply chains. European Journal of Operational Research, 149(1), 185-196. https://doi.org/10.1016/S0377-2217(02)00441-1

Gill, A. (2009). Determining loading dock requirements in production-distribution facilities under uncertainty. Computers \& Industrial Engineering, 57(1), 161-168.

https://doi.org/10.1016/j.cie.2008.11.002

Gitinavard, H., Shirazi, M. A., \& Zarandi, M. H. F. (2020). Sustainable feedstocks selection and renewable products allocation: A new hybrid adaptive utility-based consensus model. Journal of Environmental Management, 264, 110428. https://doi.org/10.1016/j.jenvman.2020.110428

Goguen, J. A. (1967). L-fuzzy sets. Journal of Mathematical Analysis and Applications, 18(1), 145-174. https://doi.org/10.1016/0022-247x(67)90189-8

Goker, N., Dursun, M., \& Cedolin, M. (2020). A novel IFCM integrated distance based hierarchical intuitionistic decision making procedure for agile supplier selection. Journal of Intelligent \& Fuzzy Systems, 38(1), 653-662. https://doi.org/10.3233/JIFS-179438

Govindan, K., Khodaverdi, R., \& Jafarian, A. (2013). A fuzzy multi criteria approach for measuring sustainability performance of a supplier based on triple bottom line approach. Journal of Cleaner Production, 47, 345-354. https://doi.org/10.1016/j.jclepro.2012.04.014

Govindan, K., Khodaverdi, R., \& Vafadarnikjoo, A. (2015). Intuitionistic fuzzy based DEMATEL method for developing green practices and performances in a green supply chain. Expert Systems with Applications, 185(1), 146-158. https://doi.org/10.1016/j.eswa.2015.04.030

Grewal, D., \& Levy, M. (2007). Retailing research: Past, present, and future. Journal of Retailing, 83(4), 447-464. https://doi.org/10.1016/j.jretai.2007.09.003

Grillo, H., Alemany, M. M. E., Ortiz, A., \& Mula, J. (2018). A fuzzy order promising model with nonuniform finished goods. International Journal of Fuzzy Systems, 42(20), 7207-7220. https://doi.org/10.1007/s40815-017-0317-y

Grillo, H., Peidro, D., Alemany, M. M. E., \& Mula, J. (2015). Application of particle swarm optimisation with backward calculation to solve a fuzzy multi-objective supply chain master planning model. International Journal of Bio-Inspired Computation, 7(3), 157-169.

https://doi.org/10.1504/IJBIC.2015.069557 
Gunduz, C., \& Gunduz, G. S. (2019). Supplier selection under fuzzy environment. Tekstil Ve Konfeksiyon, 29(4), 344-352. https://doi.org/10.32710/tekstilvekonfeksiyon.551911

Gupta, M., \& Mohanty, B. K. (2015). Multi-stage multi-objective production planning using linguistic and numeric data-a fuzzy integer programming model. Computers \& Industrial Engineering, 87, 454-464. https://doi.org/10.1016/j.cie.2015.06.001

Gupta, S., Soni, U., \& Kumar, G. (2019). Green supplier selection using multi-criterion decision making under fuzzy environment: A case study in automotive industry. Computers \& Industrial Engineering, 136, 663-680. https://doi.org/10.1016/j.cie.2019.07.038

Haldar, A., Qamaruddin, U., Raut, R., Kamble, S., Kharat, M. G., \& Kamble, S. J. (2017). 3PL evaluation and selection using integrated analytical modeling. Journal of Modelling in Management, 12(2), 224-242. https://doi.org/10.1108/JM2-04-2015-0016

Handfield, R., Warsing, D., \& Wu, X. M. (2009). (Q, r) inventory policies in a fuzzy uncertain supply chain environment. European Journal of Operational Research, 197(2), 609-619.

https://doi.org/10.1016/j.ejor.2008.07.016

Hendiani, S., Liao, H. C., \& Jabbour, C. J. C. (2020a). A new sustainability indicator for supply chains: theoretical and practical contribution towards sustainable operations. International Journal of Logistics-Research and Applications. https://doi.org/10.1080/13675567.2020.1761308

Hendiani, S., Mahmoudi, A., \& Liao, H. C. (2020b). A multi-stage multi-criteria hierarchical decisionmaking approach for sustainable supplier selection. Applied Soft Computing, 94, 106456. https://doi.org/10.1016/j.asoc.2020.106456

Ho, T. F., Lin, C. C., \& Lin, C. L. (2020). Using fuzzy sets and Markov chain method to carry out inventory strategies with different recovery levels. Symmetry, 12(8), 1226. https://doi.org/10.3390/sym12081226

Hou, Q., \& Xie, L. (2019). Research on supplier evaluation in a green supply chain. Discrete Dynamics in Nature and Society, 2019, 2601301. https://doi.org/10.1155/2019/2601301

Igoulalene, I., Benyoucef, L., \& Tiwari, M. K. (2015). Novel fuzzy hybrid multi-criteria group decision making approaches for the strategic supplier selection problem. Expert Systems with Applications, 42(7), 3342-3356. https://doi.org/10.1016/j.eswa.2014.12.014

Islam, M. S., Tseng, M. L., Karia, N., \& Lee, C. H. (2018). Assessing green supply chain practices in Bangladesh using fuzzy importance and performance approach. Resources Conservation and Recycling, 131, 134-145. https://doi.org/10.1016/j.resconrec.2017.12.015

Jafarian, E., Razmi, J., \& Tavakkoli-Moghaddam, R. (2019). Forward and reverse flows pricing decisions for two competing supply chains with common collection centers in an intuitionistic fuzzy environment. Soft Computing, 23(17), 7865-7888. https://doi.org/10.1007/s00500-018-3418-0

Jain, V., Wadhwa, S., \& Deshmukh, S. G. (2005). E-commerce and supply chains: modelling of dynamics through fuzzy enhanced high level petri net. Sadhana-Academy Proceedings in Engineering Sciences, 30, 403-429. https://doi.org/10.1007/BF02706253

Jana, D. K., Pramanik, S., \& Maiti, M. (2016). A parametric programming method on Gaussian type-2 fuzzy set and its application to a multilevel supply chain. International Journal of Uncertainty Fuzziness and Knowledge-Based Systems, 24(3), 451-477. https://doi.org/10.1142/S0218488516500239

Jana, D. K., Pramanik, S., \& Maiti, M. (2017). Mean and CV reduction methods on Gaussian type-2 fuzzy set and its application to a multilevel profit transportation problem in a two-stage supply chain network. Neural Computing \& Applications, 28(9), 2703-2726. https://doi.org/10.1007/s00521-016-2202-2

Janssen, L., Claus, T., \& Sauer, J. (2016). Literature review of deteriorating inventory models by key topics from 2012 to 2015. International Journal of Production Economics, 182, 86-112. https://doi.org/10.1016/j.ijpe.2016.08.019 
Jiang, W., \& Huang, C. (2018). A multi-criteria decision-making model for evaluating suppliers in green SCM. International Journal of Computers Communications \& Control, 13(3), 337-352. https://doi.org/10.15837/ijccc.2018.3.3283

Jung, H., \& Jeong, S. J. (2012). Managing demand uncertainty through fuzzy inference in supply chain planning. International Journal of Production Research, 50(19), 5415-5429.

https://doi.org/10.1080/00207543.2011.631606

Kabak, O., \& Ulengin, F. (2011). Possibilistic linear-programming approach for supply chain networking decisions. European Journal of Operational Research, 209(3), 253-264.

https://doi.org/10.1016/j.ejor.2010.09.025

Kang, H. Y., Lee, A. H. I., \& Chan, Y. C. (2019). An integrated fuzzy multi-criteria decision-making approach for evaluating business process information systems. Mathematics, 7(10), 982. https://doi.org/10.3390/math7100982

Kannan, D., Jabbour, A. B. L. D., \& Jabbour, C. J. C. (2014). Selecting green suppliers based on GSCM practices: Using fuzzy TOPSIS applied to a Brazilian electronics company. European Journal of Operational Research, 233(2), 432-447. https://doi.org/10.1016/j.ejor.2013.07.023

Ke, H., Wu, Y., Huang, H., \& Chen, Z. Y. (2018). Optimal pricing decisions for a closed-loop supply chain with retail competition under fuzziness. Journal of the Operational Research Society, 69(9), 1468-1482. https://doi.org/10.1080/01605682.2017.1404184

Kefer, P., Milanovic, D. D., Misita, M., \& Zunjic, A. (2016). Fuzzy multicriteria ABC supplier classification in global supply chain. Mathematical Problems in Engineering, 2016, 9139483. https://doi.org/10.1155/2016/9139483

Keshavarz Ghorabaee, M., Amiri, M., Sadaghiani, J. S., \& Goodarzi, G. H. (2014). Multiple criteria group decision-making for supplier selection based on COPRAS method with interval type-2 fuzzy sets. International Journal of Advanced Manufacturing Technology, 75(5-8), 1115-1130. https://doi.org/10.1007/s00170-014-6142-7

Keshavarz Ghorabaee, M., Amiri, M., Zavadskas, E. K., \& Antucheviciene, J. (2017). Supplier evaluation and selection in fuzzy environments: a review of MADM approaches. Economic Research-Ekonomska Istraživanja, 30(1), 1073-1118. https://doi.org/10.1080/1331677x.2017.1314828

Keshavarz Ghorabaee, M., Zavadskas, E. K., Amiri, M., \& Antucheviciene, J. (2016a). A new method of assessment based on fuzzy ranking and aggregated weights (AFRAW) for MCDM problems under type-2 fuzzy environment. Economic Computation and Economic Cybernetics Studies and Research, 50(1), 39-68.

Keshavarz Ghorabaee, M., Zavadskas, E. K., Amiri, M., \& Esmaeili, A. (2016b). Multi-criteria evaluation of green suppliers using an extended WASPAS method with interval type-2 fuzzy sets. Journal of Cleaner Production, 137, 213-229. https://doi.org/10.1016/j.jclepro.2016.07.031

Khalifehzadeh, S., \& Fakhrzad, M. B. (2019). A modified firefly algorithm for optimizing a multi stage supply chain network with stochastic demand and fuzzy production capacity. Computers \& Industrial Engineering, 133, 42-56. https://doi.org/10.1016/j.cie.2019.04.048

Khalili-Damghani, K., \& Ghasemi, P. (2016). Uncertain centralized/decentralized production-distribution planning problem in multi-product supply chains: fuzzy mathematical optimization approaches. Industrial Engineering and Management Systems, 15(2), 156-172.

https://doi.org/10.7232/iems.2016.15.2.156

Khalili-Damghani, K., \& Tavana, M. (2013). A new fuzzy network data envelopment analysis model for measuring the performance of agility in supply chains. International Journal of Advanced Manufacturing Technology, 69(1-4), 291-318. https://doi.org/10.1007/s00170-013-5021-y

Khalili-Damghani, K., Tavana, M., \& Amirkhan, M. (2014). A fuzzy bi-objective mixed-integer programming method for solving supply chain network design problems under ambiguous and vague conditions. International Journal of Advanced Manufacturing Technology, 73(9-12), 1567-1595. https://doi.org/10.1007/s00170-014-5891-7 
Khalilzadeh, M., Karami, A., \& Hajikhani, A. (2020). The multi-objective supplier selection problem with fuzzy parameters and solving the order allocation problem with coverage. Journal of Modelling in Management, 15(3), 705-725. https://doi.org/10.1108/JM2-04-2018-0049

Khemiri, R., Elbedoui-Maktouf, K., Grabot, B., \& Zouari, B. (2017). A fuzzy multi-criteria decisionmaking approach for managing performance and risk in integrated procurement-production planning. International Journal of Production Research, 55(18), 5305-5329.

https://doi.org/10.1080/00207543.2017.1308575

Ko, M. D. (2020). An intelligent, empty container dispatching system model using fuzzy set theory and genetic algorithm in the context of industry 4.0. Enterprise Information Systems, 2020, 1-24. https://doi.org/10.1080/17517575.2020.1807060

Kristianto, Y., Gunasekaran, A., Helo, P., \& Hao, Y. Q. Q. (2014). A model of resilient supply chain network design: A two-stage programming with fuzzy shortest path. Expert Systems with Applications, 41(1), 39-49. https://doi.org/10.1016/j.eswa.2013.07.009

Kulak, O., \& Kahraman, C. (2005). Fuzzy multi-attribute selection among transportation companies using axiomatic design and analytic hierarchy process. Information Sciences, 170(2-4), 191-210. https://doi.org/10.1016/j.ins.2004.02.021

Kumar, A., \& Anbanandam, R. (2019). Location selection of multimodal freight terminal under STEEP sustainability. Research in Transportation Business and Management, 33, 100434. https://doi.org/10.1016/j.rtbm.2020.100434

Kumar, A., \& Anbanandam, R. (2020). Environmentally responsible freight transport service providers' assessment under data-driven information uncertainty. Journal of Enterprise Information Management, 34(1), 506-542. https://doi.org/10.1108/JEIM-12-2019-0403

Kumar, A., Mangla, S. K., Luthra, S., Rana, N. P., \& Dwivedi, Y. K. (2018). Predicting changing pattern: building model for consumer decision making in digital market. Journal of Enterprise Information Management, 31(5), 674-703. https://doi.org/10.1108/JEIM-01-2018-0003

Kumar, A., Zavadskas, E. K., Mangla, S. K., Agrawal, V., Sharma, K., \& Gupta, D. (2019). When risks need attention: adoption of green supply chain initiatives in the pharmaceutical industry. International Journal of Production Research, 57(11), 3554-3576. https://doi.org/10.1080/00207543.2018.1543969

Kumar, M., Vrat, P., \& Shankar, R. (2004). A fuzzy goal programming approach for vendor selection problem in a supply chain. Computers \& Industrial Engineering, 46(1), 69-85. https://doi.org/10.1016/j.cie.2003.09.010

Kumar, P., Singh, R. K., \& Vaish, A. (2017). Suppliers' green performance evaluation using fuzzy extended ELECTRE approach. Clean Technologies and Environmental Policy, 19(3), 809-821. https://doi.org/10.1007/s10098-016-1268-y

Kumar, R. S. (2018). Modelling a type-2 fuzzy inventory system considering items with imperfect quality and shortage backlogging. Sadhana-Academy Proceedings in Engineering Sciences, 43, 163. https://doi.org/10.1007/s12046-018-0920-0

Kuo, R. J., Lee, L. Y., \& Hu, T. L. (2010). Developing a supplier selection system through integrating fuzzy AHP and fuzzy DEA: a case study on an auto lighting system company in Taiwan. Production Planning \& Control, 21(5), 468-484. https://doi.org/10.1080/09537280903458348

Lee, C. S., Chung, C. C., Lee, H. S., Gan, G. Y., \& Chou, M. T. (2016). An interval-valued fuzzy number approach for supplier selection. Journal of Marine Science and Technology-Taiwan, 24(3), 384-389. https://doi.org/10.6119/JMST-015-0521-8

Li, D. F., \& Wan, S. P. (2014). A fuzzy inhomogenous multiattribute group decision making approach to solve outsourcing provider selection problems. Knowledge-Based Systems, 67, 71-89. https://doi.org/10.1016/j.knosys.2014.06.006

Li, F. C., Li, L., Jin, C. X., Wang, R. J., Wang, H., \& Yang, L. L. (2012a). A 3PL supplier selection model based on fuzzy sets. Computers \& Operations Research, 39(8), 1879-1884.

https://doi.org/10.1016/j.cor.2011.06.022 
Li, M., Wu, C., Zhang, L., \& You, L. N. (2015). An intuitionistic fuzzy-TODIM method to solve distributor evaluation and selection problem. International Journal of Simulation Modelling, 14(3), 511-524. https://doi.org/10.2507/IJSIMM14(3)CO12

Li, Y., Liu, X. D., \& Chen, Y. (2012b). Supplier selection using axiomatic fuzzy set and TOPSIS methodology in supply chain management. Fuzzy Optimization and Decision Making, 11(2), 147-176. https://doi.org/10.1007/s10700-012-9117-X

Li, Y., Liu, X. D., \& Chen, Y. (2012c). Supplier evaluation and selection using axiomatic fuzzy set and DEA methodology in supply chain management. International Journal of Fuzzy Systems, 14(2), $215-225$.

Liang, T. F. (2008). Fuzzy multi-objective production/distribution planning decisions with multi-product and multi-time period in a supply chain. Computers \& Industrial Engineering, 55(3), 676-694. https://doi.org/10.1016/j.cie.2008.02.008

Liang, T. F. (2013). Imprecise multi-objective production/distribution planning decisions using possibilistic programming method. Journal of Intelligent \& Fuzzy Systems, 25(1), 219-230. https://doi.org/10.3233/IFS-2012-0629

Liao, H. C., Wen, Z., \& Liu, L. (2019). Integrating BWM and ARAS under hesitant linguistic environment for digital supply chain finance supplier selection. Technological and Economic Development of Economy, 25(6), 1188-1212. https://doi.org/10.3846/tede.2019.10716

Liao, H. C., Xu, Z. S., \& Herrera, F. (2020). Applications of contemporary decision-making methods to the development of economy and technology. Technological and Economic Development of Economy, 26(3), 546-548. https://doi.org/10.3846/tede.2020.12476

Lin, R. J. (2013). Using fuzzy DEMATEL to evaluate the green supply chain management practices. Journal of Cleaner Production, 40, 32-39. https://doi.org/10.1016/j.jclepro.2011.06.010

Liou, J. J. H., Tamošaitiené, J., Zavadskas, E. K., \& Tzeng, G.-H. (2016). New hybrid COPRAS-G MADM Model for improving and selecting suppliers in green supply chain management. International Journal of Production Research, 54(1), 114-134. https://doi.org/10.1080/00207543.2015.1010747

Liu, A. J., Ji, X. H., Lu, H., \& Liu, H. Y. (2019a). The selection of 3PRLs on self-service mobile recycling machine: Interval-valued pythagorean hesitant fuzzy best-worst multi-criteria group decisionmaking. Journal of Cleaner Production, 230, 734-750. https://doi.org/10.1016/j.jclepro.2019.04.257

Liu, A. J., Ji, X. H., Xu, L., \& Lu, H. (2019b). Research on the recycling of sharing bikes based on time dynamics series, individual regrets and group efficiency. Journal of Cleaner Production, 208, 666-687. https://doi.org/10.1016/j.jclepro.2018.10.146

Liu, L. M., Cao, W. Z., Shi, B., \& Tang, M. (2019c). Large-scale green supplier selection approach under a q-rung interval-valued orthopair fuzzy environment. Processes, 7(9), 573. https://doi.org/10.3390/pr7090573

Liu, S. K., Gao, J., \& Xu, Z. S. (2019d). Fuzzy supply chain coordination mechanism with imperfect quality items. Technological and Economic Development of Economy, 25(2), 239-257. https://doi.org/10.3846/tede.2019.6620

Liu, S. T., \& Kao, C. (2004). Solving fuzzy transportation problems based on extension principle. European Journal of Operational Research, 153(3), 661-674. https://doi.org/10.1016/S0377-2217(02)00731-2

Liu, Y. M., Zhou, P., Li, L. Y., \& Zhu, F. (2020). An interactive decision-making method for third-party logistics provider selection under hybrid multi-criteria. Symmetry, 12(5), 729. https://doi.org/10.3390/sym12050729

Lu, S., Su, H. Y., Xiao, L., \& Zhu, L. (2015). Application of two-phase fuzzy optimization approach to multiproduct multistage integrated production planning with linguistic preference under uncertainty. Mathematical Problems in Engineering, 2015, 780830. https://doi.org/10.1155/2015/780830

Mahdiraji, H. A., Beheshti, M., Hajiagha, S. H., \& Zavadskas, E. K. (2018a). A fuzzy binary bi objective transportation model: Iranian steel supply network. Transport, 33(3), 810-820.

https://doi.org/10.3846/transport.2018.5800 
Mahdiraji, H. A., Hajiagha, S. H. R., Hashemi, S. S., \& Zavadskas, E. K. (2018b). Bi-objective meanvariance method based on Chebyshev inequality bounds for multi-objective stochastic problems. Rairo-Operations Research, 52(4-5), 1201-1217. https://doi.org/10.1051/ro/2018018

Mahdiraji, H. A., Zavadskas, E. K., Skare, M., Kafshgar, F. Z. R., \& Arab, A. (2020). Evaluating strategies for implementing industry 4.0: a hybrid expert oriented approach of BWM and interval valued intuitionistic fuzzy TODIM. Economic Research-Ekonomska Istraživanja, 33(1), 1600-1620. https://doi.org/10.1080/1331677x.2020.1753090

Mahmoodirad, A., Niroomand, S., \& Shafiee, M. (2020). A closed loop supply chain network design problem with multi-mode demand satisfaction in fuzzy environment. Journal of Intelligent \& Fuzzy Systems, 39(1), 503-524. https://doi.org/10.3233/JIFS-191528

Mahmoudi, A., Sadi-Nezhad, S., \& Makui, A. (2016). An extended fuzzy VIKOR for group decisionmaking based on fuzzy distance to supplier selection. Scientia Iranica, 23(4), 1879-1892. https://doi.org/10.24200/sci.2016.3934

Mahnam, M., Yadollahpour, M. R., Famil-Dardashti, V., \& Hejazi, S. R. (2009). Supply chain modeling in uncertain environment with bi-objective approach. Computers \& Industrial Engineering, 56(4), 1535-1544. https://doi.org/10.1016/j.cie.2008.09.038

Malviya, R. K., \& Kant, R. (2016). Hybrid decision making approach to predict and measure the success possibility of green supply chain management implementation. Journal of Cleaner Production, 135, 387-409. https://doi.org/10.1016/j.jclepro.2016.06.046

Malviya, R. K., Kant, R., \& Gupta, A. D. (2018). Evaluation and selection of sustainable strategy for green supply chain management implementation. Business Strategy and the Environment, 27(4), 475-502. https://doi.org/10.1002/bse.2016

Matawale, C. R., Datta, S., \& Mahapatra, S. S. (2016). Supplier selection in agile supply chain application potential of FMLMCDM approach in comparison with fuzzy-TOPSIS and fuzzy-MOORA. Benchmarking-An International Journal, 23(7), 2027-2060. https://doi.org/10.1108/BIJ-07-2015-0067

Mavi, R. K., Kazemi, S., Najafabadi, A. F., \& Mousaabadi, H. B. (2013). Identification and assessment of logistical factors to evaluate a green supplier using the fuzzy logic DEMATEL method. Polish Journal of Environmental Studies, 22(2), 445-455.

Meksavang, P., Shi, H., Lin, S. M., \& Liu, H. C. (2019). An extended picture fuzzy VIKOR approach for sustainable supplier management and its application in the beef industry. Symmetry, 11(4), 468. https://doi.org/10.3390/sym11040468

Meng, Q. Q., Liu, X. W., Song, Y., \& Wang, W. Z. (2019). An extended generalized TODIM method for risk assessment of supply chain in social commerce under interval type-2 fuzzy environment. Journal of Intelligent \& Fuzzy Systems, 37(6), 8551-8565. https://doi.org/10.3233/JIFS-190061

Mezei, J., \& Bjork, K. M. (2015). An economic production quantity problem with backorders and fuzzy cycle times. Journal of Intelligent \& Fuzzy Systems, 28(4), 1861-1868. https://doi.org/10.3233/IFS-141472

Mi, X. M., Liao, H. C., Liao, Y., Lin, Q., Lev, B., \& Al-Barakati, A. (2020). Stochastic multi-criteria acceptability analysis integrated with MULTIMOORA method and its application in green suppler selection. Technological and Economic Development of Economy, 26(3), 549-572. https://doi.org/10.3846/tede.2020.11964

Mirakhorli, A. (2014). Fuzzy multi-objective optimization for closed loop logistics network design in bread-producing industries. International Journal of Advanced Manufacturing Technology, 70(1-4), 349-362. https://doi.org/10.1007/s00170-013-5264-7

Mirhedayatian, S. M., Azadi, M., \& Saen, R. F. (2014). A novel network data envelopment analysis model for evaluating green supply chain management. International Journal of Production Economics, 147, 544-554. https://doi.org/10.1016/j.ijpe.2013.02.009 
Mishra, A. R., Rani, P., Pardasani, K. R., \& Mardani, A. (2019). A novel hesitant fuzzy WASPAS method for assessment of green supplier problem based on exponential information measures. Journal of Cleaner Production, 238, 117901. https://doi.org/10.1016/j.jclepro.2019.117901

Mohaghar, A., Fathi, M. R., \& Jafarzadeh, A. H. (2013). A supplier selection method using AR-DEA and fuzzy VIKOR. International Journal of Industrial Engineering, 20(5-6), 387-400.

Mohammadi, H., Farahani, F. V., Noroozi, M., \& Lashgari, A. (2017). Green supplier selection by developing a new group decision-making method under type 2 fuzzy uncertainty. International Journal of Advanced Manufacturing Technology, 93(1-4), 1443-1462. https://doi.org/10.1007/s00170-017-0458-Z

Mohammed, A., Harris, I., \& Govindan, K. (2019). A hybrid MCDM-FMOO approach for sustainable supplier selection and order allocation. International Journal of Production Economics, 217, 171-184. https://doi.org/10.1016/j.ijpe.2019.02.003

Mohd, W. R. W., Abdullah, L., Yusoff, B., Taib, C. M. I. C., \& Merigo, J. M. (2019). An integrated MCDM model based on Pythagorean fuzzy sets for green supplier development program. Malaysian Journal of Mathematical Sciences, 13, 23-37.

Mousavi, S. M., Antucheviciene, J., Zavadskas, E. K., Vahdani, B., \& Hashemi, H. (2019). A new decision model for cross-docking center location in logistics networks under interval-valued intuitionistic fuzzy uncertainty. Transport, 34(1), 30-40. https://doi.org/10.3846/transport.2019.7442

Mousavi, S. M., Foroozesh, N., Zavadskas, E. K., \& Antucheviciene, J. (2020). A new soft computing approach for green supplier selection problem with interval type-2 trapezoidal fuzzy statistical group decision and avoidance of information loss. Soft Computing, 24(16), 12313-12327. https://doi.org/10.1007/s00500-020-04675-4

Mousavi, S. M., \& Vahdani, B. (2016). Cross-docking location selection in distribution systems: a new intuitionistic fuzzy hierarchical decision model. International Journal of Computational Intelligence Systems, 9(1), 91-109. https://doi.org/10.1080/18756891.2016.1144156

Mula, J., Peidro, D., \& Poler, R. (2010). The effectiveness of a fuzzy mathematical programming approach for supply chain production planning with fuzzy demand. International Journal of Production Economics, 128(1), 136-143. https://doi.org/10.1016/j.ijpe.2010.06.007

Muneeb, S. M., Nomani, M. A., Masmoudi, M., \& Adhami, A. Y. (2020). A bi-level decision-making approach for the vendor selection problem with random supply and demand. Management Decision, 58(6), 1164-1189. https://doi.org/10.1108/MD-10-2017-1017

Nakandala, D., Lau, H., \& Zhang, J. J. (2016). Cost-optimization modelling for fresh food quality and transportation. Industrial Management \& Data Systems, 116(3), 564-583. https://doi.org/10.1108/IMDS-04-2015-0151

Narayanan, A. E., Sridharan, R., \& Kumar, P. N. R. (2019). Analyzing the interactions among barriers of sustainable supply chain management practices: A case study. Journal of Manufacturing Technology Management, 30(6), 937-971. https://doi.org/10.1108/JMTM-06-2017-0114

Nestic, S., Ljepava, N., \& Aleksic, A. (2018). Stakeholder management in reverse supply chains - the ranking of reverse supply chains entities upon requirements' fulfillment. International Journal for Quality Research, 12(4), 975-987. https://doi.org/10.18421/IJQR12.04-12

Ocampo, L. A., Clark, E. E., Tanudtanud, K. V. G., Ocampo, C. O. V., Impas, C. G., Vergara, V. G., Pastoril, J., \& Tordillo, J. A. S. (2015). An integrated sustainable manufacturing strategy framework using fuzzy analytic network process. Advances in Production Engineering \& Management, 10(3), 125-139. https://doi.org/10.14743/apem2015.3.197

Olfat, L., Pishdar, M., \& Ghasemzadeh, F. (2019). A type-2 fuzzy network data envelopment analysis for FMCG distributors' performance evaluation with sustainability approach. International Journal of Industrial Engineering, 26(5), 663-687.

Onar, S. C., \& Ates, N. Y. (2008). A fuzzy model for operational supply chain optimization problems. Journal of Multiple-Valued Logic and Soft Computing, 14(3-5), 355-370. 
Osiro, L., Lima, F. R., \& Carpinetti, L. C. R. (2018). A group decision model based on quality function deployment and hesitant fuzzy for selecting supply chain sustainability metrics. Journal of Cleaner Production, 183, 964-978. https://doi.org/10.1016/j.jclepro.2018.02.197

Ou, C. W., \& Chou, S. Y. (2009). International distribution center selection from a foreign market perspective using a weighted fuzzy factor rating system. Expert Systems with Applications, 36(2), 1773-1782. https://doi.org/10.1016/j.eswa.2007.12.007

Ozbek, A., \& Yildiz, A. (2020). Digital supplier sselection for a garment business using interval type-2 fuzzy TOPSIS. Tekstil Ve Konfeksiyon, 30(1), 61-72. https://doi.org/10.32710/tekstilvekonfeksiyon.569884

Ozkan, B., Basligil, H., Kaya, I., \& Ozkir, V. (2015). A fuzzy mixed integer linear programming model for a reverse logistics system with a real case application. Journal of Multiple-Valued Logic and Soft Computing, 25(2-3), 269-289.

Paksoy, T., Pehlivan, N. Y., \& Ozceylan, E. (2012). Application of fuzzy optimization to a supply chain network design: A case study of an edible vegetable oils manufacturer. Applied Mathematical Modelling, 36(6), 2762-2776. https://doi.org/10.1016/j.apm.2011.09.060

Pamucar, D., Chatterjee, K., \& Zavadskas, E. K. (2019). Assessment of third-party logistics provider using multi-criteria decision-making approach based on interval rough numbers. Computers \& Industrial Engineering, 127, 383-407. https://doi.org/10.1016/j.cie.2018.10.023

Pandey, P., Shah, B. J., \& Gajjar, H. (2017). A fuzzy goal programming approach for selecting sustainable suppliers. Benchmarking-An International Journal, 24(5), 1138-1165.

https://doi.org/10.1108/BIJ-11-2015-0110

Pang, Q. H., Yang, T. T., Li, M. Z., \& Shen, Y. (2017). A fuzzy-grey multicriteria decision making approach for green supplier selection in low-carbon supply chain. Mathematical Problems in Engineering, 2017, 9653261. https://doi.org/10.1155/2017/9653261

Pang, J. H., Zhang, Q., \& Yang, G. W. (2006). Coalition and distribution in fuzzy dynamic supply chain systems. Dynamics of Continuous Discrete and Impulsive Systems-Series A-Mathematical Analysis, 13, 698-702.

Peidro, D., Mula, J., Jimenez, M., \& Botella, M. D. (2010a). A fuzzy linear programming based approach for tactical supply chain planning in an uncertainty environment. European Journal of Operational Research, 205(1), 65-80. https://doi.org/10.1016/j.ejor.2009.11.031

Peidro, D., Mula, J., \& Poler, R. (2010b). Fuzzy linear programming for supply chain planning under uncertainty. International Journal of Information Technology \& Decision Making, 9(3), 373-392. https://doi.org/10.1142/S0219622010003865

Peidro, D., Mula, J., Poler, R., \& Verdegay, J. L. (2009). Fuzzy optimization for supply chain planning under supply, demand and process uncertainties. Fuzzy Sets and Systems, 160(18), 2640-2657. https://doi.org/10.1016/j.fss.2009.02.021

Petrovic, D. (2001). Simulation of supply chain behaviour and performance in an uncertain environment. International Journal of Production Economics, 71(1-3), 429-438.

https://doi.org/10.1016/S0925-5273(00)00140-7

Petrovic, D., Roy, R., \& Petrovic, R. (1998). Modelling and simulation of a supply chain in an uncertain environment. European Journal of Operational Research, 59(1-3), 443-453. https://doi.org/10.1016/S0377-2217(98)00058-7

Petrovic, D., Roy, R., \& Petrovic, R. (1999). Supply chain modelling using fuzzy sets. International Journal of Production Economics, 109(2), 299-309. https://doi.org/10.1016/S0925-5273(98)00109-1

Petrovic, D., Xie, Y., Burnham, K., \& Petrovic, R. (2008). Coordinated control of distribution supply chains in the presence of fuzzy customer demand. European Journal of Operational Research, 185(1), 146-158. https://doi.org/10.1016/j.ejor.2006.12.020 
Phochanikorn, P., \& Tan, C. Q. (2019). A new extension to a multi-criteria decision-making model for sustainable supplier selection under an intuitionistic fuzzy environment. Sustainability, 11(19), 5413. https://doi.org/10.3390/su11195413

Pinar, A., \& Boran, F. E. (2020). A q-rung orthopair fuzzy multi-criteria group decision making method for supplier selection based on a novel distance measure. International Journal of Machine Learning and Cybernetics, 11(8), 1749-1780. https://doi.org/10.1007/s13042-020-01070-1

Pirayesh, M., \& Yazdi, M. M. (2010). Modeling (r, Q) policy in a two-level supply chain system with fuzzy demand. International Journal of Uncertainty Fuzziness and Knowledge-Based Systems, 18(6), 819-841. https://doi.org/10.1142/S0218488510006817

Poornikoo, M., \& Qureshi, M. A. (2019). System dynamics modeling with fuzzy logic application to mitigate the bullwhip effect in supply chains. Journal of Modelling in Management, 14(3), 610-627. https://doi.org/10.1108/JM2-04-2018-0045

Pourjavad, E., \& Shahin, A. (2018a). Hybrid performance evaluation of sustainable service and manufacturing supply chain management: An integrated approach of fuzzy dematel and fuzzy inference system. Intelligent Systems in Accounting Finance \& Management, 25(3), 134-147. https://doi.org/10.1002/isaf.1431

Pourjavad, E., \& Shahin, A. (2018b). The application of Mamdani fuzzy inference system in evaluating green supply chain management performance. International Journal of Fuzzy Systems, 20(3), 901-912. https://doi.org/10.1007/s40815-017-0378-y

Pournader, M., Rotaru, K., Kach, A. P., \& Hajiagha, S. H. R. (2016). An analytical model for systemwide and tier-specific assessment of resilience to supply chain risks. Supply Chain Management-An International Journal, 21(5), 589-609. https://doi.org/10.1108/SCM-11-2015-0430

Pournamazi, S. R., Yaghin, R. G., \& Jolai, F. (2020). Positioning push-pull boundary in a hesitant fuzzy environment. Expert Systems, 38(2), e12616. https://doi.org/10.1111/exsy.12616

Qin, J. D., Liu, X. W., \& Pedrycz, W. (2017a). A multiple attribute interval type-2 fuzzy group decision making and its application to supplier selection with extended LINMAP method. Soft Computing, 21(12), 3207-3226. https://doi.org/10.1007/s00500-015-2004-y

Qin, J. D., Liu, X. W., \& Pedrycz, W. (2017b). An extended TODIM multi-criteria group decision making method for green supplier selection in interval type-2 fuzzy environment. European Journal of Operational Research, 258(2), 626-638. https://doi.org/10.1016/j.ejor.2016.09.059

Rabbani, M., \& Talebi, E. (2019). A comprehensive mathematical model for designing an organ transplant supply chain network under uncertainty. International Journal of Engineering, 32(6), 835-841. https://doi.org/10.5829/ije.2019.32.06c.06

Rahmanzadeh, S., Pishvaee, M. S., \& Rasouli, M. R. (2020). Integrated innovative product design and supply chain tactical planning within a blockchain platform. International Journal of Production Research, 58(7), 2242-2262. https://doi.org/10.1080/00207543.2019.1651947

Ramezani, M., Kimiagari, A. M., Karimi, B., \& Hejazi, T. H. (2014). Closed-loop supply chain network design under a fuzzy environment. Knowledge-Based Systems, 59, 108-120.

https://doi.org/10.1016/j.knosys.2014.01.016

Rani, P., Mishra, A. R., Krishankumar, R., Mardani, A., Cavallaro, F., Ravichandran, K. S., \& Balasubramanian, K. (2020a). Hesitant fuzzy SWARA-complex proportional assessment approach for sustainable supplier selection (HF-SWARA-COPRAS). Symmetry, 12(7), 1152. https://doi.org/10.3390/sym12071152

Rani, P., Mishra, A. R., Rezaei, G., Liao, H. C., \& Mardani, A. (2020b). Extended Pythagorean fuzzy TOPSIS method based on similarity measure for sustainable recycling partner selection. International Journal of Fuzzy Systems, 22(2), 735-747. https://doi.org/10.1007/s40815-019-00689-9

Reimann, F., Kosmol, T., \& Kaufmann, L. (2017). Responses to supplier-induced disruptions: a fuzzy-set analysis. Journal of Supply Chain Management, 53(4), 37-66. https://doi.org/10.1111/jscm.12141 
Rodríguez, R. M., Martinez, L., \& Herrera, F. (2012). Hesitant fuzzy linguistic term sets for decision making. IEEE Transactions on Fuzzy Systems, 20(1), 109-119. https://doi.org/10.1109/tfuzz.2011.2170076

Rostamzadeh, R., Esmaeili, A., Nia, A. S., Saparauskas, J., \& Keshavarz Ghorabaee, M. (2017). A fuzzy ARAS method for supply chain management performance measurement in SMEs under uncertainty. Transformations in Business \& Economics, 16(2A), 319-348.

Rostamzadeh, R., Govindan, K., Esmaeili, A., \& Sabaghi, M. (2015a). Application of fuzzy VIKOR for evaluation of green supply chain management practices. Ecological Indicators, 49, 188-203. https://doi.org/10.1016/j.ecolind.2014.09.045

Rostamzadeh, R., Keshavarz Ghorabaee, M., Govindan, K., Esmaeili, A., \& Nobar, H. B. K. (2018). Evaluation of sustainable supply chain risk management using an integrated fuzzy TOPSIS- CRITIC approach. Journal of Cleaner Production, 175, 651-669. https://doi.org/10.1016/j.jclepro.2017.12.071

Rostamzadeh, R., Sabaghi, M., Sofian, S., \& Ismail, Z. (2015b). Hybrid GA for material routing optimization in supply chain. Applied Soft Computing, 26, 107-122.

https://doi.org/10.1016/j.asoc.2014.09.033

Rouyendegh, B. D., Yildizbasi, A., \& Ustunyer, P. (2020). Intuitionistic fuzzy TOPSIS method for green supplier selection problem. Soft Computing, 24(3), 2215-2228.

https://doi.org/10.1007/s00500-019-04054-8

Ruppert, T., Dorgo, G., \& Abonyi, J. (2020). Fuzzy activity time-based model predictive control of openstation assembly lines. Journal of Manufacturing Systems, 54, 12-23. https://doi.org/10.1016/j.jmsy.2019.11.005

Ryu, K., \& Yucesan, E. (2010). A fuzzy newsvendor approach to supply chain coordination. European Journal of Operational Research, 200(2), 421-438. https://doi.org/10.1016/j.ejor.2009.01.011

Sahin, B., \& Soylu, A. (2020). Multi-layer, multi-segment iterative optimization for maritime supply chain operations in a dynamic fuzzy environment. IEEE Access, 8, 144993-145005. https://doi.org/10.1109/ACCESS.2020.3014968

Sahu, A. K., Sahu, N. K., \& Sahu, A. K. (2016). Application of integrated TOPSIS in ASC index: partners benchmarking perspective. Benchmarking: An International Journal, 23(3), 540-563. https://doi.org/10.1108/BIJ-03-2014-0021

Sahu, A. K., Narang, H. K., Rajput, M. S., Sahu, N. K., \& Sahu, A. K. (2018). Performance modeling and benchmarking of green supply chain management: An integrated fuzzy approach. Benchmarking: An International Journal, 25(7), 2248-2271. https://doi.org/10.1108/BIJ-02-2017-0032

Salam, M. A., Ali, M., \& Seny Kan, K. A. (2017). Analyzing supply chain uncertainty to deliver sustainable operational performance: symmetrical and asymmetrical modeling approaches. Sustainability, 9(12), 2217. https://doi.org/10.3390/su9122217

Samantra, C., Datta, S., Mishra, S., \& Mahapatra, S. S. (2013). Agility appraisal for integrated supply chain using generalized trapezoidal fuzzy numbers set. International Journal of Advanced Manufacturing Technology, 68(5-8), 1491-1503. https://doi.org/10.1007/s00170-013-4937-6

Sanayei, A., Mousavi, S. F., \& Yazdankhah, A. (2010). Group decision making process for supplier selection with VIKOR under fuzzy environment. Expert Systems with Applications, 37(1), 24-30. https://doi.org/10.1016/j.eswa.2009.04.063

Sang, S. J. (2016a). Revenue sharing contract in a multi-echelon supply chain with fuzzy demand and asymmetric information. International Journal of Computational Intelligence Systems, 9(6), 10281040. https://doi.org/10.1080/18756891.2016.1256569

Sang, S. J. (2016b). The coordinating contracts of supply chain in a fuzzy decision environment. SpringerPlus, 5, 953. https://doi.org/10.1186/s40064-016-2401-4

Sang, S. J. (2017). Decentralized channel decisions of green supply chain in a fuzzy decision making environment. International Journal of Computational Intelligence Systems, 10(1), 986-1001. https://doi.org/10.2991/ijcis.2017.10.1.66 
Sang, X. Z., \& Liu, X. W. (2016). An interval type-2 fuzzy sets-based TODIM method and its application to green supplier selection. Journal of the Operational Research Society, 67(5), 722-734. https://doi.org/10.1057/jors.2015.86

Sen, D. K., Datta, S., \& Mahapatra, S. S. (2018). Sustainable supplier selection in intuitionistic fuzzy environment: a decision-making perspective. Benchmarking: An International Journal, 25(2), 545-574. https://doi.org/10.1108/BIJ-11-2016-0172

Sengupta, D., Das, A., \& Bera, U. K. (2018). A gamma type-2 defuzzification method for solving a solid transportation problem considering carbon emission. Applied Intelligence, 48(11), 3995-4022. https://doi.org/10.1007/s10489-018-1173-7

Shamout, M. D. (2020). Supply chain data analytics and supply chain agility: a fuzzy sets (fsQCA) approach. International Journal of Organizational Analysis, 28(5), 1055-1067. https://doi.org/10.1108/IJOA-05-2019-1759

Shankar, R., Choudhary, D., \& Jharkharia, S. (2018). An integrated risk assessment model: A case of sustainable freight transportation systems. Transportation Research Part D-Transport and Environment, 63, 662-676. https://doi.org/10.1016/j.trd.2018.07.003

Sharahi, S. J., Khalili-Damghani, K., Abtahi, A. R., \& Rashidi-Komijan, A. (2018). Type-II fuzzy multiproduct, multi-level, multi-period location-allocation, production-distribution problem in supply chains: modelling and optimisation approach. Fuzzy Information and Engineering, 10(2), 260-283. https://doi.org/10.1080/16168658.2018.1517978

Sharanlou, H., Kashan, A. H., \& Tavakkoli-Moghaddam, R. (2021). Determining the price and refund of products in a supply chain with quality and advertising costs in a fuzzy environment. Soft Computing, 25, 2351-2370. https://doi.org/10.1007/s00500-020-05307-7

Shekarian, E., Olugu, E. U., Abdul-Rashid, S. H., \& Bottani, E. (2016). A fuzzy reverse logistics inventory system integrating economic order/production quantity models. International Journal of Fuzzy Systems, 18(6), 1141-1161. https://doi.org/10.1007/s40815-015-0129-x

Shen, C. Y., \& Yu, K. T. (2009). A generalized fuzzy approach for strategic problems: the empirical study on facility location selection of authors' management consultation client as an example. Expert Systems with Applications, 36(3), 4709-4716. https://doi.org/10.1016/j.eswa.2008.06.035

Shen, L. X., Olfat, L., Govindan, K., Khodaverdi, R., \& Diabat, A. (2013). A fuzzy multi criteria approach for evaluating green supplier's performance in green supply chain with linguistic preferences. Resources Conservation and Recycling, 74, 170-179. https://doi.org/10.1016/j.resconrec.2012.09.006

Shete, P. C., Ansari, Z. N., \& Kant, R. (2020). A Pythagorean fuzzy AHP approach and its application to evaluate the enablers of sustainable supply chain innovation. Sustainable Production and Consumption, 23, 77-93. https://doi.org/10.1016/j.spc.2020.05.001

Shi, H., Quan, M. Y., Liu, H. C., \& Duan, C. Y. (2018). A novel integrated approach for green supplier selection with interval-valued intuitionistic uncertain linguistic information: a case study in the agri-food industry. Sustainability, 10(3), 733. https://doi.org/10.3390/su10030733

Singh, A. (2015). Multi-period demand allocation among supplier in a supply chain. Journal of Modelling in Management, 10(2), 138-157. https://doi.org/10.1108/JM2-09-2013-0046

Soheilirad, S., Govindan, K., Mardani, A., Zavadskas, E. K., Nilashi, M., \& Zakuan, N. (2018). Application of data envelopment analysis models in supply chain management: a systematic review and meta-analysis. Annals of Operations Research, 271(2), 915-969.

https://doi.org/10.1007/s10479-017-2605-1

Sremac, S., Zavadskas, E. K., Matic, B., Kopic, M., \& Stevic, Z. (2019). Neuro-fuzzy inference systems approach to decision support system for economic order quantity. Economic Research-Ekonomska Istraživanja, 32(1), 1114-1137. https://doi.org/10.1080/1331677x.2019.1613249

Sun, Y. (2020a). Fuzzy approaches and simulation-based reliability modeling to solve a road-rail intermodal routing problem with soft delivery time windows when demand and capacity are uncertain. International Journal of Fuzzy Systems, 22(7), 2119-2148.

https://doi.org/10.1007/s40815-020-00905-x 
Sun, Y. (2020b). Green and reliable freight routing problem in the road-rail intermodal transportation network with uncertain parameters: a fuzzy goal programming approach. Journal of Advanced Transportation, 2020, 7570686. https://doi.org/10.1155/2020/7570686

Sun, Y., \& Li, X. Y. (2019). Fuzzy programming approaches for modeling a customer-centred freight routing problem in the road-rail intermodal hub-and-spoke network with fuzzy soft time windows and multiple sources of time uncertainty. Mathematics, 7(8), 739. https://doi.org/10.3390/math7080739

Sun, Y., Liang, X., Li, X. Y., \& Zhang, C. (2019a). A fuzzy programming method for modeling demand uncertainty in the capacitated road-rail multimodal routing problem with time windows. Symmetry, 11(1), 91. https://doi.org/10.3390/sym11010091

Sun, Y., Lu, Y., \& Zhang, C. (2019b). Fuzzy linear programming models for a green logistics center location and allocation problem under mixed uncertainties based on different carbon dioxide emission reduction methods. Sustainability, 11(22), 6448. https://doi.org/10.3390/su11226448

Tabrizi, B. H., \& Razmi, J. (2013). Introducing a mixed-integer non-linear fuzzy model for risk management in designing supply chain networks. Journal of Manufacturing Systems, 32(2), 295-307. https://doi.org/10.1016/j.jmsy.2012.12.001

Tamošaitienė, J., Zavadskas, E. K., Šileikaite, I., \& Turskis, Z. (2017). A novel hybrid MCDM approach for complicated supply chain management problems in construction. Modern Building Materials, Structures and Techniques, 172, 1137-1145. https://doi.org/10.1016/j.proeng.2017.02.168

Temur, G. T. (2016). A novel multi attribute decision making approach for location decision under high uncertainty. Applied Soft Computing, 40, 674-682. https://doi.org/10.1016/j.asoc.2015.12.027

Tian, Z. P., Zhang, H. Y., Wang, J. Q., \& Wang, T. L. (2018). Green supplier selection using improved TOPSIS and best-worst method under intuitionistic fuzzy environment. Informatica, 29(4), $773-$ 800. https://doi.org/10.15388/Informatica.2018.192

Torra, V. (2010). Hesitant fuzzy sets. International Journal of Intelligent Systems, 25(6), 529-539. https://doi.org/10.1002/int.20418

Tsai, K. M., You, S. Y., Lin, Y. H., \& Tsai, C. H. (2008). A fuzzy goal programming approach with priority for channel allocation problem in steel industry. Expert Systems with Applications, 34(3), 1870-1876. https://doi.org/10.1016/j.eswa.2007.02.034

Tseng, M. L. (2011). Green supply chain management with linguistic preferences and incomplete information. Applied Soft Computing, 11(8), 4894-4903. https://doi.org/10.1016/j.asoc.2011.06.010

Tseng, M. L., Islam, M. S., Karia, N., Fauzi, F. A., \& Afrin, S. (2019). A literature review on green supply chain management: Trends and future challenges. Resources Conservation and Recycling, 141, 145-162. https://doi.org/10.1016/j.resconrec.2018.10.009

Tseng, M. L., Lim, M. K., Wong, W. P., Chen, Y. C., \& Zhan, Y. Z. (2018). A framework for evaluating the performance of sustainable service supply chain management under uncertainty. International Journal of Production Economics, 195, 359-372. https://doi.org/10.1016/j.ijpe.2016.09.002

Tseng, M. L., Lin, R. J., Lin, Y. H., Chen, R. H., \& Tan, K. (2014a). Close-loop or open hierarchical structures in green supply chain management under uncertainty. Expert Systems with Applications, 41(7), 3250-3260. https://doi.org/10.1016/j.eswa.2013.10.062

Tseng, M. L., Lin, Y. H., Tan, K., Chen, R. H., \& Chen, Y. H. (2014b). Using TODIM to evaluate green supply chain practices under uncertainty. Applied Mathematical Modelling, 38(11-12), 2983-2995. https://doi.org/10.1016/j.apm.2013.11.018

Tseng, M. L., Tan, K. H., \& Chiu, A. S. F. (2016). Identifying the competitive determinants of firms' green supply chain capabilities under uncertainty. Clean Technologies and Environmental Policy, 18(5), 1247-1262. https://doi.org/10.1007/s10098-015-1064-0

Tseng, M. L., Tan, K. H., Lim, M., Lin, R. J., \& Geng, Y. (2014c). Benchmarking eco-efficiency in green supply chain practices in uncertainty. Production Planning \& Control, 25(13-14), 1079-1090. https://doi.org/10.1080/09537287.2013.808837 
Tseng, M. L., Tran, T. P. T., Wu, K. J., Tan, R. D. R., \& Bui, T. D. (2020). Exploring sustainable seafood supply chain management based on linguistic preferences: collaboration in the supply chain and lean management drive economic benefits. International Journal of Logistics-Research and Applications, 2020, 1-23. https://doi.org/10.1080/13675567.2020.1800608

Tuzkaya, G., Ozgen, A., Ozgen, D., \& Tuzkaya, U. R. (2009). Environmental performance evaluation of suppliers: A hybrid fuzzy multi-criteria decision approach. International Journal of Environmental Science and Technology, 6(3), 477-490. https://doi.org/10.1007/BF03326087

Tyagi, M., Kumar, P., \& Kumar, D. (2015). Permutation of fuzzy AHP and AHP methods to prioritizing the alternatives of supply chain performance system. International Journal of Industrial EngineeringTheory Applications and Practice, 22(6), 729-752.

Ulutas, A. (2019). Supplier selection by using a fuzzy integrated model for a textile company. Inzinerine Ekonomika-Engineering Economics, 30(5), 579-590. https://doi.org/10.5755/j01.ee.30.5.20546

Vahdani, B., \& Zandieh, M. (2010). Selecting suppliers using a new fuzzy multiple criteria decision model: the fuzzy balancing and ranking method. International Journal of Production Research, 48(18), 5307-5326. https://doi.org/10.1080/00207540902933155

Van Eck, N. J., \& Waltman, L. (2020). VOSviewer (version 1.6.16) [Computer software]. Centre for Science and Technology Studies, Leiden University. https://www.vosviewer.com/

Van, L. H., Yu, V. F., Dat, L. Q., Dung, C. C., Chou, S. Y., \& Loc, N. V. (2018). New integrated quality function deployment approach based on interval neutrosophic set for green supplier evaluation and selection. Sustainability, 10(3), 838. https://doi.org/10.3390/su10030838

Villa Silva, A. J., Dominguez, L. A. P., Gomez, E. M., Alvarado-Iniesta, A., \& Olguin, I. J. C. P. (2019). Dimensional analysis under Pythagorean fuzzy approach for supplier selection. Symmetry, 11(3), 336. https://doi.org/10.3390/sym11030336

Wadhwa, S., Madaan, J., \& Chan, F. T. S. (2009). Flexible decision modeling of reverse logistics system: A value adding MCDM approach for alternative selection. Robotics and Computer-Integrated Manufacturing, 25(2), 460-469. https://doi.org/10.1016/j.rcim.2008.01.006

Wan, S. P., \& Li, D. F. (2013). Fuzzy LINMAP approach to heterogeneous MADM considering comparisons of alternatives with hesitation degrees. Omega, 41(6), 925-940. https://doi.org/10.1016/j.omega.2012.12.002

Wan, S. P., \& Li, D. F. (2015). Fuzzy mathematical programming approach to heterogeneous multiattribute decision-making with interval-valued intuitionistic fuzzy truth degrees. Information Sciences, 325, 484-503. https://doi.org/10.1016/j.ins.2015.07.014

Wan, Y. C., \& Chen, Q. C. (2020). Research on risk-averse retailer's spot procurement decision under fuzzy demand. Engineering Letters, 28(2), 433-444.

Wang, C. N., Viet, V. T. H., Ho, T. P., Nguyen, V. T., \& Nguyen, V. T. (2020). Multi-criteria decision model for the selection of suppliers in the textile industry. Symmetry, 12(6), 979.

https://doi.org/10.3390/sym12060979

Wang, G., Gunasekaran, A., Ngai, E. W. T., \& Papadopoulos, T. (2016). Big data analytics in logistics and supply chain management: Certain investigations for research and applications. International Journal of Production Economics, 176, 98-110. https://doi.org/10.1016/j.ijpe.2016.03.014

Wang, J., \& Lin, H. Y. (2006). A fuzzy hybrid decision-aid model for selecting partners in the design chain. International Journal of Production Research, 44(10), 2047-2069.

https://doi.org/10.1080/00207540500354028

Wang, J. L. (2009). A supply chain application of fuzzy set theory to inventory control models - DRP system analysis. Expert Systems with Applications, 36(5), 9229-9239.

https://doi.org/10.1016/j.eswa.2008.12.047

Wang, J. T., \& Shu, Y. F. (2005). Fuzzy decision modeling for supply chain management. Fuzzy Sets and Systems, 150(1), 107-127. https://doi.org/10.1016/j.fss.2004.07.005 
Wang, J. T., \& Shu, Y. F. (2007). A possibilistic decision model for new product supply chain design. European Journal of Operational Research, 177(2), 1044-1061. https://doi.org/10.1016/j.ejor.2005.12.032

Wang, K. Q., Liu, H. C., Liu, L. P., \& Huang, J. (2017a). Green supplier evaluation and selection using cloud model theory and the QUALIFLEX method. Sustainability, 9(5), 688. https://doi.org/10.3390/su9050688

Wang, L., Ma, L., Wu, K. J., Chiu, A. S. F., \& Nathaphan, S. (2018). Applying fuzzy interpretive structural modeling to evaluate responsible consumption and production under uncertainty. Industrial Management \& Data Systems, 118(2), 432-462. https://doi.org/10.1108/IMDS-03-2017-0109

Wang, R., \& Li, Y. L. (2018). A novel approach for green supplier selection under a q-Rung orthopair fuzzy environment. Symmetry, 10(12), 687. https://doi.org/10.3390/sym10120687

Wang, W., Huang, L., Zhu, Y. L., Jiang, L. P., Sahu, A. K., Sahu, A. K., \& Sahu, N. K. (2019). Decision support system toward evaluation of resilient supplier: A novel fuzzy gain-loss computational approach. Kybernetes, 49(6), 1741-1765. https://doi.org/10.1108/K-05-2019-0345

Wang, X. J., \& Chan, H. K. (2013). A hierarchical fuzzy TOPSIS approach to assess improvement areas when implementing green supply chain initiatives. International Journal of Production Research, 51(10), 3117-3130. https://doi.org/10.1080/00207543.2012.754553

Wang, X. J., Li, D., \& Shi, X. L. (2012). A fuzzy model for aggregative food safety risk assessment in food supply chains. Production Planning \& Control, 23(5), 377-395. https://doi.org/10.1080/09537287.2011.561812

Wang, X. J., Tiwari, P., \& Chen, X. (2017b). Communicating supply chain risks and mitigation strategies: a comprehensive framework. Production Planning \& Control, 28(13), 1023-1036. https://doi.org/10.1080/09537287.2017.1329562

Wang, Y., Ma, X. L., Lao, Y. T., \& Wang, Y. H. (2014). A fuzzy-based customer clustering approach with hierarchical structure for logistics network optimization. Expert Systems with Applications, 41(2), 521-534. https://doi.org/10.1016/j.eswa.2013.07.078

Wicher, P., Zapletal, F., Lenort, R., \& Stas, D. (2016). Measuring the metallurgical supply chain resilience using fuzzy analytic network process. Metalurgija, 55(4), 783-786.

Wen, Z., Liao, H. C., Zavadskas, E. K., \& Al-Barakati, A. (2019). Selection third-party logistics service providers in supply chain finance by a hesitant fuzzy linguistic combined compromise solution method. Economic Research-Ekonomska Istraživanja, 32(1), 4033-4058. https://doi.org/10.1080/1331677x.2019.1678502

Woo, H. S., \& Saghiri, S. (2011). Order assignment considering buyer, third-party logistics provider, and suppliers. International Journal of Production Economics, 130(2), 144-152. https://doi.org/10.1016/j.ijpe.2010.10.019

Wu, C. W., Liao, M. Y., \& Lin, C. Y. (2014). On ranking multiple touch-screen panel suppliers through the CTQ: applied fuzzy techniques for inspection with unavoidable measurement errors. Neural Computing \& Applications, 25(2), 481-490. https://doi.org/10.1007/s00521-013-1500-1

Wu, C., \& Barnes, D. (2014). Partner selection in agile supply chains: a fuzzy intelligent approach. Production Planning \& Control, 25(10), 821-839. https://doi.org/10.1080/09537287.2013.766037

Wu, C., \& Barnes, D. (2016). Partner selection for reverse logistics centres in green supply chains: a fuzzy artificial immune optimization approach. Production Planning \& Control, 27(16), 1356-1372. https://doi.org/10.1080/09537287.2016.1221159

Wu, D. X., Wu, D. D., Zhang, Y. D., \& Olson, D. L. (2013). Supply chain outsourcing risk using an integrated stochastic-fuzzy optimization approach. Information Sciences, 235, 242-258. https://doi.org/10.1016/j.ins.2013.02.002

Wu, K. J., Liao, C. J., Tseng, M. L., \& Chiu, A. S. F. (2015). Exploring decisive factors in green supply chain practices under uncertainty. International Journal of Production Economics, 159, 147-157. https://doi.org/10.1016/j.ijpe.2014.09.030 
Wu, K. J., Tseng, M. L., Chiu, A. S. F., \& Lim, M. K. (2017). Achieving competitive advantage through supply chain agility under uncertainty: A novel multi-criteria decision-making structure. International Journal of Production Economics, 190, 96-107. https://doi.org/10.1016/j.ijpe.2016.08.027

Wu, Q., Zhou, L. G., Chen, Y., \& Chen, H. Y. (2019). An integrated approach to green supplier selection based on the interval type-2 fuzzy best-worst and extended VIKOR methods. Information Sciences, 502, 394-417. https://doi.org/10.1016/j.ins.2019.06.049

$\mathrm{Wu}, \mathrm{X}$. L., \& Liao, H. C. (2020). Utility-based hybrid fuzzy axiomatic design and its application in supply chain finance decision making with credit risk assessments. Computers in Industry, 114, 103144. https://doi.org/10.1016/j.compind.2019.103144

Wu, Y. N., Xu, C. B., Huang, Y., \& Li, X. Y. (2020). Green supplier selection of electric vehicle charging based on Choquet integral and type-2 fuzzy uncertainty. Soft Computing, 24(5), 3781-3795. https://doi.org/10.1007/s00500-019-04147-4

Xie, Y., Petrovic, D., \& Burnham, K. (2006). A heuristic procedure for the two-level control of serial supply chains under fuzzy customer demand. International Journal of Production Economics, 102(1), 37-50. https://doi.org/10.1016/j.ijpe.2005.01.016

Xiong, L., Zhong, S. Q., Liu, S., Zhang, X., \& Li, Y. F. (2020). An approach for resilient-green supplier selection based on WASPAS, BWM, and TOPSIS under intuitionistic fuzzy sets. Mathematical Problems in Engineering, 2020, 1761893. https://doi.org/10.1155/2020/1761893

$\mathrm{Xu}$, J. P., He, Y. A., \& Gen, M. (2009). A class of random fuzzy programming and its application to supply chain design. Computers \& Industrial Engineering, 56(3), 937-950. https://doi.org/10.1016/j.cie.2008.09.045

Xu, Z., Qin, J. D., Liu, J., \& Martinez, L. (2019). Sustainable supplier selection based on AHPSort II in interval type-2 fuzzy environment. Information Sciences, 483, 273-293. https://doi.org/10.1016/j.ins.2019.01.013

Yazdani, M., Zarate, P., Coulibaly, A., \& Zavadskas, E. K. (2017). A group decision making support system in logistics and supply chain management. Expert Systems with Applications, 88, 376-392. https://doi.org/10.1016/j.eswa.2017.07.014

Yazici, E., Buyukozkan, G., \& Baskak, M. (2016). A new extended MILP MRP approach to production planning and its application in the jewelry industry. Mathematical Problems in Engineering, 2016, 7915673. https://doi.org/10.1155/2016/7915673

Yu, G. D., Zhang, L., \& Sun, H. P. (2018). A method for partner selection of supply chain using intervalvalued fuzzy sets - fuzzy choquet integral and improved Dempster-Shafer theory. International Journal of Information Technology \& Decision Making, 17(6), 1777-1804. https://doi.org/10.1142/S0219622018500438

Yu, Y., \& Jin, T. D. (2011). The return policy model with fuzzy demands and asymmetric information. Applied Soft Computing, 11(2), 1669-1678. https://doi.org/10.1016/j.asoc.2010.05.004

Zadeh, L. A. (1965). Fuzzy sets. Information and Control, 8(3), 338-353. https://doi.org/10.1016/s0019-9958(65)90241-x

Zadeh, L. A. (1975). Concept of a linguistic variable and its application to approximate reasoning - 1 . Information Sciences, 8(3), 199-249. https://doi.org/10.1016/0020-0255(75)90036-5

Zandi, F., Tavana, M., \& Martin, D. (2011). A fuzzy group Electre method for electronic supply chain management framework selection. International Journal of Logistics-Research and Applications, 14(1), 35-60. https://doi.org/10.1080/13675567.2010.550872

Zhang, G. Q., Shang, J., \& Li, W. L. (2011). Collaborative production planning of supply chain under price and demand uncertainty. European Journal of Operational Research, 215(3), 590-603. https://doi.org/10.1016/j.ejor.2011.07.007 
Zhao, J. S., You, X. Y., Liu, H. C., \& Wu, S. M. (2017). An extended VIKOR method using intuitionistic fuzzy sets and combination weights for supplier selection. Symmetry, 9(9), 169. https://doi.org/10.3390/sym9090169

Zhao, X., Xia, X. H., Wang, L., \& Cao, J. H. (2019). A fuzzy multi-objective immune genetic algorithm for the strategic location planning problem. Cluster Computing-the Journal of Networks Software Tools and Applications, 22(2), S3621-S3641. https://doi.org/10.1007/s10586-018-2212-1

Zheng, H. Y., Deng, Y., \& Hu, Y. (2017). Fuzzy evidential influence diagram and its evaluation algorithm. Knowledge-Based Systems, 131, 28-45. https://doi.org/10.1016/j.knosys.2017.05.024

Zhou, X. Y., Pedrycz, W., Kuang, Y. X., \& Zhang, Z. (2016). Type-2 fuzzy multi-objective DEA model: An application to sustainable supplier evaluation. Applied Soft Computing, 46, 424-440. https://doi.org/10.1016/j.asoc.2016.04.038

Zhou, X. Y., Wang, Y., Chai, J., Wang, L. Q., Wang, S. Y., \& Lev, B. (2019). Sustainable supply chain evaluation: A dynamic double frontier network DEA model with interval type-2 fuzzy data. Information Sciences, 504, 394-421. https://doi.org/10.1016/j.ins.2019.07.033 